\title{
Test Program for a Dual-mode Scramjet
}

\author{
A Dissertation \\ Presented to the Faculty of the \\ School of Engineering and Applied Science \\ University of Virginia \\ In partial fulfillment \\ of the requirements for the degree of \\ Doctor of Philosophy in \\ Mechanical and Aerospace Engineering \\ by \\ Michael G. Smayda
}

May 2012

Approved for public release; distribution is unlimited. AEDC PA 2012-083 


\section{Approval sheet}

The dissertation is submitted in partial fulfillment of the

requirements for the degree of

Doctor of Philosophy in

Mechanical and Aerospace Engineering

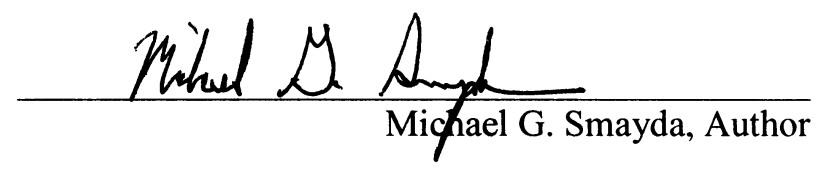

This dissertation has been read and approved by the examining Committee:

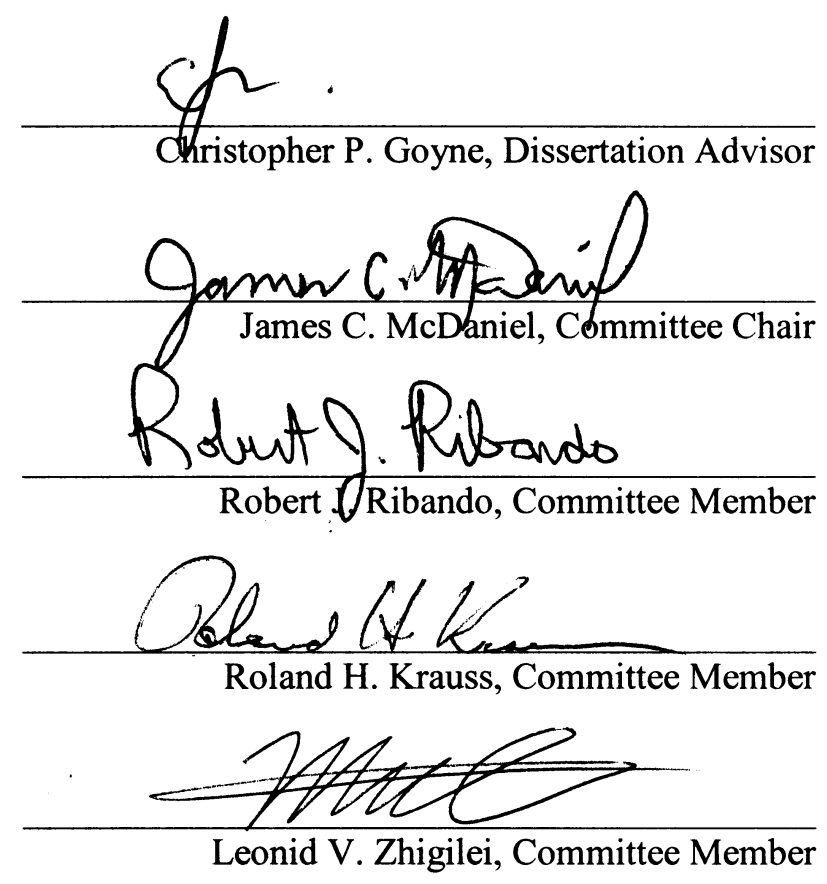

Accepted for the School of Engineering and Applied Science:

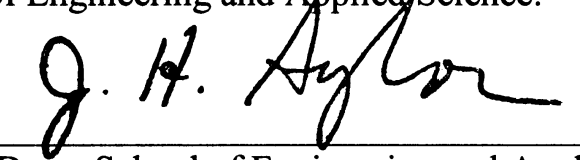

James H. Aylor, Dean, School of Engineering and Applied Science

May 2012

Approved for public release; distribution is unlimited. AEDC PA 2012-083 


\begin{abstract}
Since flow at hypersonic Mach numbers $(M \geq 5)$ behaves very differently from flow at subsonic or supersonic Mach numbers, the testing of hypersonic engines involves challenges not encountered in engine testing for flight in other regimes. For hypersonic Mach numbers, thermal, chemical, radiative, and ablative effects become important. Energy and heat transfer considerations make continuous-run, full scale testing at hypersonic Mach numbers difficult or impossible. While facilities have been devised specifically to study certain aspects of hypersonic flight, no single facility has the ability to simulate all the flow conditions that a hypersonic vehicle or engine may encounter.

Flight can be considered the ultimate test of a hypersonic vehicle or engine because no facility effects are present. It is often the case, however, that budgetary, thermal, structural, or other logistical limitations restrict the range of diagnostics available for flight vehicle testing. Flight programs also incur significant risk that is generally not present or is significantly reduced for ground testing programs. If an unguided rocket is used to minimize cost, the likelihood that the payload will achieve the desired test conditions decreases. If a reactive control system is utilized to increase the likelihood that the payload will achieve the desired test conditions, both complexity and cost increase significantly. As such, flight programs are nearly always augmented with significant ground testing to reduce risk and confirm engine operability limits. Often a range of wind tunnels is used in order to resolve the inherent deficiencies of any one type of ground test facility. Two common shortcomings of hypersonic test facilities are the short test time associated with shock-heated facilities and the contaminated or vitiated test gas associated with combustion-heated facilities.
\end{abstract}

Approved for public release; distribution is unlimited. AEDC PA 2012-083 
This dissertation details a test program for a dual-mode scramjet which involves both ground and flight experiments in support of the Short Duration Propulsion Test and Evaluation (SDPTE) program, which aims to resolve the effects of a short test time and vitiated test medium on the operation and performance of a dual-mode scramjet (DMSJ). Included is background information related to previous scramjet test programs and their objectives, information on the design of the ground and flight tests for this program, as well as a novel rocket dispersion reduction scheme aimed at increasing the probability of a successful scramjet test flight.

As part of this work, a hypersonic inlet for flight and freejet ground testing was designed and tested in an impulse facility. In these same tests, dual-mode operation of a DMSJ was demonstrated. Since only one test flight is planned for the SDPTE program and a scramjet's operation is directly influenced by the freestream conditions it encounters, a novel method was devised to reduce dispersion in test conditions seen by a scramjet flight-tested aboard a two-stage, unguided, spin-stabilized, sounding rocket. This involved altering the second stage ignition time to ensure that the vehicle passes through the test Mach number at the desired altitude. This method was tested through Monte Carlo simulation and was shown to increase the chances of a successful test flight from $71 \%$ to over $99 \%$. The work presented in this dissertation advances the state of scramjet testing and serves as a framework for the design of a scramjet ground and flight test campaign. 


\section{Acknowledgements}

Much of the work presented in this dissertation represents the efforts of many collaborators and would not have been possible without the support of individuals from government, industry, and academia.

I would like to thank all employees at ATK-GASL who were involved in this program. Their expertise and experience in scramjet testing was invaluable as was their collective contribution to this program. Specifically, I would like to thank Dr. Ching-Yi Tsai for his assistance throughout the program and specifically with all things related to the HyPulse facility. I would like to thank Troy Custodio for his work on the mechanical design of the flight vehicle and ground test articles, Dr. Rob Foelsche and Dr. Akiva Sklar for their roles in experiment design and data analysis and Dan Cresci for his technical management of the program at ATK-GASL. Obtaining experimental data would not have been possible without the countless hours spent by technicians at ATKGASL who fabricated, built, and installed the test articles and also physically conducted the ground tests. Their contribution to the program is gratefully acknowledged.

I would like to thank the members of my committee for their service. Further, I would like to thank Dr. Chris Goyne for his advisement and assistance preparing documents throughout my graduate career. His expertise and guidance has been invaluable. I would also like to acknowledge the contribution of Dr. Alexandrina Untaroiu, who performed the CFD on the flight and ground test vehicles presented in this dissertation.

I would also like to acknowledge the assistance of various NASA employees, particularly Mark Simko and Brent Edwards who were both instrumental when I was first 
learning to run the GEM trajectory simulation software. I would also like to thank Scott Berry for his advice regarding the design of the hypersonic boundary layer trip for the SDPTE vehicle.

This work was funded primarily by the Test Resource Management Center (TRMC) Test and Evaluation/Science and Technology (T\&E/S\&T) Program, through the High Speed Systems Test (HSST) Test Technology Area (TTA) with technical monitors Jonathan Osborne and Wade Burfitt as well as executing agent Ed Tucker. Further financial support from the University of Virginia department of Mechanical and Aerospace Engineering, Aerojet and the Virginia Space Grant Consortium (VSGC) is also gratefully acknowledged. 


\section{Contents}

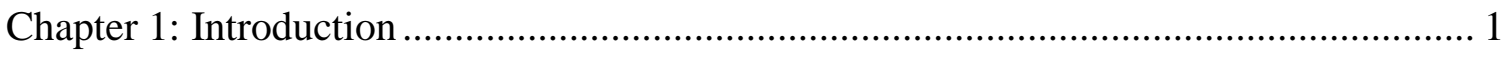

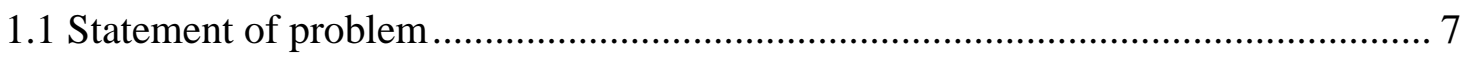

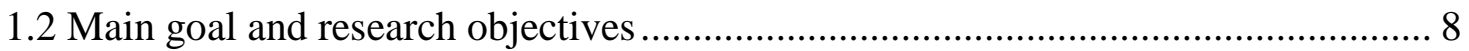

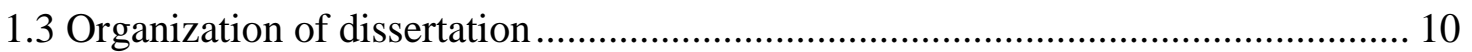

Chapter 2: Design and test of an inlet for a scramjet flight and ground test program ...... 13

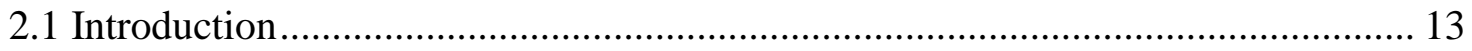

2.1.1 General inlet design considerations .................................................... 15

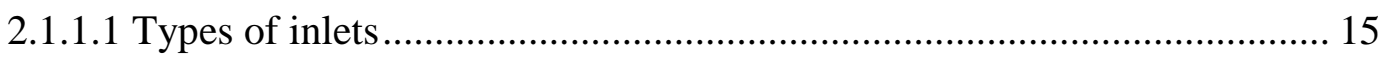

2.1.1.2 Contraction and starting limit considerations .................................... 16

2.1.1.3 Boundary layer separation considerations ........................................... 18

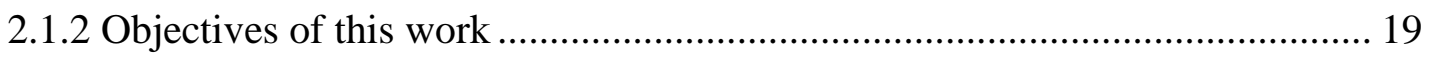

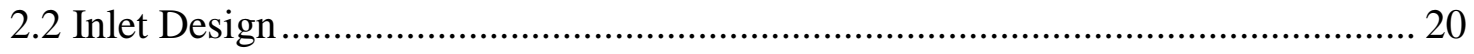

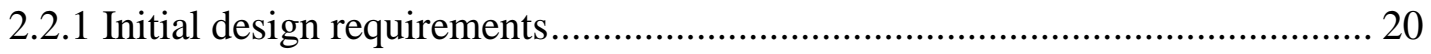

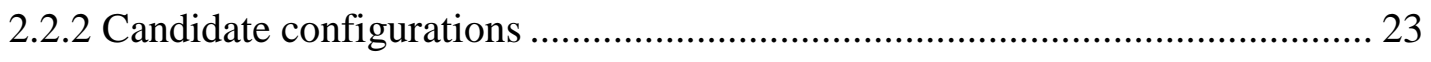

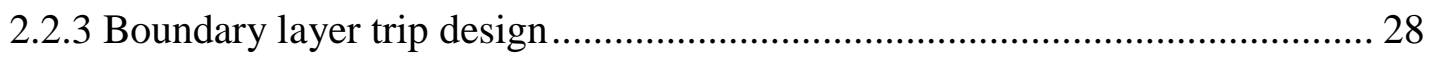

2.3 Predicted Performance and operability ........................................................ 31

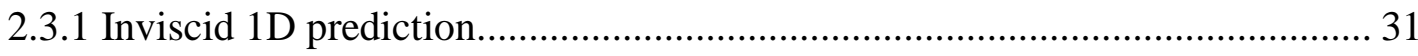

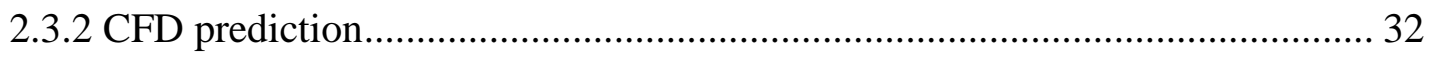

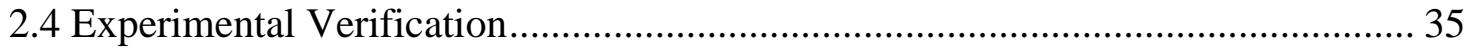

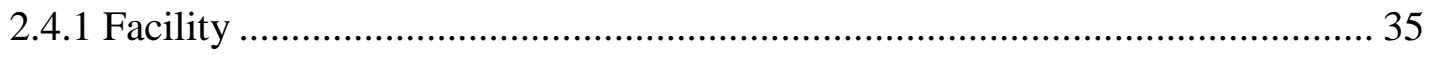

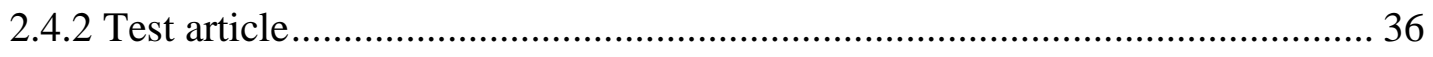

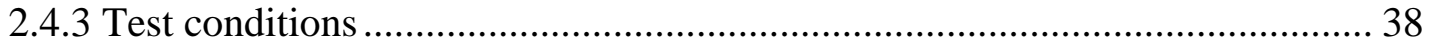

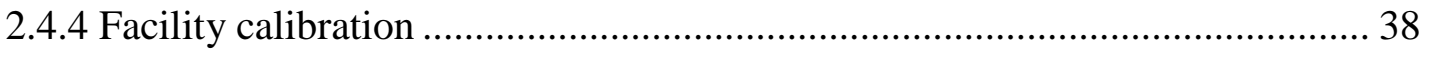

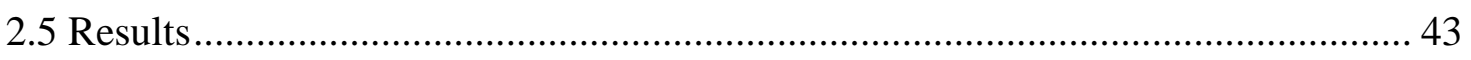

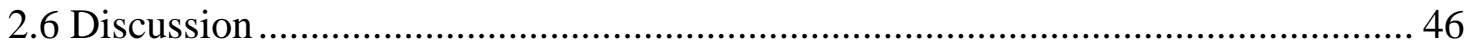

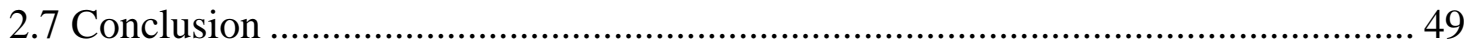

Chapter 3: Freejet testing of a dual-mode scramjet combustor in an impulse facility ..... 53

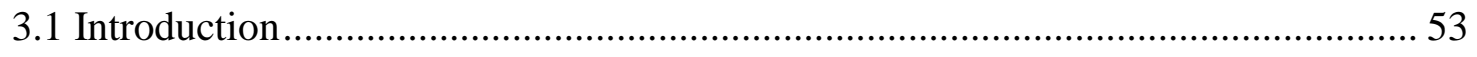

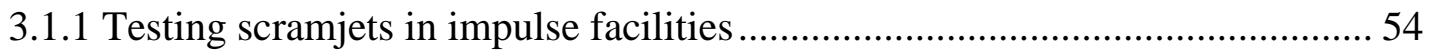




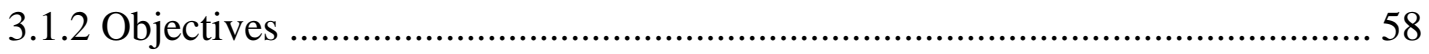

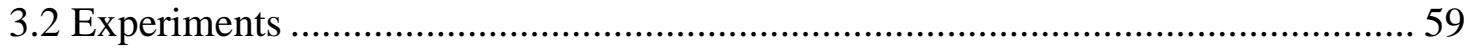

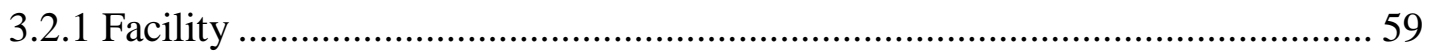

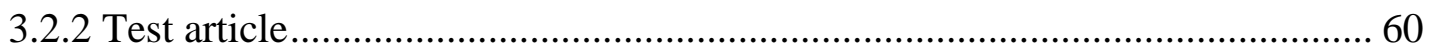

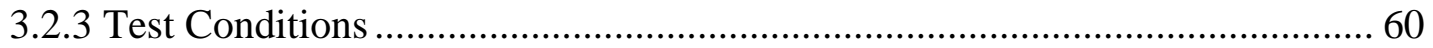

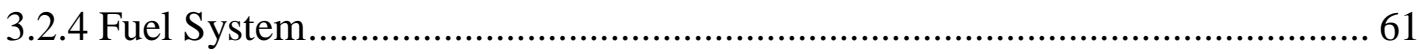

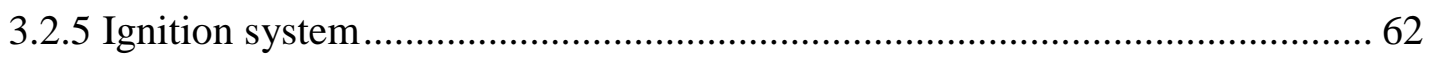

3.2.6 Nozzle starting process and test time determination.......................................... 64

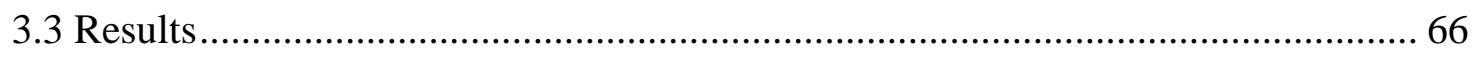

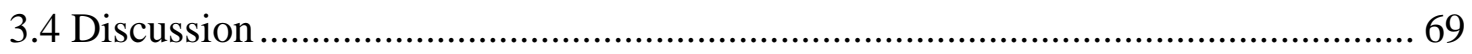

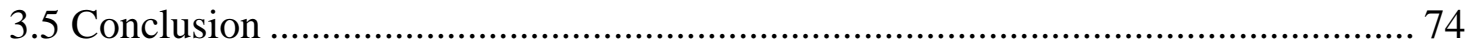

Chapter 4: Dispersion and dispersion reduction ....................................................... 77

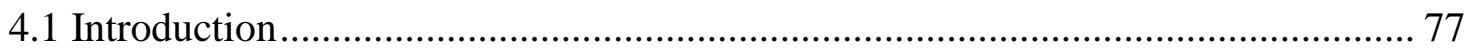

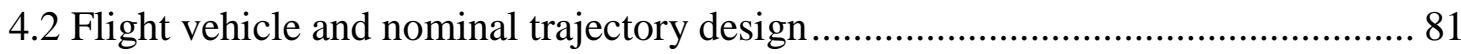

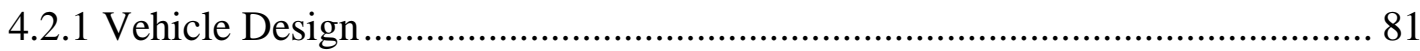

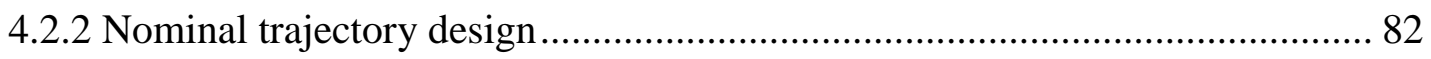

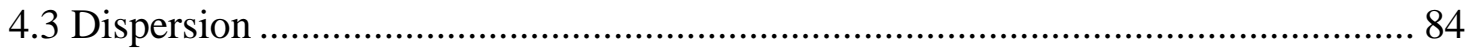

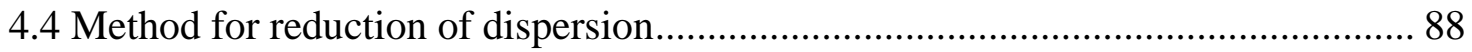

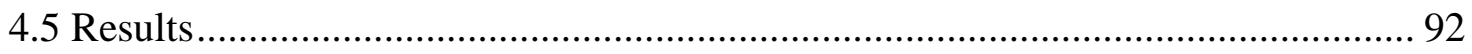

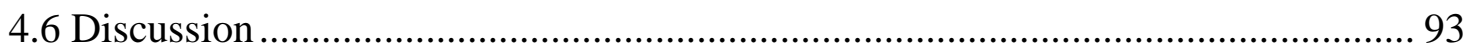

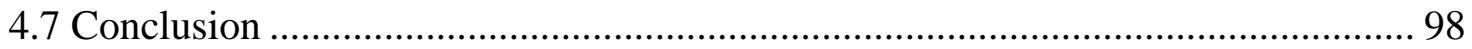

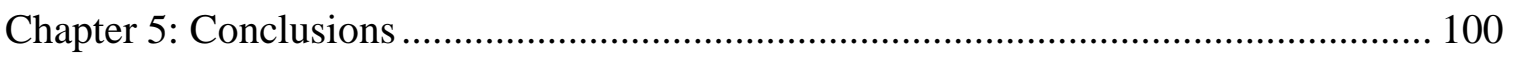

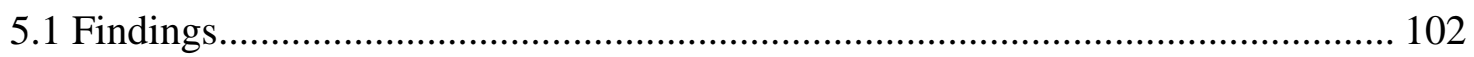

5.1.1 Nominal trajectory and inlet development.................................................... 102

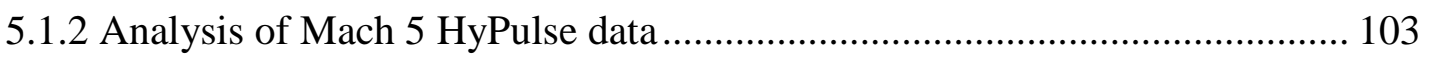

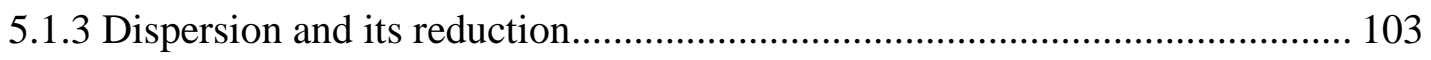

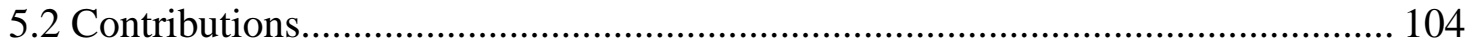

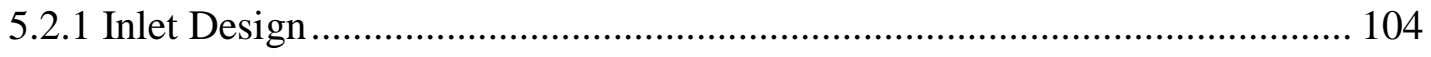

5.2.2 Freejet testing of a dual-mode scramjet combustor in an impulse facility .... 104

5.2.3 Dispersion reduction ................................................................................. 105

5.3 Future work 


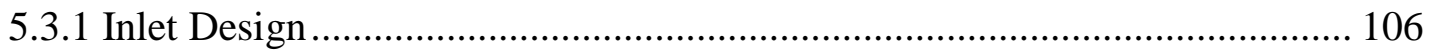

5.3.2 Freejet testing of a dual-mode scramjet combustor in an impulse facility .... 107

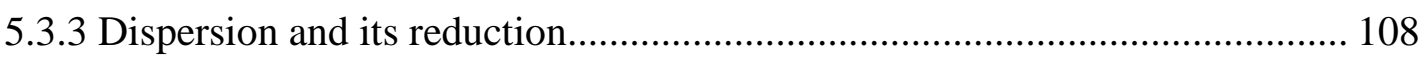

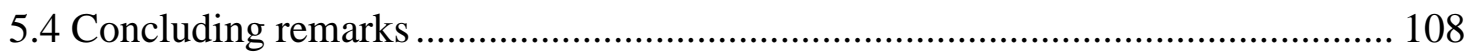

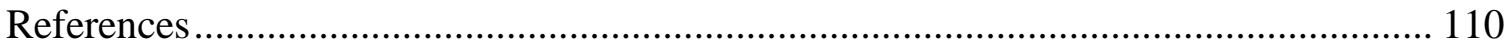

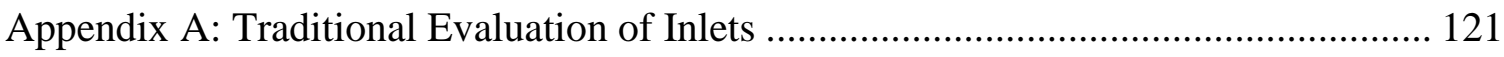

Appendix B: Additional Mach 5 flight CFD results ................................................. 124

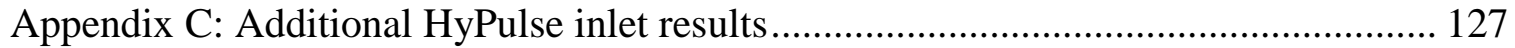

Appendix D: Monte Carlo Method Background …................................................ 137 


\section{List of Figures}

Figure 2.1: UVaSCF direct-connect flowpath schematic. ( Adapted from Goyne et al.,

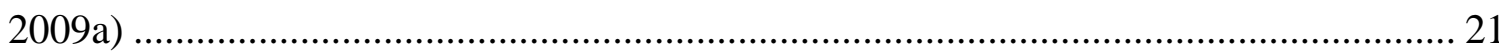

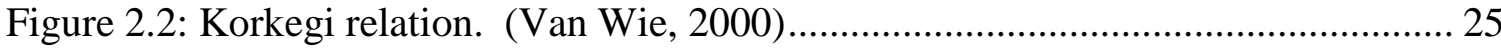

Figure 2.3: 2D Mach number contours for CFD simulations of forebody and inlet flow a) without cowl modification and b) with cowl modification. (Goyne et al., 2009b) .......... 27

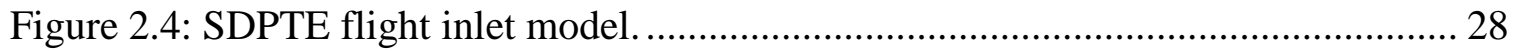

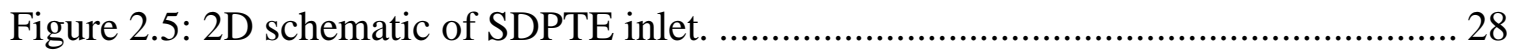

Figure 2.6: Structured mesh for inlet CFD. (Top of domain truncated) ........................ 33

Figure 2.7: Mach number contour along inlet centerline .......................................... 34

Figure 2.8: SDPTE HyPulse test article. (Goyne et al., 2009a).................................... 37

Figure 2.9: Average stagnation pressure vs. time. Nominal test time indicated by vertical

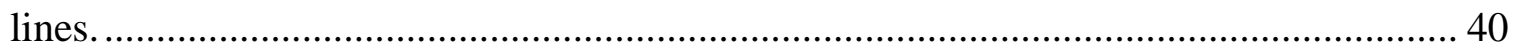

Figure 2.10: Average pitot pressure vs. time. Nominal test time indicated by vertical

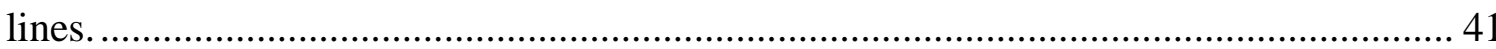

Figure 2.11: Pitot pressure vs. position for both HyPulse Mach 5 calibration runs........ 41

Figure 2.12: Pitot pressure vs. position for test with jet stretcher and new diaphragm

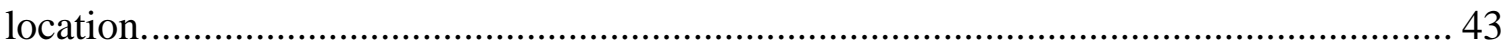

Figure 2.13: Pressure traces for flowpath A inlet at a) 0-10 ms, and b) 10-20 ms......... 45

Figure 2.14: Pressure traces for flowpath B inlet at a) 0-10 ms, and b) $10-20 \mathrm{~ms}$.......... 46

Figure 2.15: Pressure vs. time (shifted) on forebody at $\mathrm{x}=15$ inches. .......................... 47

Figure 2.16: Comparison of CFD with average pressure traces from HyPulse experiment.

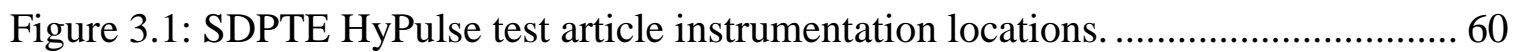

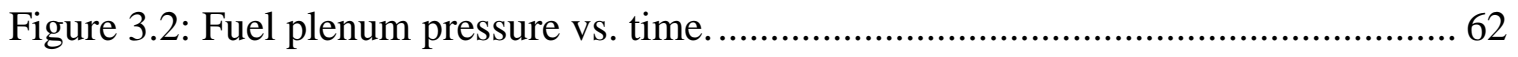

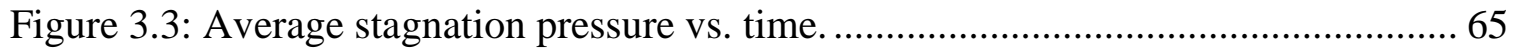

Figure 3.4: Ratio of time shifted static pressure at nozzle exit plenum pressure. A) Nozzle started, B) scramjet flow features started, beginning of test time, and C) end of test time. 66 
Figure 3.5: Pressure traces for test 1 at a) $0-10 \mathrm{~ms}$, and b) average pressure through test time (2-6ms). Error bars are 1 standard deviation.

Figure 3.6: Pressure traces for test 3 at a) $0-10 \mathrm{~ms}$, and b) average pressure through test time (2-6ms). Error bars are 1 standard deviation.

Figure 3.7: Pressure traces for test 9 at a) $0-10 \mathrm{~ms}$, and b) average pressure through test time (2-6ms). Error bars are 1 standard deviation.

Figure 3.8: Test pressure traces with time for the pressure taps at a) $x=11.0$ inches, b) $x$ $=19.0$ inches, and c) $\mathrm{x}=22.5$ inches. 73

Figure 4.1: A schematic of the SDPTE launch vehicle model. (dimensions in inches) Reprinted with permission of the American Institute of Aeronautics and Astronautics. . 82 Figure 4.2: Nominal trajectory a) Mach number and altitude vs. time and b) Mach number and dynamic pressure vs. time within test window. A) First stage ignition, B) First stage burnout, C) Stage separation, D) Second stage ignition, E) Deploy shroud, begin primary experiment, F) Nominal test point, G) Second stage burnout, primary experiment end, H) Dynamic pressure reaches 1,000 psf, secondary experiment end, and I) Apogee. Reprinted with permission of the American Institute of Aeronautics and Astronautics. 84

Figure 4.3: a) Mach number vs. time +/- 1, 2, and 3 standard deviations, and b) Dynamic pressure vs. time $+/-1,2$, and 3 standard deviations. Primary test window is from 56.4 seconds (E) to 57.5 seconds $(\mathrm{G})$ and secondary test window is from 67.5 to 74.0 seconds $(\mathrm{H})$, as indicated by vertical bars. Reprinted with permission of the American Institute of Aeronautics and Astronautics.

Figure 4.4: Relationship between a) optimal second stage ignition time and b) optimal test time and the Mach number and altitude measured at $t=27.0$ seconds. The curves represent the polynomial regression at the limits of the $+/-0.25 \mathrm{kft}$ range for each nominal altitude. Reprinted with permission of the American Institute of Aeronautics and Astronautics.

Figure 4.5: a) Dynamic pressure and Mach number for each trajectory without and b) with the application of dispersion reduction method, at the expected test time. Boxes represent success criteria. Reprinted with permission of the American Institute of Aeronautics and Astronautics. 
Figure 4.6: Histogram of dynamic pressures at the time the vehicle passes through Mach 5.0 for trajectories a) without dispersion reduction and b) with dispersion reduction. Reprinted with permission of the American Institute of Aeronautics and Astronautics. . 93 Figure 4.7: a) Mach number vs. time for the nominal trajectory and two with adjusted second stage ignition and test times, and b) Dynamic pressure vs. time near the test window for the nominal trajectory and two with adjusted second stage ignition and test times. Approximate test points are where trajectories cross $\mathrm{M}=5.0$ and $\mathrm{q}=1500 \mathrm{psf}$ as indicated by horizontal dashed lines. Reprinted with permission of the American Institute of Aeronautics and Astronautics.

Figure 4.8: Impact location for all trajectories with (corrected) and without (uncorrected) dispersion reduction. Vehicle enters figure from the upper left. Reprinted with permission of the American Institute of Aeronautics and Astronautics. 98

Figure A.1: Simple 2D scramjet inlet schematic (SDPTE inlet). 122

Figure B.1: Isometric view of Mach number contours. 124

Figure B.2: Mach number contour on center plane. 125

Figure B.3: Temperature contour on center plane. 125

Figure B.4: Mass flux density contour on center plane 126

Figure C.1: Test I18 inlet pressure traces for flowpath A for a) 0-10 ms and b) 10-20ms.

Figure C.2: Test I18 inlet pressure traces for flowpath B for a) 0-10 ms and b) 10-20ms. 128

Figure C.3: Test I19 inlet pressure traces for flowpath A for a) 0-10 ms and b) 10-20ms. 129

Figure C.4: Test I19 inlet pressure traces for flowpath B for a) 0-10 ms and b) 10-20ms.

Figure C.5: Test I20 inlet pressure traces for flowpath A for a) 0-10 ms and b) 10-20ms. 130

Figure C.6: Test I20 inlet pressure traces for flowpath B for a) 0-10 ms and b) 10-20ms. 131

Figure C.7: Test 121 inlet pressure traces for flowpath A for a) 0-10 ms and b) 10-20ms. 
Figure C.8: Test I21 inlet pressure traces for flowpath B for a) 0-10 ms and b) 10-20ms. 132

Figure C.9: Test I22 inlet pressure traces for flowpath A for a) 0-10 ms and b) 10-20ms. 133

Figure C.10: Test I22 inlet pressure traces for flowpath B for a) 0-10 ms and b) 10-20ms. 133

Figure C.11: Test I23 inlet pressure traces for flowpath A for a) 0-10 ms and b) 10-20ms. 134

Figure C.12: Test I23 inlet pressure traces for flowpath B for a) 0-10 ms and b) 10-20ms. 134

Figure C.13: Test I24 inlet pressure traces for flowpath A for a) 0-10 ms and b) 10-20ms. 135

Figure C.14: Test I24 inlet pressure traces for flowpath B for a) 0-10 ms and b) 10-20ms. 135

Figure C.15: Test I26 inlet pressure traces for flowpath A for a) 0-10 ms and b) 10-20ms. 136

Figure C.16: Test I26 inlet pressure traces for flowpath B for a) 0-10 ms and b) 10-20m 136 


\section{List of Tables}

Table 1-1: Hyper-X ground test facilities. ............................................................... 5

Table 2-1: Flow properties along SDPTE inlet. (variable gamma) ................................ 32

Table 2-2: SDPTE inlet shock parameters. (variable gamma) ...................................... 32

Table 2-3: HyPulse Mach 4.8 simulation nozzle exit conditions. ................................... 38

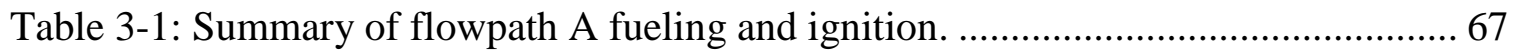

Table 4-1: Monte Carlo dispersion contributors and ranges......................................... 85

Table B-1: Mach 5 flight CFD inflow conditions and predicted mass capture............. 124 


\section{List of Symbols and Abbreviations}

\begin{tabular}{|c|c|}
\hline 1D & One Dimensional \\
\hline $2 \mathrm{D}$ & Two Dimensional \\
\hline 3D & Three Dimensional \\
\hline a & Speed of sound \\
\hline A & Area \\
\hline 8'HTT & NASA Langley Research Center 8 Foot High Temperature Tunnel \\
\hline AEDC & Arnold Engineering Development Center \\
\hline AHSTF & NASA Langley Research Center Arc-Heated Scramjet Test Facility \\
\hline AoA & Angle of Attack \\
\hline ATK & Alliant Techsystems Inc. \\
\hline $\mathrm{C}$ & Specific Heat \\
\hline CFD & Computational Fluid Dynamics \\
\hline$D$ & Arbitrary domain \\
\hline DARPA & Defense Advanced Research Projects Agency \\
\hline DCR & Dual-Combustion Ramjet \\
\hline DLR & German Aerospace Center \\
\hline DMSJ & Dual-Mode Scramjet \\
\hline FASTT & Freeflight Atmospheric Scramjet Test Technique \\
\hline FFV1 & Free Flight Vehicle for the FASTT Program \\
\hline FPA & Flowpath A \\
\hline FPB & Flowpath B \\
\hline$G$ & Nondimensional establishment time \\
\hline$g(x)$ & Arbitrary function \\
\hline GASL & General Applied Science Laboratory \\
\hline GASP & General Aerodynamic Simulation Program \\
\hline GEM & 6 degree of freedom trajectory analysis program \\
\hline$h$ & Enthalpy \\
\hline HEG & High Enthalpy shock tunnel in Göttingen, Germany \\
\hline HFG & Heat Flux Gauge \\
\hline
\end{tabular}




\begin{tabular}{|c|c|}
\hline$I$ & Arbitrary integral \\
\hline$\hat{I}_{m}$ & Approximation to arbitrary integral \\
\hline$\hat{\hat{I}}_{m}$ & Approximation to integral where importance sampling is used \\
\hline IML & Inner Mold Line \\
\hline ITAR & International Traffic in Arms Regulations \\
\hline$L$ & Length \\
\hline LaRC & NASA Langley Research Center \\
\hline LHI & Laser Holographic Interferometry \\
\hline$M$ & Mach number \\
\hline M4BDF & Mach 4 Blowdown Facility \\
\hline NASA & National Aeronautics and Space Administration \\
\hline NSROC & NASA Sounding Rocket Operations Contract \\
\hline OML & Outer Mold Line \\
\hline ONR & Office of Naval Research \\
\hline OTT & Optimal Test Time \\
\hline$P$ & Pressure \\
\hline$q$ & Dynamic pressure \\
\hline $\mathrm{QE}$ & Quartile Elevation (launch angle) \\
\hline $\operatorname{Re}$ & Reynolds number \\
\hline RANS & Reynolds Averaged Navier Stokes Equations \\
\hline REST & Rectangular to Elliptic Shape Transition \\
\hline RST & Reflected Shock Tunnel \\
\hline$s$ & Entropy \\
\hline SDPTE & Short Duration Propulsion Test and Evaluation Program \\
\hline SET & Shock-Expansion Tunnel \\
\hline SPV1 & Surrogate Payload Vehicle flight 1 for the FASTT Program \\
\hline SPV2 & Surrogate Payload Vehicle flight 2 for the FASTT Program \\
\hline SSIT & Second Stage Ignition Time \\
\hline$t$ & Time variable \\
\hline TNT & Theoretical Nose Tip \\
\hline
\end{tabular}


T3 Free-piston shock tunnel located in Canberra, Australia

T4 Free-piston shock tunnel located in Brisbane, Australia

TBIV Test Bay 4

$\mathrm{u} \quad \mathrm{X}$-component of velocity

USGPO United States Government Printing Office

UVaSCF University of Virginia Supersonic Combustion Tunnel

$\mathrm{V} \quad$ Y-component of velocity

V Velocity

VKF von Karman Gas Dynamics Facility

$x \quad$ Axial position

$y^{+} \quad$ Dimensionless wall distance

$\gamma \quad$ Ratio of specific heats $\left(\mathrm{C}_{\mathrm{p}} / \mathrm{C}_{\mathrm{v}}\right)$

$\eta \quad$ An efficiency

$\theta \quad$ Momentum thickness

$\pi(x) \quad$ Arbitrary non-uniform distribution

$\rho \quad$ Density

$\sigma \quad$ Standard deviation

$\sigma^{2} \quad$ Variance

\section{$\underline{\text { Subscripts }}$}

0

$1 \quad$ Behind forebody shock in inlet

2 Entrance to cowl in inlet

3 Entrance to internal contraction of inlet

$4 \quad$ Behind cowl shocks

AD Adiabatic

e Edge of boundary layer

flight Flight conditions

i Isolator entrance

KE Kinetic Energy 


$\begin{array}{ll}\text { L } & \text { Length } \\ \mathrm{p} & \text { Constant pressure } \\ \mathrm{s} & \text { Static conditions } \\ \mathrm{t} & \text { Total conditions } \\ v & \text { Constant volume } \\ \theta & \text { Momentum thickness }\end{array}$




\section{Chapter 1: Introduction}

Ever since the invention of powered flight, there has been a drive to expand the flight performance envelope of flying vehicles. Advances in propulsion have been instrumental in flying farther and faster than ever before. To this end, ramjets and supersonic combustion ramjets (scramjets) have been identified as key enabling technologies for interatmospheric flight significantly faster than the speed of sound (Heiser and Pratt, 1994). While a rocket engine can be used to accelerate a vehicle to these flight conditions, an airbreathing engine is more efficient at its operational speeds because it has a much larger specific impulse over a variety of flight conditions. This is due to the fact that a rocket powered vehicle must carry both fuel and oxidizer whereas an airbreathing vehicle only needs to carry fuel, using oxygen from atmospheric air as the oxidizer (Fry, 2004).

In a ramjet operating at supersonic speeds, incoming air is decelerated to subsonic Mach numbers and is compressed aerodynamically through a series of shocks. Fuel is injected into this compressed subsonic airstream and burned in the combustor before it is expanded through a nozzle producing thrust. For flight speeds nearing Mach 6, it is advantageous to maintain a supersonic airflow through the combustor. For these flight speeds, if the flow of air to the combustor is to remain subsonic, total pressure losses over the inlet shock train become prohibitive. The temperature rise over the inlet shock train also creates structural/material problems in the combustor. This temperature rise can also lead to chemical dissociation and thus energy loss from the engine cycle. In a scramjet, the airflow remains supersonic and these problems are mitigated (Smart, 2007).

Since flow at hypersonic Mach numbers $(M \geq 5)$ behaves very differently from flow at 
subsonic or supersonic Mach numbers, the testing of hypersonic engines involves challenges not encountered in engine testing for flight in other regimes. For hypersonic Mach numbers, thermal, chemical, radiative, and ablative effects become important. Energy and heat transfer considerations make continuous-run, full scale testing at hypersonic Mach numbers difficult or impossible. While facilities have been devised specifically to study certain aspects of hypersonic flight, no single facility has the ability to simulate all flow conditions a hypersonic vehicle or engine may encounter (Lu and Marren, 2002).

Even at a given test condition, various types of facilities have different advantages and limitations regarding scramjet testing. Facilities commonly used for scramjet testing can be divided into three main categories: blowdown, continuous run, and impulse. Furthermore, these facilities can sometimes also be configured for direct-connect testing. In a direct-connect facility, the nozzle exits directly to the engine's isolator or combustor and the flow distortions produced by the engine's inlet in flight are generally not present.

A blowdown facility uses stored pressurized gas which is expanded through a nozzle over the test article or through the flowpath in a direct-connect configuration. Exhaust often exits the test section into a vacuum chamber to reproduce an exit pressure less than that of the atmospheric air. To simulate appropriate static temperatures in the test section and prevent liquefaction in the test chamber, the test gas must be heated before expansion. This test gas heating is commonly accomplished by burning fuel in the test gas (often with oxygen added to the flow in order to maintain the correct mole fraction of oxygen for combustion studies), passing the test gas through a heat exchanger, or some combination of the two. Test times are often limited to minutes or seconds by the storage 
capacity of the compressed air system, heat storage capacity of the test gas heating system, or the capacity of the vacuum system if the tunnel does not exhaust to the atmosphere (Lu and Marren, 2002).

Continuous run facilities for scramjet testing continuously compress air and heat it to proper stagnation pressures and temperatures before expanding it through a supersonic nozzle over the test article or through the flowpath in a direct-connect configuration. These facilities often have test times on the order of hours and allow for incremental changes in the test configuration during a single run of the facility. Total temperature of the test gas is often limited by the available heat transfer to the test gas while total pressure and mass flow are limited by the capability of the compressor system (Lu and Marren, 2002).

Impulse facilities commonly achieve high pressures and temperatures upstream of the nozzle by utilizing a shock wave propagating through a high-pressure reservoir. The test gas is expanded through a nozzle over the test article in the test chamber. While this type of facility can produce flight Mach numbers in excess of 20, test times are on the order of milliseconds to tens of milliseconds depending on the conditions simulated and design of the facility. Quick expansion of high-enthalpy stagnant air to hypersonic velocities can give rise to non-equilibrium flow, dissimilar to that seen in atmospheric flight. Since the acceleration of the test gas to hypersonic conditions is an inherently transient process, drift in test conditions during the useful test time can be observed. One must often account for the movement of the usable test gas over the model by time-shifting results. Flow over the rear of the model might be completely acceptable at the same time that the flow over the front of the model is contaminated by the driver gas. Despite these 
limitations, shock heated facilities remain the predominant tool for aerodynamic and scramjet testing at Mach numbers greater than approximately 8 (Lu and Marren, 2002).

Flight can be considered the ultimate test of a hypersonic vehicle or engine because no facility effects are present. It is often the case, however, that budgetary, thermal, structural, or other logistical limitations restrict the range of diagnostics available for flight vehicles. Flight programs also incur significant risk that is generally not present or significantly reduced for ground testing programs. If an unguided rocket is used to minimize cost, the likelihood that the payload will achieve the desired test conditions decreases. If a reactive control system is utilized to increase the likelihood that the payload will achieve the desired test conditions, complexity and cost both increase significantly. As such, flight programs are nearly always augmented with significant ground testing to reduce risk and confirm engine operability limits. Often a range of wind tunnels is used in order to resolve the inherent deficiencies of any one type of ground test facility.

There have been several notable scramjet flight test programs over the past few decades, which have combined both flight and ground testing. From 1994-1998, Russia and the USA worked together collaboratively to test an axisymmetric, regeneratively cooled, hydrogen fueled scramjet engine with a target Mach number of 6.5. This program utilized ground testing in a vitiated wind tunnel as well as a flight test aboard a “flying laboratory" propelled by modified Russian SA5 missile boosters. Pressure and temperature data were relayed back to the ground for comparison with ground test data with the aim of exploring supersonic combustion and validating design and analysis techniques (Roudakov et al., 1998).

Approved for public release; distribution is unlimited. AEDC PA 2012-083 
Hyper-X was a massive scramjet test program with significant ground testing and 3 flights, two at Mach 7, and one at Mach 10. It was intended to demonstrate and validate the design tools, experimental techniques, performance predictions, and computational methods required to design an airframe integrated, hydrogen fueled hypersonic vehicle. The flight vehicle itself was approximately 12 feet long, weighed 2,700 lbs (Holland et al., 2001) and was boosted to operating conditions aboard an Orbital Sciences Pegasus derived booster (Marshall et al., 2005). Significant wind tunnel testing took place with the aim of characterizing engine operation, boundary layer transition, aerodynamic heating, transonic, supersonic, and hypersonic aerodynamics, as well as stage separation dynamics and aerodynamics (McClinton et al., 1998).

The Hyper-X ground testing campaign utilized a wide range of ground test facilities for both hypersonic and transonic/supersonic aerodynamic testing and combustion studies. These facilities and their use are summarized in Table 1-1.

Table 1-1: Hyper-X ground test facilities.

\begin{tabular}{|c|c|c|c|}
\hline Function & Tunnel & Type & Reference \\
\hline Hypersonic aerodynamics & $\begin{array}{c}\text { NASA Langley 20" } \\
\text { Mach } 6 \\
\end{array}$ & Blowdown & Miller, 1990 \\
\hline Hypersonic aerodynamics & $\begin{array}{c}\text { NASA Langley } 31 " \\
\text { Mach } 10\end{array}$ & Blowdown & Miller, 1990 \\
\hline Hypersonic aerodynamics & $\begin{array}{c}\text { AEDC VKF Tunnel } \\
\text { B }\end{array}$ & $\begin{array}{c}\text { Continuous, combustion } \\
\text { heated }\end{array}$ & $\begin{array}{c}\text { Pirrello et al., } \\
1971 \\
\end{array}$ \\
\hline $\begin{array}{c}\text { Transonic/supersonic } \\
\text { aerodynamics }\end{array}$ & $\begin{array}{l}\text { Boeing Polysonic } \\
\text { Wind Tunnel }\end{array}$ & Blowdown & $\begin{array}{l}\text { Penaranda and } \\
\text { Freda, } 1985\end{array}$ \\
\hline $\begin{array}{c}\text { Transonic/supersonic } \\
\text { aerodynamics }\end{array}$ & $\begin{array}{c}\text { Lockheed Martin } \\
\text { Vought High Speed } \\
\text { Wind Tunnel }\end{array}$ & Blowdown & $\begin{array}{c}\text { Pirrello et al., } \\
1971\end{array}$ \\
\hline $\begin{array}{c}\text { Transonic/supersonic } \\
\text { aerodynamics }\end{array}$ & $\begin{array}{c}\text { NTS Trisonic Wind } \\
\text { Tunnel }\end{array}$ & Blowdown & $\begin{array}{c}\text { Pirrello et al., } \\
1972 \\
\end{array}$ \\
\hline Low speed aerodynamics & Vigyan subsonic & 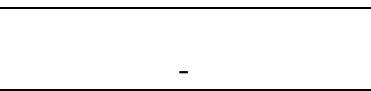 & $\begin{array}{c}\text { McClinton et al., } \\
1998\end{array}$ \\
\hline Low speed aerodynamics & $\begin{array}{c}\text { Boeing North } \\
\text { American Subsonic }\end{array}$ & - & $\begin{array}{c}\text { McClinton et al., } \\
1999\end{array}$ \\
\hline Propulsion & $\begin{array}{c}\text { LaRC Mach } 4 \\
\text { Blowdown Facility } \\
\text { (M4BDF) }\end{array}$ & $\begin{array}{l}\text { Ambient temperature air, } \\
\text { blowdown }\end{array}$ & $\begin{array}{l}\text { Emami et al., } \\
1995\end{array}$ \\
\hline
\end{tabular}




\begin{tabular}{|c|c|c|c|}
\hline Propulsion & GASL Leg II & $\begin{array}{l}\text { Direct connect, hydrogen } \\
\text { combustion heated, } \\
\text { blowdown }\end{array}$ & Roffe et al., 1997 \\
\hline Propulsion & $\begin{array}{l}\text { NASA LaRC Arc- } \\
\text { Heated Scramjet Test } \\
\text { Facility }\end{array}$ & Arc heated blowdown & Guy et al., 1996 \\
\hline Propulsion & $\begin{array}{c}\text { NASA LaRC } \\
\text { Combustion-heated } \\
\text { Scramjet Test } \\
\text { Facility } \\
\end{array}$ & $\begin{array}{l}\text { Oxygen replenished, } \mathrm{H} 2 \\
\text { combustion heated } \\
\text { blowdown }\end{array}$ & Guy et al., 1996 \\
\hline Propulsion & GASL Leg IV & $\begin{array}{c}\text { Storage or hydrogen } \\
\text { combustion heated } \\
\text { blowdown }\end{array}$ & Roffe et al., 1997 \\
\hline Propulsion & GASL Leg V & $\begin{array}{l}\text { Hydrogen combustion } \\
\text { heated, blowdown }\end{array}$ & Roffe et al., 1997 \\
\hline Propulsion & $\begin{array}{l}\text { NASA LaRC 8' High } \\
\text { Temperature Tunnel }\end{array}$ & $\begin{array}{l}\text { Methane combustion heated, } \\
\text { blowdown }\end{array}$ & Guy et al., 1996 \\
\hline Propulsion & $\begin{array}{c}\text { HASA Hypersonic } \\
\text { Pulse Facility } \\
\text { (HyPulse) }\end{array}$ & Shock-heated impulse & Roffe et al., 1997 \\
\hline
\end{tabular}

HyShot was a much smaller program, initially aimed at validating the use of short duration, shock-heated ground test facilities and achieve supersonic combustion at a Mach number of 7.5. It did so though a campaign comprised of ground testing and flight tests aboard a two-stage Terrier-Orion Mk70 rocket. In order to achieve the high design Mach number, the scramjet was tested towards the end of a ballistic re-entry trajectory. Supersonic combustion was achieved and the flight is widely considered a success (Smart et al., 2006). Further flights were planned incorporating different payloads and program goals.

Freeflight Atmospheric Scramjet Test Technique (FASTT) was a program funded by the Defense Advanced Research Projects Agency (DARPA) and the Office of Naval Research (ONR) with the aim of demonstrating a hydrocarbon fueled Dual-Combustor Ramjet (DCR) propelled hypersonic vehicle as well as the feasibility of using a groundlaunched sounding rocket as an inexpensive method for hypersonic flight testing. Two unpowered free-flight tests were followed by a successful powered flight in late 2005 
which demonstrated acceleration under scramjet power. An engine ground test program was conducted utilizing the GASL Test Bay VI vitiated heater to complement the flight test effort (Foelsche et al., 2006).

Since no ground test can perfectly simulate the flight environment, and flight testing is inherently complex and expensive, test techniques for integrated ground and flight test programs must be established to further advance scramjet development.

\subsection{Statement of problem}

Ground testing is critical for understanding the operation and performance of hypersonic airbreathing propulsion systems. For any engine tested in a freejet configuration or in flight, an inlet is needed to process the incoming air to conditions suitable for combustion. Since the experiment presented in this dissertation was partially motivated by tests performed in the University of Virginia Supersonic Combustion Facility (UVaSCF), a direct-connect facility, the inlet must be designed to deliver a specific set of conditions at the beginning of the constant area section of the flowpath, or isolator entrance. This is a unique design goal. Further geometric limits significantly constrict the design space available for the SDPTE inlet.

While scramjets operating in the supersonic combustion mode have been tested in impulse facilities, never before has a scramjet been successfully operated in the dualmode regime in this type of facility. Further the time required for a precombustion shock-train, characteristic of dual-mode DMSJ operation, to establish and stabilize has not been studied and is currently unknown.

Ground-based tests have proven very useful in the development of hypersonic airbreathing engines but often suffer from test gas vitiation, poorly matched boundary 
conditions, short flow duration, or generally poor flow quality (Goyne et al., 2006). Since many ground test facilities exhibit these limitations, their effect on the performance and operation of a dual-mode scramjet is not well characterized.

A scramjet flight test eliminates facility effects and presents a scramjet with realistic test gas. Acceleration of the test article to operating speeds can be accomplished with an unguided, spin-stabilized sounding rocket. While this is a relatively inexpensive method for achieving the desired freestream test conditions, additional risk is incurred because it is a near certainty that the vehicle will deviate from the nominal trajectory by some amount. This is due to the inherent uncertainty in various quantities modeled which affect the trajectory of the flight vehicle, giving rise to dispersion in the test condition attained. Several recent sounding rocket based scramjet flight tests have experienced significant deviation in test condition from pre-flight prediction (Smart et al., 2006 and Foelsche et al., 2006). Since a scramjet's operation is largely dictated by the freestream conditions it encounters, any reduction of the dispersion in these conditions translates directly to an increase in the likelihood of a successful flight experiment.

\subsection{Main goal and research objectives}

Since no ground test can fully simulate the flight environment, it is important to understand and characterize the discrepancies between propulsion testing in an inherently imperfect wind tunnel and actual scramjet performance in flight. To this end, the Short Duration Propulsion Test and Evaluation (SDPTE) program was combined with the Hy$\mathrm{V}$ program with the goal of investigating the effects of test gas contamination or vitiation and flow duration on a dual-mode scramjet (DMSJ). Vitiation, which results from certain test gas heating methods (combustion or arc heating), and short flow duration, which is 
characteristic of shock heated impulse facilities, are the two primary facility effects which affect scramjet operation in ground testing. To evaluate these effects, a single representative DMSJ flowpath is being tested in numerous facilities which span a range of flow durations, boundary conditions, and test gas contaminants. These include the UVa Supersonic Combustion Facility (UVaSCF) which is a continuous run, electrically heated direct connect facility, Test Bay IV (TBIV) which is a blowdown facility and can operate in either combustion heated or unvitiated storage heated modes depending on the test condition desired, and the NASA HyPulse facility which is a shock heated impulse facility. Testing is focused on a Mach 5 flight condition where dual mode operation has been observed in direct-connect testing. A Mach 5 flight experiment utilizing the same flowpath geometry is also planned. An unguided, spin-stabilized sounding rocket will be used to accelerate the payload to operating conditions (Goyne et al., 2009a).

Therefore, the primary goal of this dissertation is to advance test techniques for the testing of dual-mode scramjets through the evaluation of DMSJ inlet, isolator, and combustor performance through the SDPTE program ground and flight tests. Resulting data can also be used for subsequent CFD validation and verification. More specifically, the objectives of the proposed work are:

1. a) Design an inlet for both flight and ground testing in conjunction with a nominal flight test point to achieve the desired isolator entrance conditions.

b) Verify the inlet's operation through analysis of the Mach 5 HyPulse data.

2. a) Demonstrate both supersonic and dual-mode combustion within a DMSJ in an impulse facility.

b) Analyze and evaluate Mach 5 HyPulse data for test gas quality, determination 
of the fuel supplied to each engine, flowpath ignition, and combustor operation.

c) Evaluate whether flow through a DMSJ operating in the dual-mode regime can become fully established within the available test time and whether such a configuration can be tested in an impulse facility.

3. a) Design and simulate a nominal trajectory for the SDPTE flight vehicle which corresponds to the inlet designed for objective 1a.

b) Quantify the dispersion of the SDPTE flight vehicle through Monte Carlo simulation and investigate how this dispersion affects the likelihood of a successful scramjet flight test.

c) Develop and numerically test a novel method for the reduction of dispersion in freestream conditions seen by the scramjet during the test.

These objectives are a subset of those identified for the SDPTE program and when successfully achieved will aid in its completion. The goal of this dissertation is to provide a framework for the design and execution of a scramjet flight and ground test campaign in the context of the SDPTE program. This dissertation will also support the SDPTE program's goal of illuminating the effects of facility vitiation on the operation and performance of a dual-mode scramjet. Further, data generated from this program, particularly from tests in HyPulse, will be useful for the validation of computational models currently under development.

\subsection{Organization of dissertation}

This section summarizes the chapters of this dissertation, describing the procedures, results, and analysis employed to accomplish the goals and objectives outlined above. Chapter 2 describes the design and testing of the SDPTE scramjet inlet for both ground 
testing and flight. General design considerations are addressed as well as how they were applied to the SDPTE inlet to meet program objectives. This chapter also describes the experimental testing of this inlet in an impulse facility and presents the results of these tests. Conclusions are drawn regarding the operation of this inlet as well as its suitability for use in flight.

Chapter 3 details the scramjet combustion experiment that took place utilizing the inlet described in the previous chapter. An overview of the facility utilized and resulting test conditions is presented as well as a detailed description of the test article and its design. The design of the fuel and ignition systems is described as well as their performance. Results of these tests are presented as well as a discussion of these results and an analysis of ignition trends observed in these tests.

Chapter 4 describes the design, implementation, and numerical testing of a novel method for reducing dispersion for a sounding rocket scramjet flight experiment. The flight vehicle configuration and nominal trajectory are presented as well as background regarding their design. The concept of dispersion is introduced in relation to the freestream conditions that the vehicle will encounter during the flight test and results of a Monte Carlo analysis quantifying this dispersion for SDPTE are presented. Following is a description of the method used for reducing this dispersion and the results of a numerical test of this technique. A discussion of the results and their implication on airbreathing engine flight testing concludes the chapter.

Finally, concluding remarks are presented in Chapter 5. Here the findings of this study are presented as well as their contributions to the field and implications for future scramjet research and testing. This final chapter also describes the limitations of this 
work and outlines possible directions for future research related to this study. 


\section{Chapter 2: Design and test of an inlet for a scramjet flight and ground test program}

\subsection{Introduction}

The most promising engine cycle for sustained hypersonic flight within the atmosphere is the supersonic combustion ramjet or scramjet. To alleviate the large total pressure loss and high static temperatures associated with decelerating a hypersonic freestream to subsonic conditions, as in a ramjet, a scramjet maintains a supersonic airflow through the combustor. It is the job of the inlet to compress and heat the incoming hypersonic freestream air to a suitable pressure and temperature and supply it to the combustor at a sufficient mass flow rate to sustain the required level of combustion.

Such a hypersonic inlet has been designed for use in the Short Duration Propulsion Test and Evaluation (SDPTE) program which involves freejet and direct connect ground tests as well as a flight experiment. This program aims to investigate the effects of test gas contamination and short test times on the operation and performance of a dual-mode scramjet at Mach 5 flight enthalpy (Goyne et al., 2009a). Test gas contamination or vitiation results as a byproduct of using combustion to heat the test gas. Impulse facilities, while capable of simulating high flight enthalpies with a clean test gas, are plagued by very short test times. The SDPTE ground testing campaign consists of tests in Test Bay IV (TBIV), a blowdown facility capable of Mach 5 operation with a clean or vitiated airflow, NASA's HyPulse facility, an impulse facility utilizing a clean test gas (Roffe et al., 1997), and the University of Virginia Superonic Combustion Facility 
(UVaSCF), an electrically heated direct-connect facility capable of Mach 5 enthalpy simulations (Goyne et al., 2001). Testing in the UVaSCF requires no inlet because test gas is supplied at the appropriate conditions directly to the flowpath's isolator via a supersonic nozzle in a direct connect configuration. The tests in TBIV and HyPulse are conducted in a freejet configuration and require a forebody and inlet to process the incoming freestream. Since HyPulse presents the model with an impulsive heat load, the possibility exists to measure heat flux along the flowpath. Regarding inlet design, this information is useful because it permits evaluation of the boundary layer state. For this reason, experimental verification of the SDPTE's inlet was conducted in the HyPulse facility.

Since no single facility can perfectly replicate the hypersonic flight environment, a flight test of the same flowpath in atmospheric air has also been designed. A detailed description of the SDPTE mission profile can be found in Goyne et al. (2009a). In an effort to reduce costs, an existing flight-certified shroud was specified to protect the flight inlet from the high heat loads and dynamic pressures of launch. This placed unique limitations on the dimensions of the inlet. SDPTE program objectives placed additional restrictions on the inlet exit flowfield. Some of the restrictions on the inlet exit flowfield were relaxed later in the program. The rationale for this decision and tradeoffs encountered are discussed in later sections of this chapter. The process of designing a hypersonic flight inlet to match conditions seen in a direct-connect facility as well as a freejet inlet for ground testing and the problems encountered in such an endeavor are not reported in the open literature and is the main focus of this chapter. 


\subsubsection{General inlet design considerations}

Hypersonic inlets are generally designed with the goals of minimizing weight, providing required compression, minimizing total pressure losses, minimizing drag, maximizing uniformity of the inlet exit flow, and doing all these things over a wide range of flight conditions. (Van Wie, 2000) Often these goals compete with one another. Furthermore, aerodynamic and mechanical constraints are often placed on top of these competing goals, as was the case for this study. Scramjet inlets are typically designed to include both external and internal compression. Due to the large number of competing inlet design goals and vehicle specific constraints, it is important that the designer consider the performance of the entire compression system in the context of its intended application. While most hypersonic inlets, such as those of Hyper-X (Marshall et al., 2005) and X-51 (Hank et al., 2008), are designed for overall vehicle performance, the SDPTE flight inlet was designed, in conjunction with a nominal flight trajectory to yield specific conditions at the isolator entrance that matched those of the UVaSCF direct connect facility. A less efficient inlet was acceptable as long as the conditions at the entrance to the isolator matched those achievable on the ground when the inlet was matched with a proper flight vehicle trajectory. The inlets for freejet ground testing followed from the flight vehicle inlet design.

\subsubsection{Types of inlets}

Many types of scramjet inlets have been designed to efficiently decelerate air from the freestream and deliver it to an isolator and a combustor. One of the simplest of these geometries is that of the generic two dimensional inlet where the freestream is compressed externally by a forebody surface and internally by a cowl (Van Wie and Ault, 
1996). Addition of sidewall compression for these types of inlets has also been investigated as well as methods to increase their operability limits (Holland and Perkins, 1990). Many axisymmetric inlets have been designed where external compression is provided by a spike and various degrees of internal compression are provided by an axisymmetric cowl at the base of the spike (Molder et al., 1992 and Andrews et al., 1971). Various inward turning inlets have also been proposed which boast high theoretical efficiencies but are difficult to start and exhibit little tolerance of off-design conditions (Molder and Szpiro, 1966). Streamline traced sections of this type of inlet have been devised to capitalize on the high theoretical efficiency of this inlet design while increasing starting characteristics and operational margin (Billig, 1995). Rectangular to Elliptic Shape Transition (REST) inlets have also been devised which take advantage of a large rectangular capture area as well as the lower structural weight and lower wetted area to enclose a certain combustor cross section associated with an elliptic combustor (Smart, 1999).

Like that of the Hyper-X and X-51 program, the inlet chosen for the SDPTE program was of the simple 2D class. Unlike inward turning and streamline traced inlets for rectangular flowpaths, this type of inlet was relatively straightforward to analytically evaluate, was well characterized in the literature, and exhibited minimal mechanical complexity.

\subsubsection{Contraction and starting limit considerations}

If a scramjet inlet is operating properly, the flowfield contained by the internal portion of the inlet does not affect the ability of the inlet to capture air and is said to be operating in a started mode. If the inlet contraction is too great, flow at the throat can 
become sonic, causing an inlet unstart. An unstart can also be caused by excessive backpressure which cannot be accommodated by the inlet. In the latter case the shock system expelled by the inlet is likely strong enough to separate the boundary layer on the forebody causing a large region of separated flow. While an inlet unstarted in this fashion may continue to capture supersonic airflow, the efficiency of this capture process is lower than that for a started inlet due to the compression, expansion, and recompression of the flow around the separated region on the forebody. High heat loads are also observed at the reattachment point on the downstream edge of the separated flow and total mass capture of the inlet is decreased.

For given freestream conditions and inlet geometry, there is a contraction ratio above which the inlet will not start and there is a greater contraction ratio above which the inlet will not operate even if it is started through use of variable geometry. Much research has been conducted to understand the process by which inlets start and to determine these limiting contraction ratios for various inlet configurations (Goldberg and Hefner, 1970, McGregor et al., 1992, and Van Wie et al., 1996). Kantrowitz and Donaldson (1945) estimated a limit for the allowable internal contraction if an inlet is to be self-starting. This limit, known as the "Kantrowitz limit," assumes a normal shock at the beginning of the internal contraction and determines the one-dimensional, isentropic, internal area ratio which would produce sonic flow at the throat. According to the Kantrowitz limit, the allowable starting contraction ratio increases with the Mach number. A maximum isentropic contraction ratio can also be calculated which estimates the maximum steady flow contraction ratio an inlet can sustain once started without regard to the initial starting process and also increases with Mach number.

Approved for public release; distribution is unlimited. AEDC PA 2012-083 
Since the Kantrowitz limit assumes a normal shock at the entrance to the inlet's internal contraction, it becomes conservative at higher Mach numbers. The oblique shock compression system of a hypersonic inlet will exhibit less total pressure loss than one incorporating a normal shock and thus will be able to withstand a higher contraction ratio than the Kantrowitz limit may suggest. This effect is exaggerated at higher Mach numbers where losses associated with a single normal shock become very large.

\subsubsection{Boundary layer separation considerations}

When a shock strikes a surface on which a boundary layer has developed, as is often the case in a scramjet inlet, the boundary layer is subjected to a high adverse pressure gradient at the point of intersection. If this pressure gradient is large enough, it can cause the boundary layer to separate leading to a subsonic recirculation or separation bubble, high local pressure and heating rates, as well as undesired flow phenomena leading to loss of inlet efficiency. As such, inlets are designed to avoid boundary layer separation. There are several ways by which a shock wave can interact with and separate a boundary layer. The interactions of primary concern here are the two dimensional shock reflection and three dimensional glancing sidewall shock. Korkegi (1975) correlated existing two and three dimensional data for turbulent boundary layers to determine a relationship between the freestream Mach number upstream of the shock-boundary layer interaction and the incipient pressure rise required to cause separation for both two and three dimensional interactions. This is important because a significant separation of the boundary layer ahead of the inlet can decrease engine mass capture, degrade engine performance through increased total pressure loss, or completely unstart the inlet. 


\subsubsection{Objectives of this work}

A hypersonic inlet was designed to assess the performance of a dual-mode scramjet in ground testing and in flight as per the objectives of the SDPTE program. This flight inlet was required to provide a set of conditions at the throat which matched those achievable in the UVaSCF when exposed to atmospheric air at the proper Mach number and static pressure. As such, each proposed inlet configuration had a unique nominal flight test point (Mach number and altitude) and accompanying nominal trajectory, designed to achieve that point. Test articles utilizing the same inlet geometry as the chosen flight inlet were designed and built for the NASA HyPulse and TBIV freejet testing component of the SDPTE program. The design of the inlet for the SDPTE flight test is detailed here including design requirements and a description of other candidate geometries considered. Modifications to the chosen design aimed at increasing the inlet's starting characteristics and off-design operability are presented along with performance predictions from 1D calculations as well as two and 3 dimensional CFD. More explicitly, the objectives of this work are:

1. Design an inlet suitable for the SDPTE flight experiment which can be suitably adapted to full-scale ground testing in available facilities.

2. Through experimental testing, validate the design and verify its performance and operation.

The challenges and process of designing a scramjet flight inlet and integrating it with a vehicle to satisfy strict geometric constraints as well as provide isolator entrance conditions dictated by a direct-connect ground test facility have not been reported in the literature. The progression of this inlet design as well an explanation of the technical 
hurdles encountered and overcome is detailed here. The installation and testing of the associated freejet inlet in the HyPulse facility is also described and the results of these tests are presented with a comparison to predicted performance.

\subsection{Inlet Design}

Since the SDPTE program is primarily a combustion investigation as opposed to an engine development program, the scramjet inlet, flowpath, and exhaust nozzle have not been optimized for traditional engine system operating characteristics, such as mixing efficiency or thrust produced. As such, the conditions at the throat of the inlet were of greater concern than the efficiency by which those conditions were produced at any given flight point. Also, because the nominal flight test point, and thus nominal trajectory, was developed in parallel with the inlet, the freestream test conditions could be chosen in order to accommodate inlets with different efficiencies, compression, and total pressure loss. While this fact permitted significant flexibility in the inlet design, several competing program requirements were quite restrictive and ultimately led to the relaxation of some of the initial inlet design requirements.

\subsubsection{Initial design requirements}

A stringent set of inlet design requirements was set forth from the beginning of the program. They were:

- Inlet exit must match the existing flowpath dimensions of the UVaSCF (1 x 1.5 inches).

- Inlet must match flow properties at the UVaSCF nozzle when paired with appropriate trajectory.

- Inlet must fit within existing flight-certified shroud.

Approved for public release; distribution is unlimited. AEDC PA 2012-083 
- Inlet must be self-starting and self-restarting over all expected flight conditions.

Since the exact flowpath of the UVaSCF was to be utilized for both the flight and ground testing, it was important that the flow downstream of the inlet be similar to that of the flow in the UVaSCF just downstream of the facility nozzle. The UVaSCF flowpath consists of a Mach 2 nozzle followed by a 16 inch long, 1.0x1.5 inch rectangular, constant area isolator followed by a $0.5 \mathrm{inch}$ wide and 0.25 inch tall unswept ramp fuel injector. Beginning 2.5 inches downstream of the base of the fuel injector, the fuel injector wall has a 2.9 degree divergence. Flow exits the tunnel 14.5 inches downstream of the fuel injector and is exhausted to atmospheric pressure (Goyne et al., 2007). This flowpath is shown schematically in Figure 2.1.

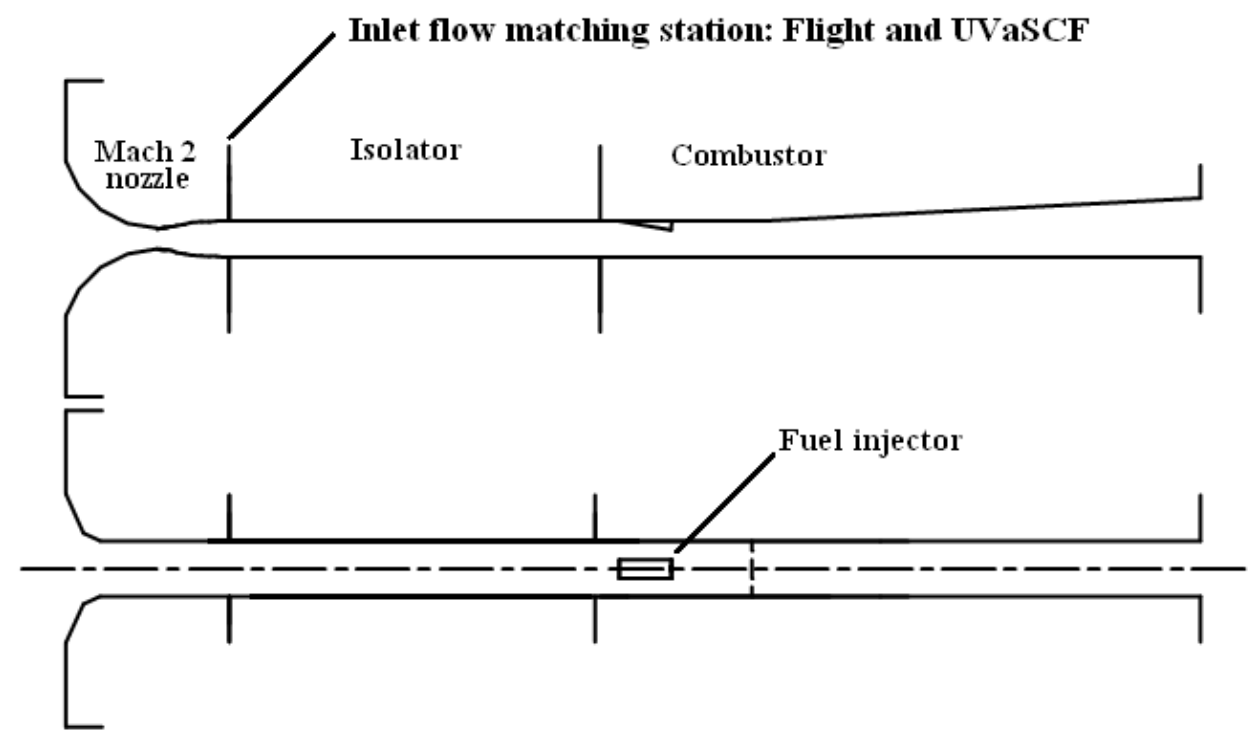

Figure 2.1: UVaSCF direct-connect flowpath schematic. (Adapted from Goyne et al., 2009a)

Perfectly matching the flow just downstream of the UVaSCF nozzle in flight was not possible because the flight inlet could not perfectly replicate the boundary layer state seen 
just downstream of the direct-connect nozzle with sufficient fidelity. In theory, though, it was possible to match both the geometry of the duct and the stream-thrust-averaged conditions just downstream of the UVaSCF facility nozzle so long as no shocks were swallowed by the inlet. To this end, a shock trap, similar to that for HyShot (Smart et al., 2006), was initially specified to ensure that any shock produced by the engine cowl lip would not disturb flow downstream of the inlet. A shock trap is a space between the forebody and the beginning of the bodyside isolator wall which allows the cowl shock to turn the flow without further reflection down the isolator.

The mission profile for the SDPTE flight experiment was based on that of the FASTT program (Foelsche et al., 2006), a sounding rocket flight experiment which successfully demonstrated a hydrocarbon-fueled, free-flying scramjet vehicle. The FASTT payload utilized a shroud to protect the scramjet inlet from the structural and heating loads produced by the high dynamic pressures of launch. Once the launch vehicle had passed through the dense air at low altitude and before the vehicle reached its insertion point, this shroud opened in a clamshell fashion and was jettisoned, exposing the inlet to the oncoming airstream. Since the SDPTE flight experiment required similar protection for the inlet on launch, an unused shroud left over from the FASTT program was obtained by permission from ATK-GASL and slated for use on the SDPTE flight experiment. This essentially eliminated development time and cost for this critical component because the shroud already existed, was available for use, and was already flight certified. Use of this shroud, however, created additional geometric constraints on the design of the inlet. Total diameter of the payload, and thus of the inlet as well, was limited to 10.8 inches at the shroud attachment point, just aft of the external portion of the inlet. The length of the 
inlet was also restricted. This ruled out use of a long isentropic compression surface for the inlet forebody.

Starting characteristics of the inlet were of primary concern. Incorporating variable inlet geometry to assist in the starting process was dismissed early within the program to reduce cost, complexity, and operational risk. A mechanically simple design was preferred to minimize design and manufacturing cost and risk. Without the potential aid of variable geometry, the SDPTE inlet needed to be self-starting when exposed to the oncoming freestream. This also ensured that the inlet would self-restart in the event of an unstart during the experiment.

A preliminary Monte-Carlo analysis, detailed in chapter 4, about a sample nominal trajectory indicated that there was significant uncertainty in the freestream conditions that the inlet was likely to experience when exposed to atmospheric air at the beginning of the experiment and throughout the rest of the flight. The Mach number during the test was shown to potentially vary from as low as 4.3 to over 6.0 . Thus, it was required that the inlet be able to operate and self-start under a variety of off-design conditions. It was also required that the inlet be tolerant of variations in angle of attack and yaw angle. Since the experiment was planned to take place during the burn of the second stage booster, these variations were expected to be mild as compared to those experienced by other sounding rocket scramjet tests which took place much later in the flight during the reentry phase of a ballistic trajectory (Smart et al., 2006).

\subsubsection{Candidate configurations}

Several inlet configurations and corresponding atmospheric test points were proposed based on preliminary $1 \mathrm{D}$ calculations. The geometric restrictions on inlet size as well as 
flowpath dimensions precluded a simple two turn inlet. Turn angles of exactly 20 degrees are required to slow a Mach 5 flow to the required Mach 2 at the entrance to the isolator if a two turn inlet is used. In order for the cowl to avoid capturing the forebody shock and for the cowl shock to be captured by a shock trap, the forebody length needed to grow beyond the allowable space within the shroud.

This idea was therefore abandoned in favor of an inlet which turned the flow 35 degrees, then expanded it by 15 degrees and was then turned back parallel to the incoming stream by the cowl. The shock from this cowl was captured in a shock trap. Since this process resulted in a Mach number below 2.0, an isentropic expansion was used to return the flow to the proper Mach number. The geometry of this expansion was such that the duct downstream of the isentropic expansion properly matched the required flowpath dimensions. Calculations showed that with the proper flight point, flow conditions at the entrance of the isolator could be made to match those in the UVaSCF. The geometry was also such that the inlet would fit within the shroud. Unfortunately, the strength of the cowl shock was such that if it was not captured by the shock trap and struck the forebody while operating off-design, it would have likely separated the forebody boundary layer according to the relations set forth by Korkegi (1975) and caused an inlet unstart. These relations, which give criteria for boundary layer separation are shown in Figure 2.2 for both a two dimensional shock reflection and a three dimensional glancing interaction. Several other inlet concepts were investigated, but all those which provided the necessary compression were inherently susceptible to boundary layer separation at off-design conditions. 


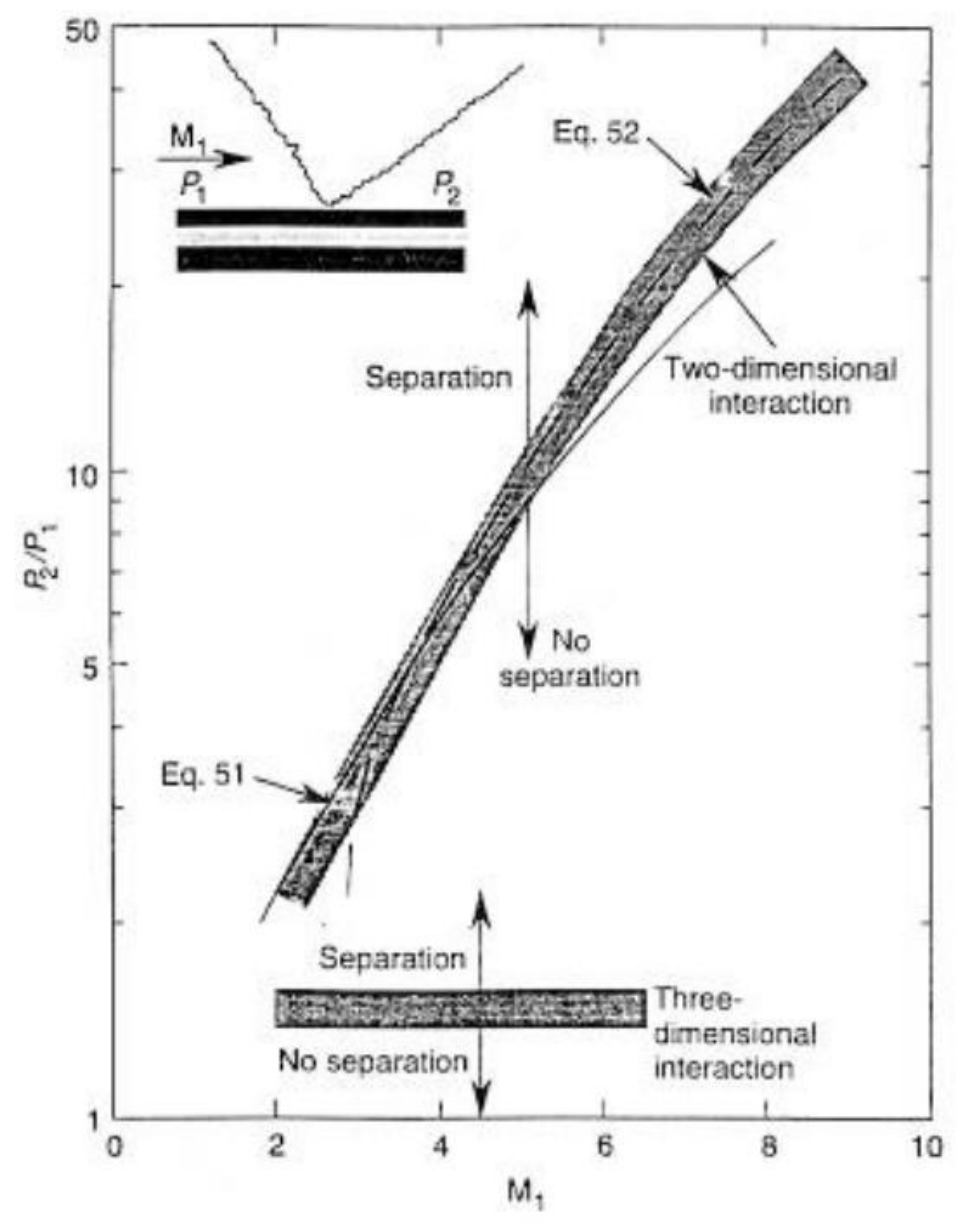

Figure 2.2: Korkegi relation. (Van Wie, 2000)

In order to increase off-design operability and minimize the likelihood of separating the forebody boundary layer, the requirement to fully match flow properties and flow uniformity of the UVaSCF was relaxed. While the flight Mach number, and thus total enthalpy, remained unchanged, requirements on the isolator entrance Mach number were relaxed. Allowing a higher throat Mach number meant less compression was required. This meant that the flow needed to turn a smaller amount and shocks would be weaker, decreasing the likelihood of separating the boundary layer on the forebody. To this end, a 10 degree half-angle wedge forebody was proposed with a single cowl turning the flow back parallel to the freestream. This geometry, however, did not include a shock trap, 
meaning that the cowl shock would be swallowed by the inlet. While the resulting flowfield no longer matched that at the entrance to the UVaSCF, it was more similar to that likely to be seen in an operational scramjet.

Preliminary 2D CFD (Goyne et al., 2009b) showed that the forebody boundary layer on this 10 degree wedge inlet was still in fact susceptible to shock-induced boundary layer separation at lower Mach numbers and sufficient angles of attack. This separation is consistent with the Korkegi relation. To minimize the likelihood of this separation, the tip of the cowl was "drooped" by 5 degrees, resulting in two cowl shocks, each of lower strength, which presented lower adverse pressure gradients to the forebody boundary layer. The cowl was also moved aft by 1 inch such that the second of these cowl shocks struck the bodyside wall behind the shoulder, making use of the expansion induced by the shoulder to accelerate the flow and significantly reduce the likelihood of separation induced by the second cowl shock. According to the Korkegi relation, this would prevent cowl shock induced boundary layer separation as long as the forebody boundary layer remained turbulent at the point of interaction. Mach number contours from the preliminary 2D CFD in Figure 2.3 show the unmodified and modified inlet at a flight Mach number of 5. As a result of this modification, inlet mass capture was reduced. This also reduced the contraction ratio to 1.3 , which is below the Kantrowitz limit (1.49), which relates the maximum allowable internal contraction for an inlet to be self-starting to the incoming Mach number and ratio of specific heats, for a flight Mach number of 4 . 

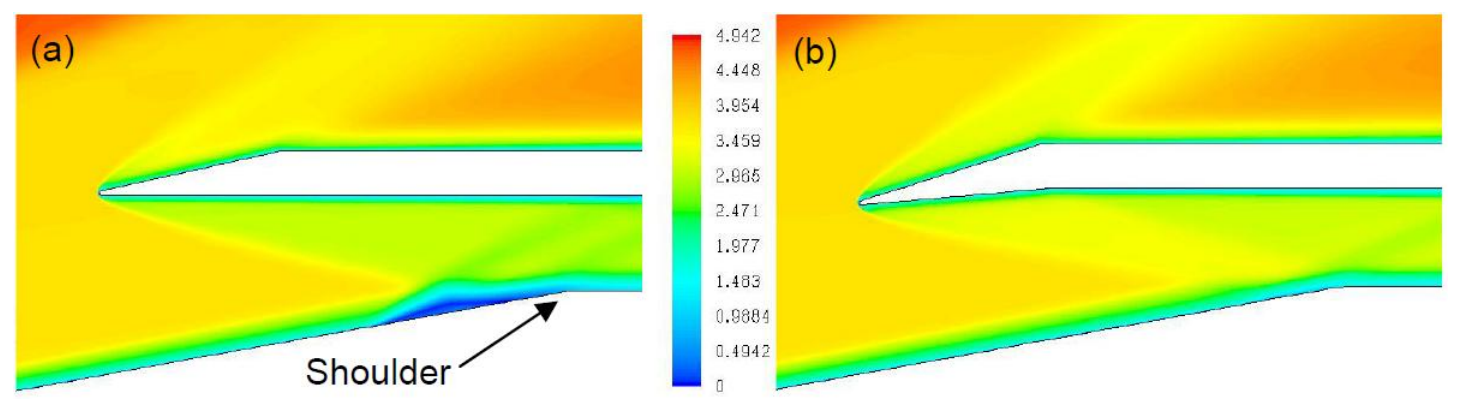

Figure 2.3: 2D Mach number contours for CFD simulations of forebody and inlet flow a) without cowl modification and b) with cowl modification. (Goyne et al., 2009b)

Fences were added to the forebody to prevent flow spillage over the edges of the forebody and to preserve the inlet's mass capture. These fences were designed such that characteristics from the forward corners of the forebody and rearward edges of the fences would not interact with flow captured by the inlet. An image showing the solid model of this final inlet configuration is given in Figure 2.4. Shroud attachment hardware can be seen on the side of the model as well as a boundary layer trip, which is discussed below, slightly less than halfway up the forebody. While not easily visible in Figure 2.4, there is a second inlet on the opposite side of the model which processes air for a second scramjet flowpath. 


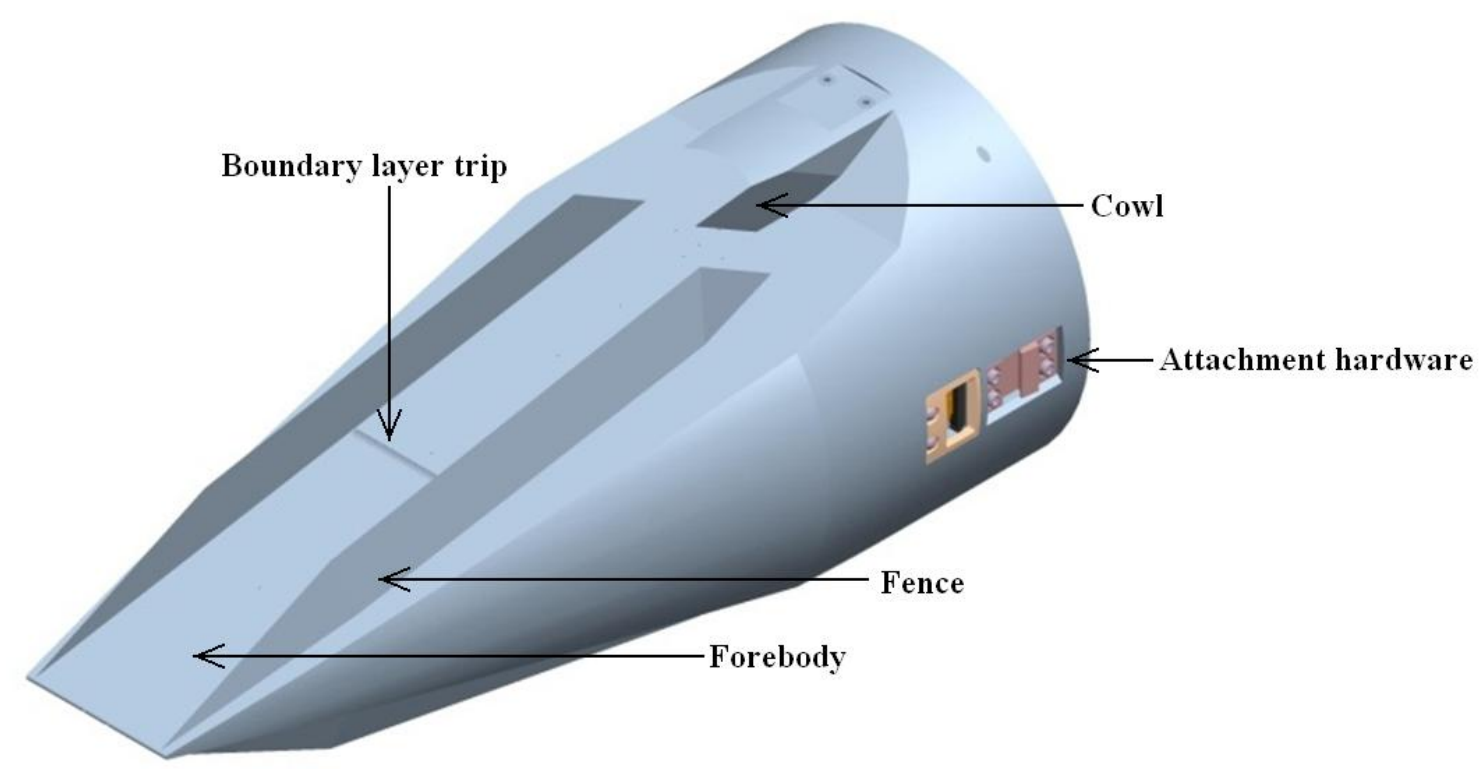

Figure 2.4: SDPTE flight inlet model.

The sidewall leading edges of the internal portion of the inlet were also swept at 30 degrees. Swept sidewalls enhance the ability of a two dimensional inlet to start at a given contraction ratio because flow is allowed to spill out of the corner of the sidewall/forebody interface for off-design, low-Mach number conditions (Cozart et al., 1992). A 2D schematic of this inlet is shown in Figure 2.5 with approximate shock locations and a generic shock train in the isolator.

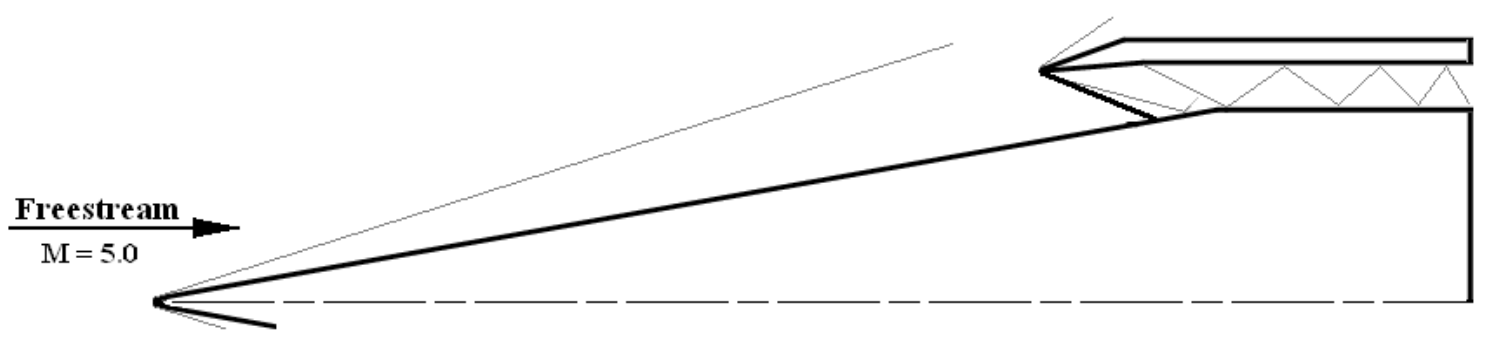

Figure 2.5: 2D schematic of SDPTE inlet.

\subsubsection{Boundary layer trip design}

For the SDPTE program, it was important to maintain a turbulent boundary layer at Approved for public release; distribution is unlimited. AEDC PA 2012-083 
the entrance to the internal section of the inlet to decrease the likelihood of boundary layer separation within the inlet. As such, a boundary layer trip was investigated for both the SDPTE flight and ground test articles.

Many types of boundary layer trips have been used in the past for supersonic flow along a flat surface including sand strips, wire trips, diamond shaped extrusions, blowing configurations, and small vortex generators. It has been demonstrated that for flow at a Mach number higher than approximately 4, two dimensional boundary layer trips, such as sand strips or wires, are mostly ineffective (Berry et al., 2000). Blowing configurations, diamond shaped extrusions, and small vortex generators were investigated for use in Hyper-X (Berry et al., 2004). The swept ramp vortex generator configuration best suited the flight conditions experienced in the Hyper-X program because it adequately induced turbulence and the generated vorticity was damped out much sooner than that of other designs (Berry et al., 2000).

Since shock tunnels have inherently high levels of pressure fluctuations as well as radiated nozzle wall acoustic noise (Schneider, 2001), transition is expected to occur sooner than in other types of tunnels. It was calculated that natural transition in HyPulse would likely be completed by a Reynolds number based on length of $3.4 \mathrm{E}+6$ (for $\mathrm{Re} / \mathrm{L}=$ $1.09 \mathrm{E}+7 \mathrm{~m}^{-1}$ ) according to measurements by Stollery (1967). This corresponds to a distance of 13.1 inches from the point along the SDPTE forebody where the nose tip would be located if there was no leading edge radius in HyPulse. Since the forebody is approximately 19 inches long, this gives a 1.5 factor of margin on length to transition before the isolator for testing in HyPulse.

The transition Reynolds number for a flight vehicle is expected to be higher than that 
in a ground test facility because in flight there is no freestream turbulence of the proper scale to prematurely induce transition to turbulence. At the worst case flight condition for transition length $(\mathrm{M}=4.5$ and $\mathrm{AOA}=+2.5 \mathrm{deg}$. $)$, transition is expected to be complete at a Reynolds number based on length of 1.02E+7 (Chen et al., 1989). This corresponds to a distance nearly 21 inches greater than the length of the SDPTE forebody. It is clear that a boundary layer trip is necessary for the flight vehicle.

Three main parameters affect the effectiveness of boundary layer trips:

- The boundary layer trip must be positioned far enough forward that the boundary layer has length to fully transition before a turbulent boundary layer is required.

- The height of the trip must be comparable to the height of the local boundary layer.

- The boundary layer must be receptive to the disturbance of the trip.

Experience with the Hyper-X program shows that at local Mach 4 conditions, a boundary layer trip height of 0.6 times the local boundary layer height was adequate to induce transition onset at the boundary layer trip (Berry et al., 2008).

In order to match the boundary layer in flight to what was expected in ground testing, the flight boundary layer trip was placed at the expected turbulent virtual origin for ground testing at the design condition. The turbulent virtual origin is commonly estimated as $82.5 \%$ of the length to completion of the transition to turbulence (Cary and Bertram, 1974). This point is located 10.7 inches from the theoretical nose tip along the forebody. Further experience from the Hyper-X program showed that effective boundary layer tripping requires a value of at least 110 for the Reynolds number based on 
momentum thickness divided by the Mach number at the edge of the boundary layer (Berry and Horvath, 2008). According to available CFD on the flight forebody, at the turbulent virtual origin, $\mathrm{Re}_{\theta} / \mathrm{M}_{\mathrm{e}}=371$. In order to satisfy the requirement that the trip height be 0.6 times the local boundary layer thickness, the boundary layer trip was specified to be 0.0415 inches in height.

Since the swept ramp design has proven successful at inducing boundary layer transition in flight, a similar design was chosen for the SDPTE flight vehicle forebody. The entire design was scaled such that the height of the swept ramp is 0.6 times the height of the local boundary layer for the flight scenario leading to the thickest local boundary layer $\left(\mathrm{M}_{\mathrm{flight}}=4.5\right.$ and an angle of attack of +2.5 degrees $)$. This boundary layer thickness is 0.6922 inches as calculated by the laminar theory of Van Driest (White, 1991) which leads to a ramp height of 0.0450 inches. Ramps were placed across the forebody with appropriate spacing at the above indicated distance from the theoretical nose tip such that the entire distance between the forebody fences is spanned.

\subsection{Predicted Performance and operability}

\subsubsection{Inviscid 1D prediction}

If an inlet is operating in a started state, simple 1-D calculations resulting from the laws of thermodynamics often offer reasonably accurate predictions describing the performance of the inlet. Further fidelity can be introduced to these calculations by considering a variable ratio of specific heats (Keenan and Kaye, 1948), which decreases with increasing static temperature.

The results of this analysis are shown in Table 2-1 and Table 2-2. Flow conditions were calculated at each station along the inlet adjusting the ratio of specific heats for the 
new static temperature behind each shock according to Keenan and Kaye (1948). The expansion was taken to cancel out any reflection downstream of the cowl shocks. As such, the isolator entrance conditions represent those behind the second cowl shock discounting the shoulder expansion and any cowl shock reflections. For these calculations, the 1976 Standard atmosphere (USGPO, 1976) was used giving a nominal test altitude for $\mathrm{M}=5.0$ and $\mathrm{q}=1500 \mathrm{psf}$ of $71,620 \mathrm{ft}$. This value is slightly different from the nominal test altitude quoted later in this dissertation and used for CFD analysis because 6 degree of freedom trajectory simulations performed incorporated a correction to the atmosphere's temperature profile based on an assumed month and location of launch. Shock angles and turn angles within the inlet as classically defined are reported in Table 2-2.

Table 2-1: Flow properties along SDPTE inlet. (variable gamma)

\begin{tabular}{|l|l|l|l|}
\hline & Freestream Conditions & Forebody & Isolator Entrance \\
\hline Mach No. & 5.00 & 4.00 & 3.32 \\
\hline Ps [psi $(\mathbf{k P a})]$ & $0.60(4.14)$ & $1.81(12.5)$ & $2.82(19.4)$ \\
\hline $\mathbf{P t}[\mathbf{p s i} \mathbf{( k P a})]$ & $315(2,172)$ & $275(1,896)$ & $273(1,882)$ \\
\hline $\mathbf{T s}[\mathbf{d e g} . \mathbf{R}(\mathbf{K})]$ & $393(218)$ & $562(312)$ & $639(355)$ \\
\hline $\mathbf{q}[\mathbf{p s f} \mathbf{( k P a})]$ & $1,500(71.8)$ & $2,922(139.9)$ & $3127(149.7)$ \\
\hline $\left.\boldsymbol{\rho}\left[\mathbf{s l u g} / \mathbf{f t}^{\mathbf{3}} \mathbf{( k g} / \mathbf{m}^{\mathbf{3}}\right)\right]$ & $1.270 \mathrm{E}-4(0.06545)$ & $2.705 \mathrm{E}-4(0.1394)$ & $3.702 \mathrm{E}-4(0.1908)$ \\
\hline $\mathbf{C p} / \mathbf{C v}$ & 1.400 & 1.400 & 1.395 \\
\hline $\mathbf{a}[\mathbf{f t} / \mathbf{s}(\mathbf{m} / \mathbf{s})]$ & $973(297)$ & $1162(354)$ & $1237(377)$ \\
\hline $\mathbf{V}[\mathbf{f t} / \mathbf{s} \mathbf{( m} / \mathbf{s})]$ & $4,863(1,482)$ & $4,649(1,417)$ & $4,110(1,253)$ \\
\hline
\end{tabular}

Table 2-2: SDPTE inlet shock parameters. (variable gamma)

\begin{tabular}{|l|l|l|}
\hline & Turn Angle (deg.) & Shock Angle (deg.) \\
\hline Forebody shock & 10 & 19.376 \\
\hline First Cowl Shock & 5 & 18.024 \\
\hline Second Cowl Shock & 5 & 19.519 \\
\hline
\end{tabular}

\subsubsection{CFD prediction}

Computational fluid dynamics was used to analyze the three dimensional behavior of the SDPTE inlet at a variety of conditions to further predict the inlet's performance as 
well as estimate operability limits. GASP (Aerosoft, 2009) was used to solve the Reynolds-averaged Navier-Stokes (RANS) equations. The realizable k-epsilon two equation turbulence closure was used with enhanced wall functions (Pope, 2000). The mesh made use of the horizontal and vertical planes of symmetry exhibited by the inlet and thus covered only $1 / 4$ of the domain around and inside the inlet. The structured mesh, shown on the symmetry plane in Figure 2.6, consisted of approximately 5.9 million hexahedral elements with a $y+$ value at the wall of 1.2. Solutions were obtained on a course, medium, and fine (final) grid. Results indicated that grid convergence was achieved with the 5.9 million element grid. A freestream Mach number, static pressure, and static temperature were specified as inflow conditions.

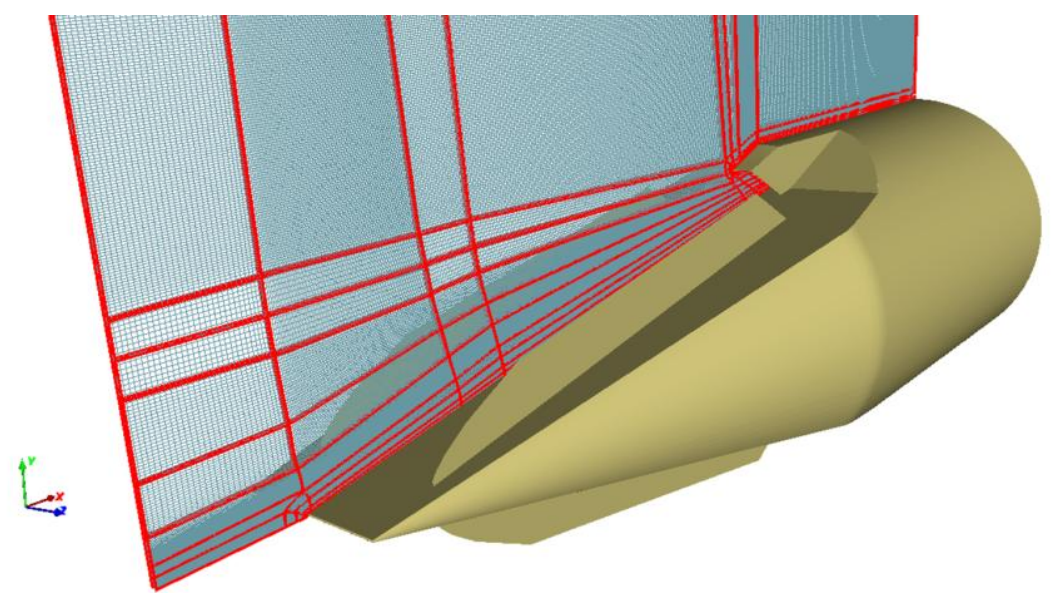

Figure 2.6: Structured mesh for inlet CFD. (Top of domain truncated)

The simulation was run until residuals fell below prespecified values. Domain exits were treated with a first order extrapolation. Solid boundaries were treated with a noslip, adiabatic boundary condition. A contour plot of Mach number along the centerline of the inlet for the nominal Mach 5.0 case shows the flowfield of characteristics of importance and is presented in Figure 2.7. Further CFD results as well as detailed inflow 
conditions are presented in Appendix B.

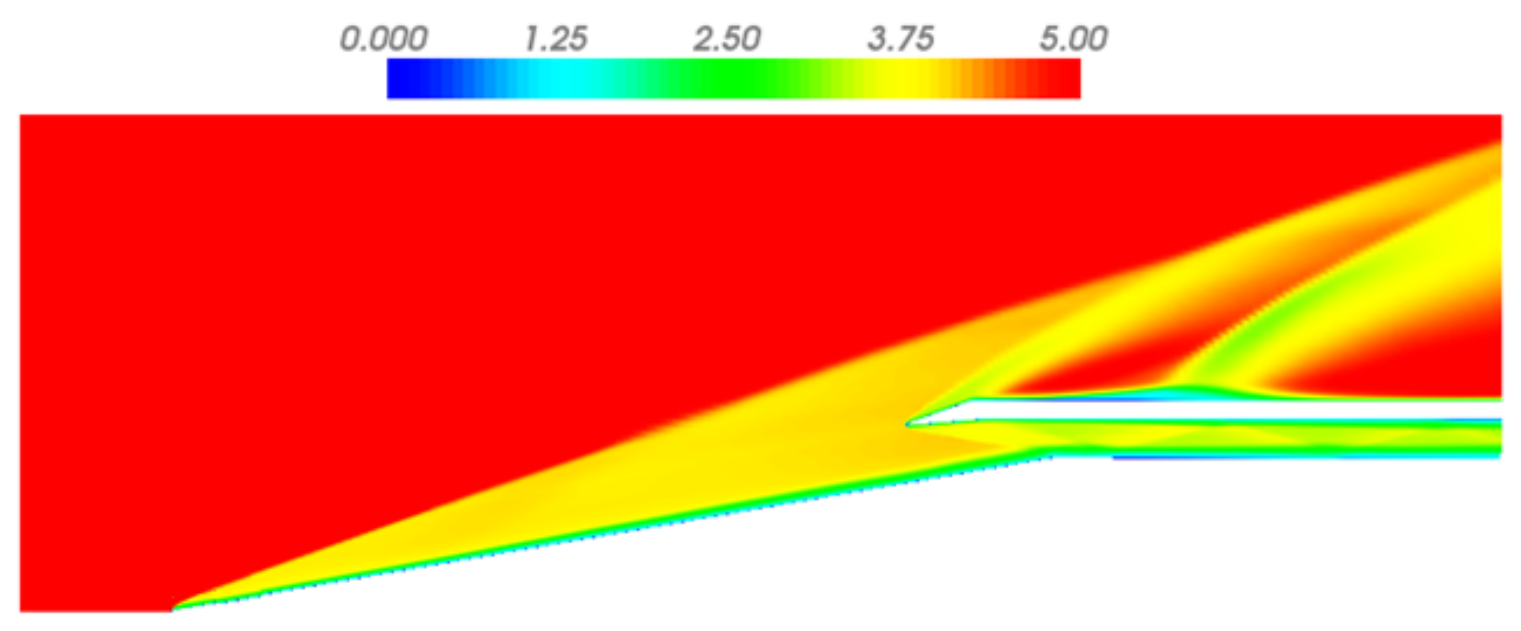

Figure 2.7: Mach number contour along inlet centerline.

One can clearly see the attached forebody shock emanating from the vehicle leading edge. A boundary layer develops and grows along the length of the forebody. Although the external aerodynamics of this vehicle are of little concern for this program, the external cowl shock and subsequent expansion are clearly shown as well as a separation on the outer cowl surface. The compression, expansion, and recompression of the flow around this separation are also apparent. Internally, the two cowl shocks, are clearly evident as well as their reflections down the beginning of the isolator. One can see the expansion at the shoulder as well as the boundary layer which grows on the cowl-side wall. The forebody boundary layer continues to grow on the bodyside wall as distance from the leading edge increases.

According to this CFD, the inlet operates as expected at the nominal test point. According to this simulation, the lowest Mach number at which the inlet remains started for a zero angle of attack is 4.46. Additional simulations at various angles of attack and 
Mach numbers up to 5.4 indicated that the inlet remained started for all flight conditions of interest.

\subsection{Experimental Verification}

As part of the SDPTE program, the flowpath and inlet were tested in HyPulse affording the opportunity to experimentally evaluate the inlet's performance.

\subsubsection{Facility}

The NASA HyPulse facility is a shock tunnel located at and operated by ATK-GASL in Ronkonkoma, NY. When configured as a Reflected Shock Tunnel (RST), it is capable of simulating flight Mach numbers from 4 to 12 . When possible, this is the desired configuration because test time is maximized. For Mach numbers from 12-20 where a higher stagnation pressure and enthalpy is required, HyPulse can be configured as a Shock Expansion Tunnel (SET). The test gas in HyPulse is clean, dry air.

In RST mode, which was used for this study, the test gas is heated by a forwardmoving shock and its reflection off the end wall of the shock tube. This shock-heated air serves exactly the same purpose as air in the plenum, or low subsonic portion, of a hypersonic nozzle. While very high simulated flight enthalpies can be obtained by heating the test gas in this manner, the resulting test time is often on the order of milliseconds depending on the desired test conditions.

While each test targeted the same test conditions, variations in diaphragm strength and scoring depth, which control the diaphragm bursting, led to slightly different conditions for each test. Initially diaphragms were too strong leading to higher than targeted total pressure, temperature, and shock velocity. In the last 6 of 9 tests, though, these quantities were measured to be within $3 \%$ of their target values. Excellent 
repeatability in test conditions was demonstrated.

\subsubsection{Test article}

Since no thermal management is required for testing in an impulse facility, the test article was made of aluminum and carbon steel with the leading edges of the forebody, flowpath inlets, and pedestal leading edge made of stainless steel. For this test, the two flowpaths were mounted side-by-side such that both could fit within the test rhombus of the HyPulse Mach 5 nozzle with the aid of an aeroappliance attached to the nozzle. A "jet stretcher" was used to extend this test rhombus over the forebody, supplying clean airflow to both inlets. CFD (not detailed here) on the ground test article indicated that the two inlets were adequately spaced to prevent the operation of one from influencing the other as long as they both operated in a started mode. For each flowpath, the cowl and two sidewalls form a single cover plate which fits on top of a machined bodyside fuel injector wall. This ensured that the assembly was capable of withstanding the maximum operating conditions expected. A pedestal assembly properly positioned the model downstream of the nozzle and housed all subassembly and support systems. A solid model of the test article is shown in Figure 2.8. The pedestal covers have been made transparent to highlight the internal pedestal structure. 


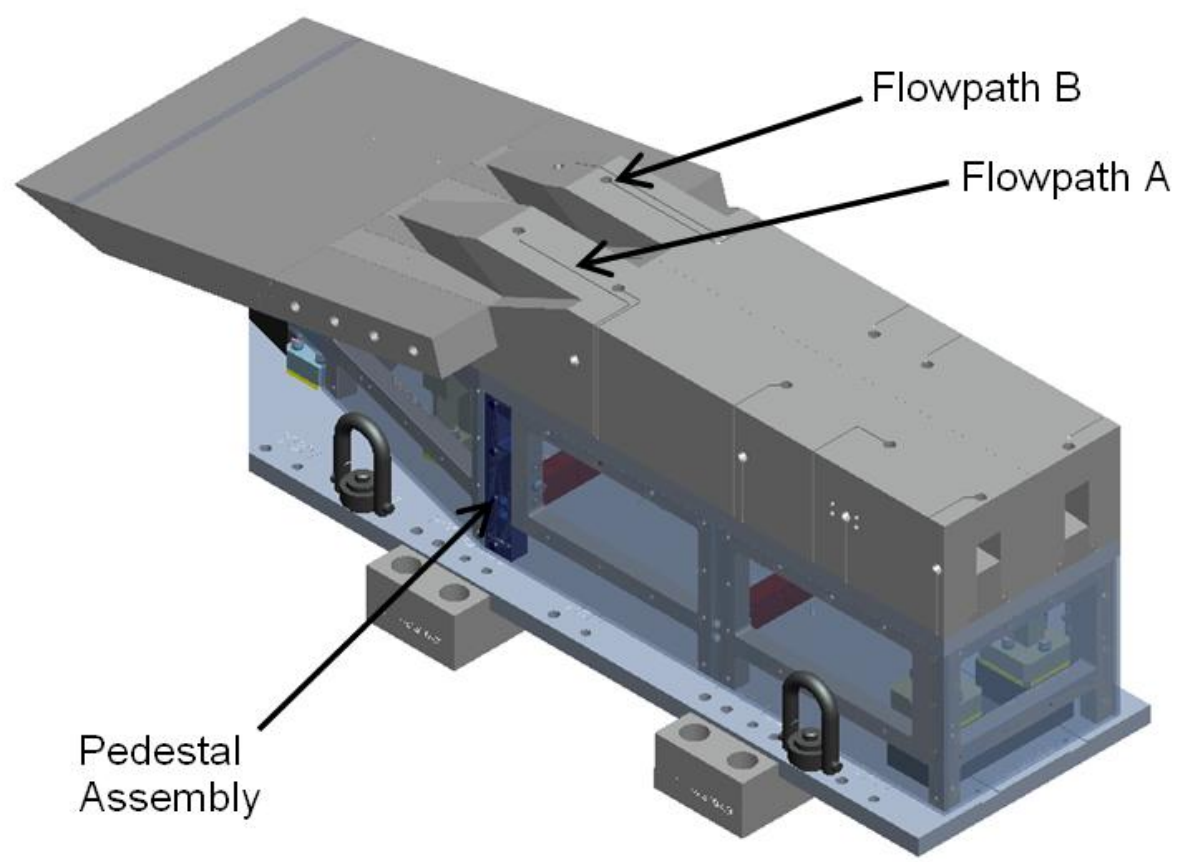

Figure 2.8: SDPTE HyPulse test article. (Goyne et al., 2009a)

The SDPTE HyPulse test article was heavily instrumented with 52 pressure taps per flowpath as well as 5 heat flux measurements at critical locations. Instrumentation locations were designed to reflect the installed instrumentation in the UVaSCF such that a meaningful comparison could be made. Pressure measurements were made using close coupled, high frequency, piezoelectric pressure transducers made by PCB Piezotronics, Inc. (series 112A20). Heat flux gauges retained the same Outer Mold Line (OML) as the PCB pressure transducers and were of the thin-film type. Unfortunately, the resulting heat flux data is unavailable due to damage during installation. The instrumentation of concern for assessing inlet operation is as follows. 6 pressure taps per inlet were placed on the forebody along the centerlines of the two inlets. 1 pressure tap was placed right at the shoulder and one was placed approximately 1.5 inches downstream of the shoulder in the center of the bodyside wall. 


\subsubsection{Test conditions}

The NASA HyPulse facility was configured to match the conditions seen at the inlet with those anticipated in flight. Testing for another program at ATK-GASL showed that the TBIV pebble bed air heater would not be unable to maintain a full Mach 5.0 enthalpy simulation $\left(T_{t}=2230\right.$ deg. $\left.R\right)$ for the entire 20 second test period required for the SDPTE blowdown dry-air tests. As such, the total enthalpy was reduced from that of a flight Mach 5.0 to flight Mach 4.8 simulation $\left(T_{t}=2089\right.$ deg. $\left.R\right)$ keeping the total pressure the same since the total temperature throughout the test is controlled through the use of a cold co-flow and unvitiated test time is limited by the energy storage capacity of the heater (Roffe, 1997). It was assumed that this change in simulated flight enthalpy did not significantly alter the inlet starting or operational characteristics. HyPulse test conditions for a dry-air Mach 4.8 flight simulation are detailed in Table 2-3.

Table 2-3: HyPulse Mach 4.8 simulation nozzle exit conditions.

\begin{tabular}{|l|l|}
\hline & Value \\
\hline Mach No. & 5.18 \\
\hline $\mathbf{P}[\mathbf{p s i} \mathbf{( k P a )}]$ & $0.513(3.54)$ \\
\hline $\mathbf{T}[\mathbf{d e g} . \mathbf{R}(\mathbf{K})]$ & $344(191)$ \\
\hline $\boldsymbol{\rho}\left[\mathbf{l b m} / \mathbf{f t}^{\mathbf{3}} \mathbf{( k g / \mathbf { m } ^ { 3 } ) ]}\right.$ & $0.00402(0.0644)$ \\
\hline $\mathbf{a}[\mathbf{f t} / \mathbf{s} \mathbf{( m / s )}]$ & $913(278)$ \\
\hline $\mathbf{V}[\mathbf{f t} / \mathbf{s}(\mathbf{m} / \mathbf{s})]$ & $4,731(1,442)$ \\
\hline $\mathbf{H t} \_\mathbf{2 9 8 K}[\mathbf{B t u} / \mathbf{l b m} \mathbf{( k J / k g )}]$ & $401(933)$ \\
\hline $\mathbf{P t}[\mathbf{p s i} \mathbf{( k P a )}]$ & $367(2,530)$ \\
\hline $\mathbf{T t}[\mathbf{d e g} . \mathbf{R}(\mathbf{K})]$ & $2,089(1,161)$ \\
\hline
\end{tabular}

\subsubsection{Facility calibration}

A Mach 5 nozzle was designed and fabricated for ground testing in HyPulse utilizing the RST configuration. The specific nozzle length was chosen to align the nozzle exit with the forward windows installed in the HyPulse test section. The nozzle exit area was maximized given the constraint that the nozzle throat diameter could not be more than $1 / 2$ 
the diameter of the shock tube diameter (6 inches). This resulted in an exit diameter of 16 inches with a throat diameter of 3 inches. Upon incorporation of viscous effects, the nozzle throat diameter was decreased to 2.705 inches giving a total area ratio of 35 , which resulted in an acceptable shock tube Mach number of 0.12 .

Since this nozzle had never been used for testing, its operation was characterized through experiment. As such, three tests were dedicated to this calibration. The first two tests simulated dry-air operation while the third simulated a vitiated test condition, which is not discussed here. The facility's pitot rake consisted of 27 pitot probes, each spaced 1 inch apart. The rake was mounted approximately 1 inch from the nozzle exit with the center probe at the center of the nozzle. Figure 2.9 shows the average nozzle plenum total pressure variation with time taken at multiple points on the flat subsonic section of the nozzle plenum. Vertical lines show the approximate test time.

Usable test time is taken as $t=4.2-6 \mathrm{~ms}$. Since the helium driver gas does not arrive until approximately $16 \mathrm{~ms}$, though, the clean dry air that arrives from 6-16 ms still maintains a high enthalpy and is still usable despite the decaying pressure. This is especially true if measured pressures are normalized by the time-shifted total pressure. It is important to understand the effect this will have on the equivalence ratio for a fixed fuel mass flow rate if the combustion process is to be analyzed. If total mass flow is decreasing throughout the test due to a falling static pressure, then the equivalence ratio will rise if the rate at which fuel is supplied to the engine is constant.

Figure 2.10 shows the pitot pressure variation with time, averaged over all pitot tubes contained within the 13 inch diameter nozzle core flow. The vertical lines denoting approximate test time have been shifted to account for the time it takes the test gas to 
travel from the nozzle plenum to the pitot rake. Figure 2.11 shows a comparison between the pitot pressures normalized by total pressure and averaged over the useful test time. Corresponding CFD data is included for comparison. Excellent agreement is shown between CFD and experiment with regards to both the behavior and size of the core flow. This validated the design of the nozzle. It is believed that the two aberrant probe readings at $r=-1.05$ inches and $r=-0.70$ inches respectively were due to a faulty probe.

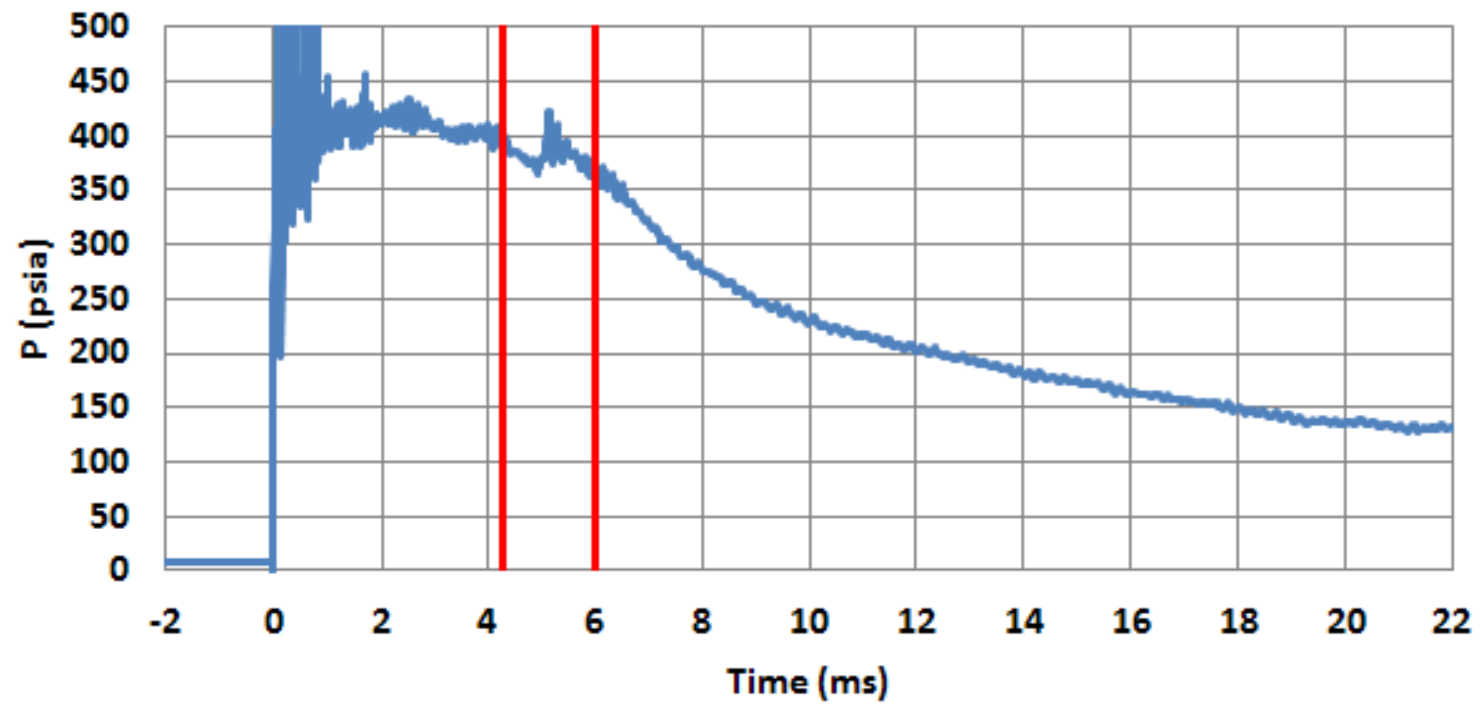

Figure 2.9: Average stagnation pressure vs. time. Nominal test time indicated by vertical lines. 


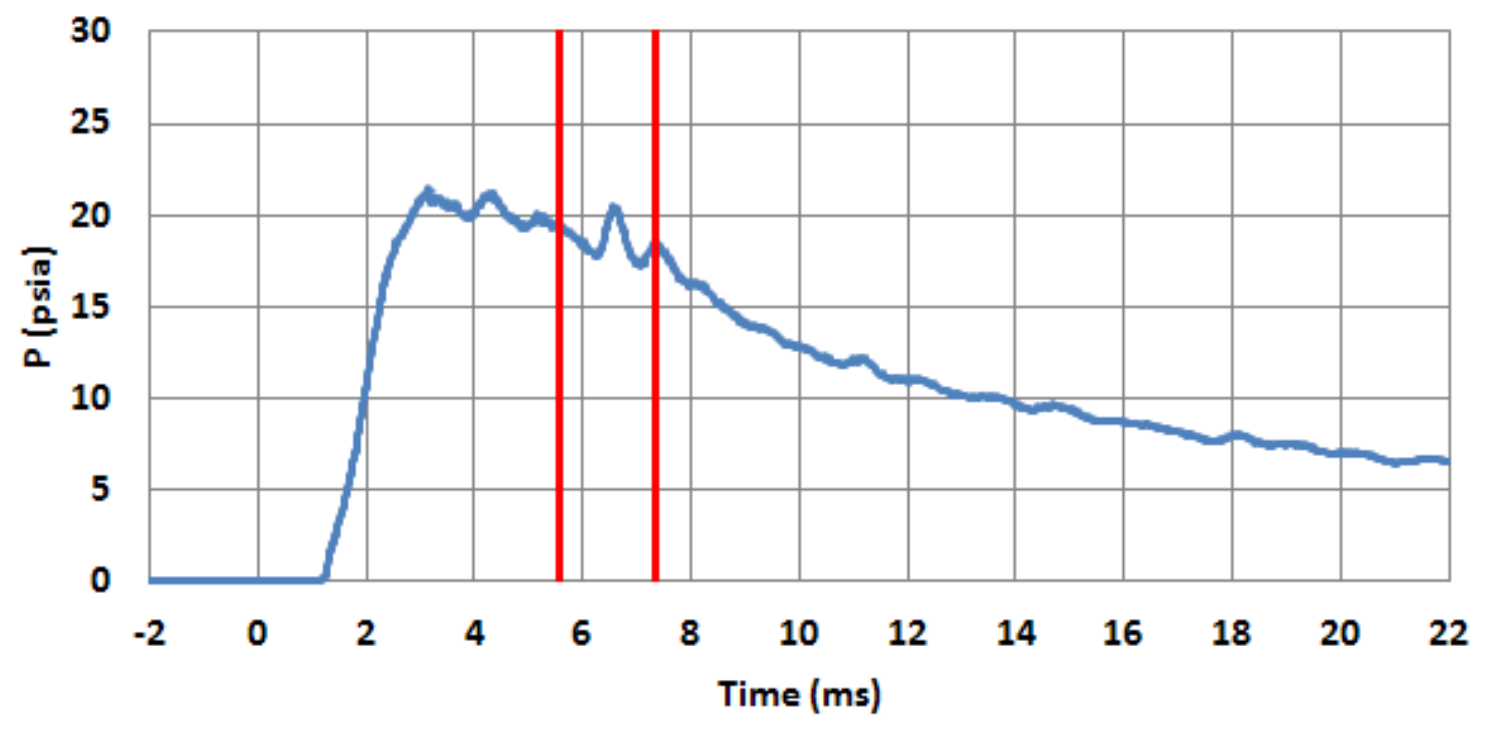

Figure 2.10: Average pitot pressure vs. time. Nominal test time indicated by vertical lines.

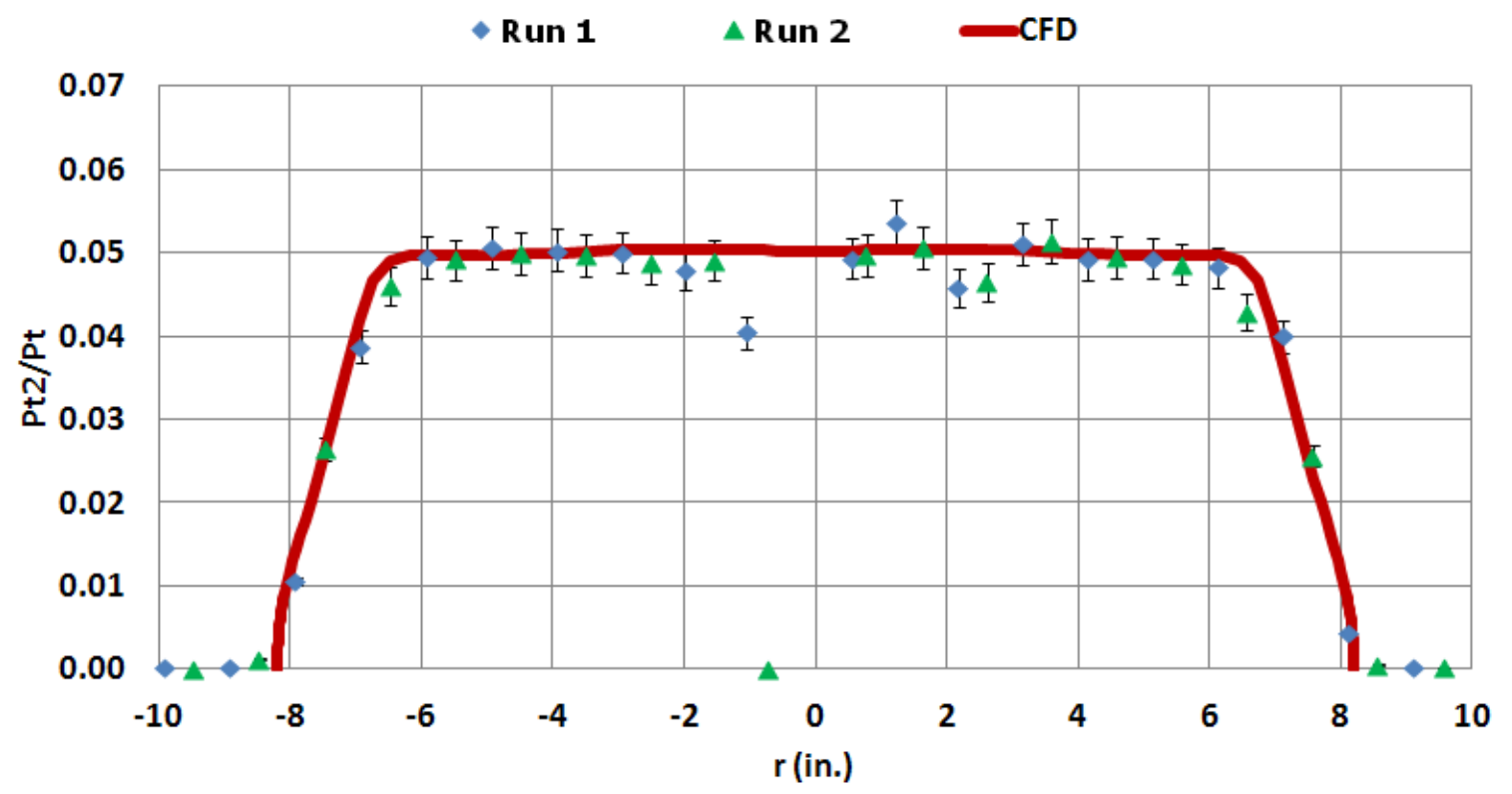

Figure 2.11: Pitot pressure vs. position for both HyPulse Mach 5 calibration runs.

The nominal test time is taken as $t=4.2-6 \mathrm{~ms}$. Since the helium driver gas does not arrive until approximately $3 \mathrm{~ms}$, though, the clean dry air that arrives from 6-3 ms still maintains a high enthalpy and is still usable despite the decaying pressure. This is 
especially true if measured pressures are normalized by the time-shifted total pressure. It is important to understand the effect this will have on the equivalence ratio for a fixed fuel mass flow rate if the combustion process is to be analyzed. It is also important to realize that the decaying static pressure will also cause a decay in the local Reynolds number, influencing boundary layer transition on the forebody.

It was later proposed that the diaphragm be moved downstream to extend the test time. The incident shock speed is much less than that of the driver gas expansion wave. As such, the driver gas expansion wave catches up with the incident shock. The movement of the driver gas and driven gas interface thus arrives much later than the expansion wave. Moving the diaphragm downstream decreases the distance and time it takes for the driver gas/driven gas interface to reach the nozzle and increases the distance that the expansion wave must travel resulting in increased test time.

Another calibration was performed with the downstream diaphragm configuration and an aeroappliance, or "jet stretcher," installed to extend the test rhombus further over the forebody preventing characteristics from the nozzle edge from interacting with the forebody shock and making their way into the inlet. The pitot rake was positioned at the expected location of the inlet cowl lips. Figure 2.12 shows the average pitot pressures obtained as a function of position as compared with CFD. The green triangles represent quantities that have been averaged over the first half of the extended test window and hollow red diamonds indicate quantities that have been averaged over the second half. This shows that nozzle flow is steady over the entire test period and that the nozzle and aeroappliance give the flowfield as designed. Results from later tests are virtually identical and demonstrate excellent repeatability. 


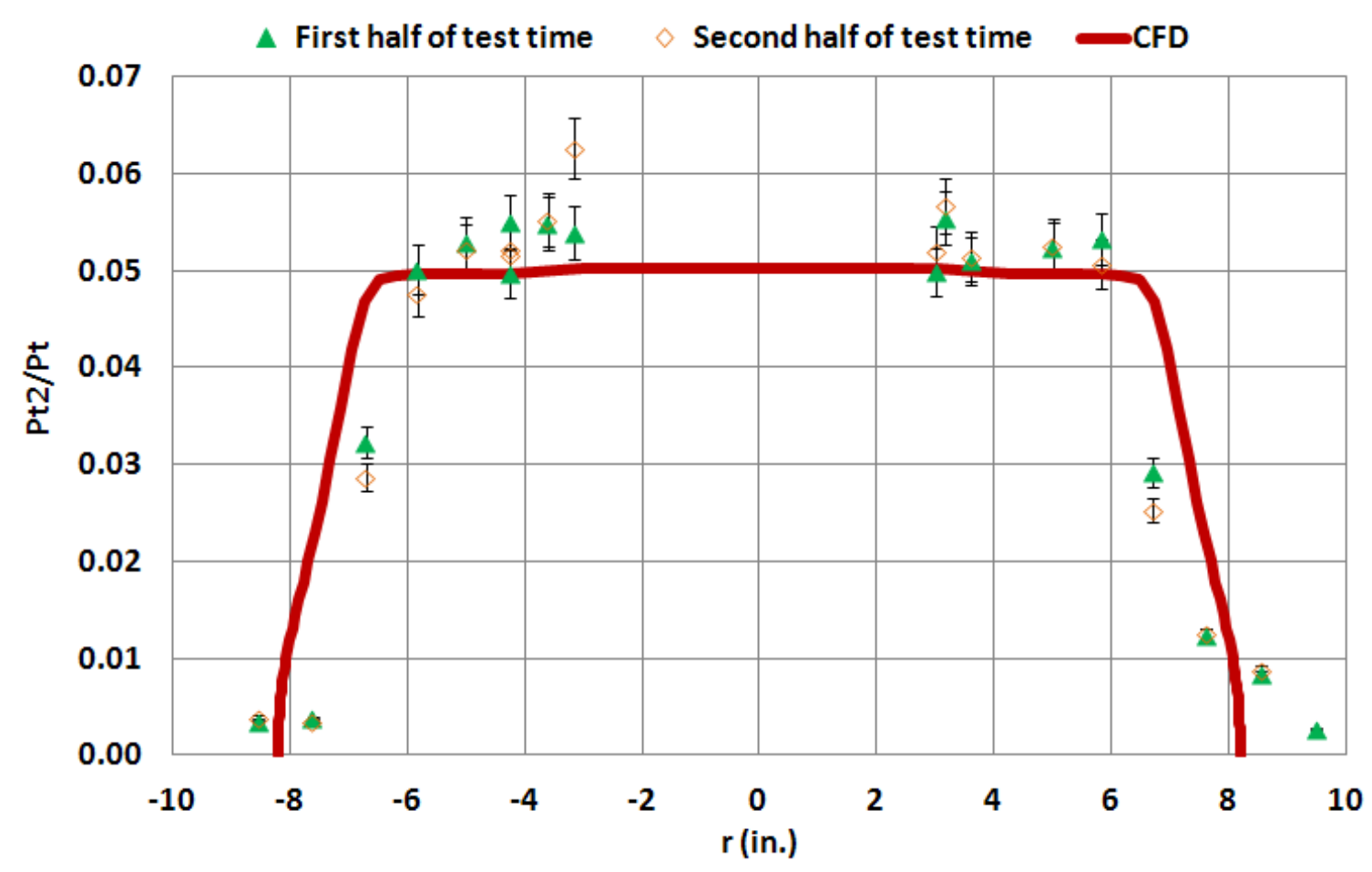

Figure 2.12: Pitot pressure vs. position for test with jet stretcher and new diaphragm location.

\subsection{Results}

Each test gives a set of pressure profiles along the test article which evolve in time. Unfortunately, the heat flux gauges were damaged during installation and the resulting data is not usable. As such, there is no way to confirm that the tunnel's freestream turbulence initiated natural transition on the test article forebody. For the purposes here, pressures are reported at each axial location for Flowpath A and B, as they have identical inlets, up to 24 inches, which is approximately 1.5 inches downstream of the inlet "shoulder." For these tests, 1.5 inches aft of the shoulder is considered this axial location of the inlet exit and the entrance to the isolator. This location is far enough downstream 
to capture the reflection of the second cowl shock without venturing too far into the isolator. The flowpath is shown above the pressure traces in all figures for clarity. Each high-frequency pressure reading was averaged over periods of $1 \mathrm{~ms}$ and the resulting values plotted. All reported pressure measurements are time shifted and normalized by the targeted total pressure divided by the time-shifted, measured total pressure. This partially corrects for the fact that each test achieved slightly different conditions. Pressure traces for other tests are shown in Appendix C.

In the test presented here in Figure 2.13 (Test I25) the realized total pressure and temperature were within $1 \%$ of the target value. Stagnation pressure was measured in the nozzle plenum and total temperature was calculated from measured shock speeds and pressure measurements within the test gas. The cowl shocks began moving forward around $12 \mathrm{~ms}$ signaling the presence of driver gas contaminating the test gas. Since helium has a higher ratio of specific heats $\left(c_{p} / c_{v}=1.66\right)$ than air $\left(c_{p} / c_{v}=1.40\right)$ at the temperatures of concern, a mixture of helium and air will exhibit a steeper shock angle for a given turn angle than pure air at the same conditions. The pressure rise at $\mathrm{x}=19$ inches at $\mathrm{t}=8-10 \mathrm{~ms}$ suggests the possible development of a small forebody boundary layer separation. This disturbance takes about 3-4 $\mathrm{ms}$ to stabilize. Then after $8 \mathrm{~ms}$ it begins to grow again and continues to do so throughout the test. The flowpath height shown in the following two figures is not to scale.

Approved for public release; distribution is unlimited. AEDC PA 2012-083 


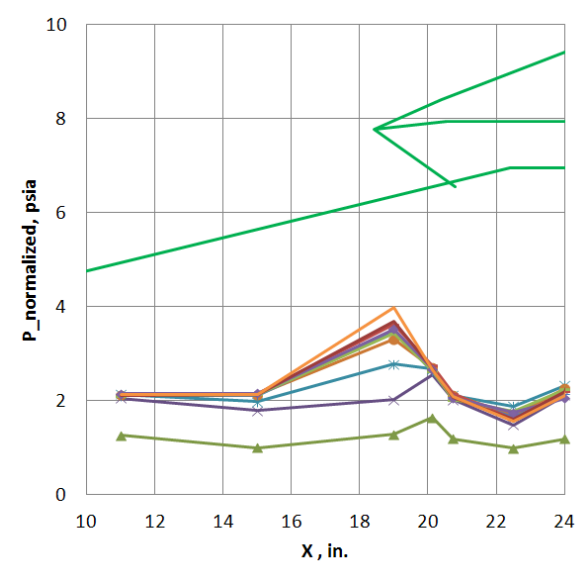

a.
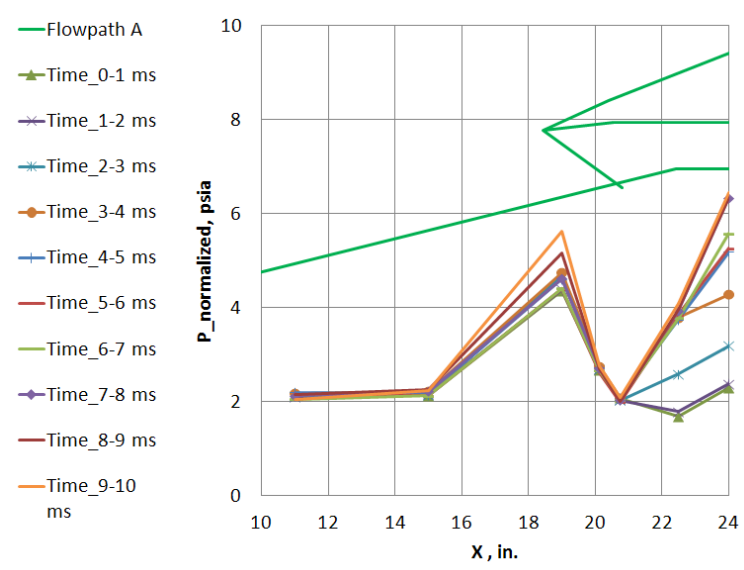

b.
—Flowpath A

$\rightarrow-$ Time_10-11 $\underset{*}{\text { ms }}$ Time_11-12 ms ms $\rightarrow-$ Time_13-14 ms - Time_14-15 ms -Time_15-16 _ms ms - Time_18-19 - Tims _19-20 $\mathrm{ms}$

\section{Figure 2.13: Pressure traces for flowpath $A$ inlet at a) 0-10 ms, and b) $10-20 \mathrm{~ms}$.}

a.

Figure 2.14 shows results from the inlet of flowpath $\mathrm{B}$, which is geometrically identical to the that of flowpath A, despite different flowpath geometry downstream. The operation of the inlet for flowpath B is markedly and unexpectedly different than that of flowpath A, although detailed assessment is difficult because there is no instrumentation between 11 and 20 inches on the forebody for this inlet. A higher than expected pressure is seen at 11 inches. While it is not immediately clear what is causes the elevated pressure at 11 inches, it may be indicative of a separation that has traveled farther forward on the forebody than the separation in front of the inlet for flowpath A. Additional instrumentation along the forebody ahead of flowpath B would help resolve the nature of this disturbance. Similar to flowpath A, cowl shock movement is seen starting around $12 \mathrm{~ms}$. The results of this test are characteristic of other tests for both flowpaths and are indicative of the operation of this inlet in HyPulse. Results for other tests can be seen in Appendix C.

Approved for public release; distribution is unlimited. AEDC PA 2012-083 


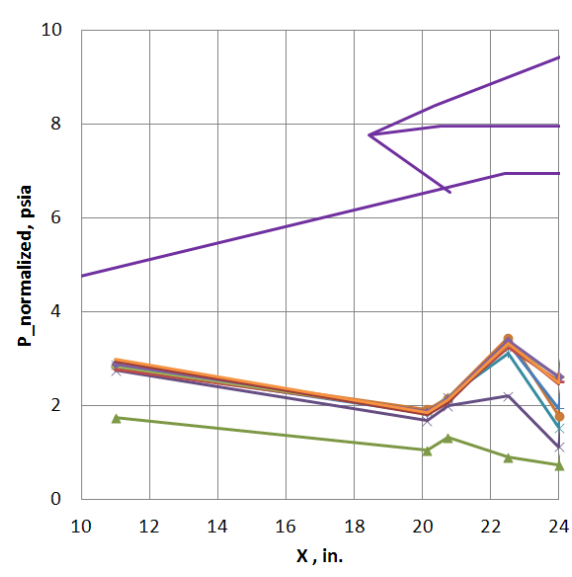

a.

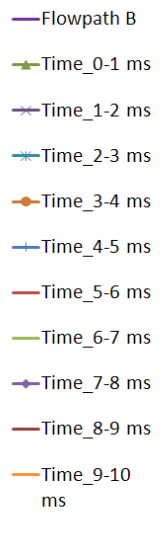

a.

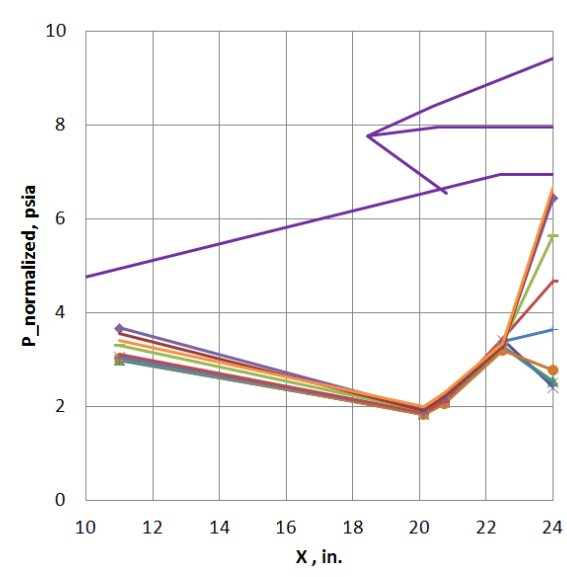

-Flowpath B -Time_10-11 ms
* Time_11-12 ms *Tims

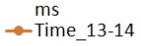
ms - Time_14-15 —Time 15-16 ms ms
Time 17-18 ms
—Time_18-19 - Time_18-19
ms
- Time_19-20 $\mathrm{ms}$

Figure 2.14: Pressure traces for flowpath $B$ inlet at a) 0-10 ms, and b) $10-20 \mathrm{~ms}$.

\subsection{Discussion}

Analysis of the experimental data obtained in these tests reveals several interesting flowfield characteristics of note. Figure 2.15 shows a pressure trace vs. time for the pressure tap on the forebody at 15 inches where the time axis has been shifted to account for the time it takes the test gas to travel from the nozzle plenum to that point on the model. The decreasing total pressure after $6 \mathrm{~ms}$ is accounted for by normalizing by the ratio of the target total pressure to the actual total pressure. As can be seen, this normalized pressure is nearly constant throughout the entire test. The steady state value is reached slightly after $2 \mathrm{~ms}$, which is the time required for flow to establish within the facility nozzle. The nozzle starting process and establishment time is discussed further in the next chapter. The fact that the steady state value for the reading of this pressure tap is reached at around $2.25 \mathrm{~ms}$ is consistent with the $0.25 \mathrm{~ms}$ boundary layer starting time predicted by Davies and Bernstein (1969). 


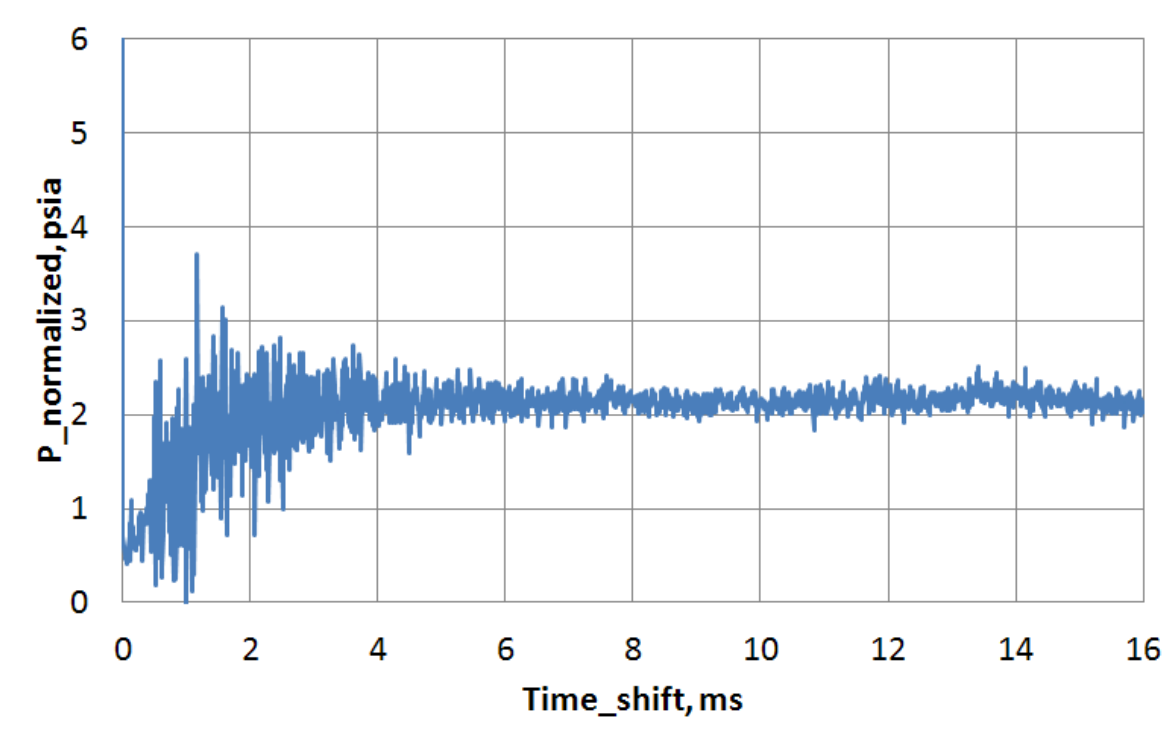

Figure 2.15: Pressure vs. time (shifted) on forebody at $x=15$ inches.

The steady static pressure reported at the isolator entrance is $53 \%$ less than that predicted by 1D calculations if the cowl shocks do not reflect and the shoulder expansion is not considered. As such, it is likely that the shoulder expansion plays an important role in the internal inlet flowfield and should not be neglected. If the cowl shocks do not reflect and the shoulder expansion is accounted for, the steady measured static pressure is $20 \%$ greater than that predicted by $1 \mathrm{D}$ calculations. A slight pressure rise due to thickening boundary layers is expected along the direction of the flow in the internal compression section of the inlet due to the contraction of the inviscid core flow.

This increased static pressure at the entrance to the isolator may be partially explained by the existence of an additional shock structure caused by the compression, expansion, and recompression of the flow over a separation bubble on the forebody, as suggested by the increased pressure at an axial location of 19 inches. The fact that the static pressure is lower at 20.8 inches than at 19 inches indicates that the flow reattaches to the forebody and supersonic flow is maintained through the rest of the inlet to the isolator entrance. 
The static pressure at 19 inches increases with time, suggesting that this separation bubble is growing throughout the test. The ratio of the pressures at 15 (before the separation) and 17 inches (within the separation) suggest that the initial flow deflection angle caused by the separation bubble grows from 5.5 to 9.4 degrees. The ratio of static pressures at 15 (before the separation) and 21.1 (after the separation) inches is consistent with the growth of the separation bubble in this manner. If a separation bubble develops as suggested above, the Mach number behind the separation bubble would be less than $5 \%$ less than that before the separation bubble throughout the above range of induced turning angles. These small differences in Mach number alone are unlikely to alter the starting characteristics of the inlet.

It is likely that this disturbance is caused by cowl shock-induced separation. While such a separation is not predicted for a turbulent boundary layer by Korkegi (1975), separation would be expected if the boundary layer was in a laminar or transitional state. This disturbance stabilizes until approximately $6 \mathrm{~ms}$. The decreasing static pressure, and thus Reynolds number, after $6 \mathrm{~ms}$ would effectively decrease turbulence within the boundary layer. This explains the subsequent increase in the strength of the separation.

Figure 2.16 shows a comparison between the average pressure profiles for both the flowpath A and B inlets in the HyPulse test detailed above and CFD on the flight vehicle inlet at zero angle of attack. Pressure profiles are averaged over the primary test time (4.2-6 ms). As expected, the pressure profile from CFD is nearly constant until the arrival of the first cowl shock near 22.5 inches indicating that the forebody disturbance consistently seen in HyPulse is not predicted by the CFD. The disturbance at 11 inches on the flowpath B inlet is also not predicted by the CFD. Downstream, the shock- 
generated pressure rises consistently shown in the experiment are slightly further downstream than those predicted in the CFD. This suggests an additional shock system in the experiment, likely generated from the unexpected separation bubble seen on the forebody. The magnitude of the pressure rises caused by shocks downstream of the isolator entrance is similar in both CFD and experiment suggesting that Mach number and temperature are reasonably predicted. This is reasonable, even with the disturbance seen in the HyPulse experiments. Also as expected, the strength of the disturbances seen on the forebody are greater when averaged over 6-12ms than when averaged over 4.26ms. This is due to the decreasing freestream static pressure, and thus Reynolds number on the forebody which causes the boundary layer to become more laminar and susceptible to separation.

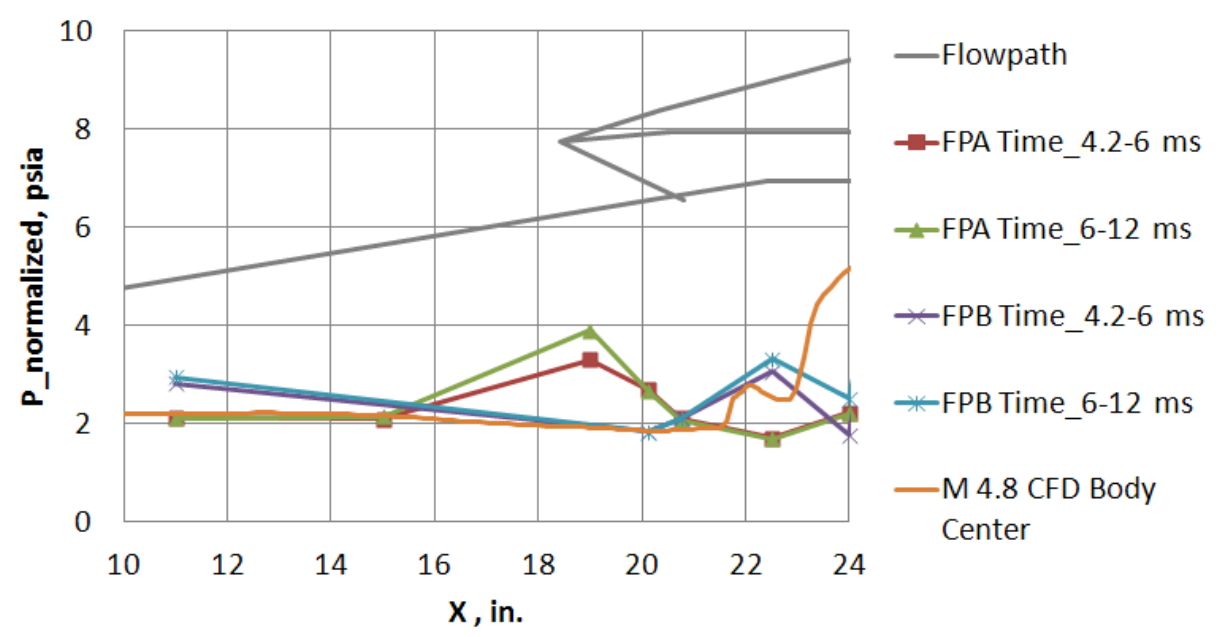

Figure 2.16: Comparison of CFD with average pressure traces from HyPulse experiment.

\subsection{Conclusion}

An inlet has been designed for the SDPTE flight vehicle. While eventually relaxed, the original primary design requirement was providing a clean flow to the isolator which 
matched the conditions at the nozzle exit of the UVaSCF, a direct connect facility. This is the first time reported in the literature that a dual-mode scramjet inlet has been designed in conjunction with a flight vehicle trajectory specifically to this end. The requirement that flow entering the isolator in the flight experiment match that supplied to the isolator in the UVaSCF direct connect facility, however, was relaxed in order to decrease the likelihood of boundary layer separation on the forebody should the inlet be exposed to off-design conditions. The fact that the cowl shocks still caused a boundary layer separation is indicative of a forebody boundary layer that did not transition to turbulence as expected. Modifications were also made to enhance the ability of the inlet to self-start and self-restart when exposed to the freestream or if an unstart was experienced unexpectedly in flight. The resulting inlet is significantly more robust than previous inlet concepts contributing to a much higher probability of a successful flight experiment.

The operation of this inlet was verified experimentally in the NASA HyPulse facility. A test article utilizing the same inlet geometry was designed, constructed, and installed in the facility. To aid in facility integration, both inlets, which are on opposite sides of the flight vehicle forebody, were placed next to each other on a shared forebody in HyPulse. All available evidence and available comparison with prediction suggests that the inlet did deliver supersonic air to the isolator entrance at conditions close to those designed for. The consistent, unexpected appearance of a pressure rise on the forebody, however, indicates that a separation bubble developed on the forebody. This separation was likely induced by the cowl shock. The inlet was designed such that the strength of this shock would be below the limit set for by Korkegi (1975) for a turbulent boundary layer. The 
fact that the separation still occurred indicates that the boundary layer did not naturally transition to turbulence by the end of the forebody as expected. While this separation likely had little influence on Mach number at the isolator entrance, the compression, expansion, and recompression of flow around it likely raised the static pressure at the isolator and decreased the efficiency of the inlet.

While the work here demonstrates operation of a scramjet inlet at Mach 4.8 flight enthalpy, several aspects of its operation remain unresolved. Shadowgraph, Schlieren, or Laser Holograph Interferometry (LHI) are all techniques available for use in HyPulse which can be used to view the flowfield structure on the forebody of the model (Tsai and Bakos, 1998). Either of these three measurement techniques would confirm the existence of or lack thereof a separation bubble on the forebody. Such measurements would also confirm its growth and shape while allowing comparisons with those predicted by $1 \mathrm{D}$ calculations applied to experimental pressure profiles obtained. Installation of new heat flux gauges would also indentify the state of the boundary layer along the forebody. This would confirm whether it was an unexpectedly laminar boundary layer which caused separation on the forebody and prevented the inlet from operating as originally expected. The test article was designed such that a boundary layer trip could be added for later tests as specified for the flight vehicle. If heat flux data revealed a laminar boundary layer along the length of the forebody, a boundary layer trip would prevent any forebody separation, allowing the inlet to operate perfectly as designed in a fully started manner. It is believed that the inlet used for tests in HyPulse would function as designed if the boundary layer fully transitioned to turbulence or was tripped before the point of cowl shock interaction. Since a boundary layer trip is specified for the flight vehicle, it is 
expected that the flight inlet will perform as expected. As mentioned above, testing the boundary layer trip on the ground would confirm this.

The design of this inlet was an integral part of the SDPTE program as it fixed both the nominal test point and the resulting nominal trajectory, and dictated the aerodynamic design of both the HyPulse and TBIV ground test articles. The inlet design also drove the design of a new nozzle for the UVaSCF in an effort to match the new isolator entrance conditions presented by this inlet. The work associated with this effort is ongoing at the time of this writing. As such, the design of this inlet can be considered a critical, enabling component of the entire SDPTE program. 


\section{Chapter 3: Freejet testing of a dual-mode scramjet combustor in an impulse facility}

\subsection{Introduction}

The dual-mode scramjet (DMSJ) has been identified as a key technology for sustained hypersonic flight within the atmosphere for both cruise and access-to-space missions (Messersmith and Castro, 2003). At lower flight Mach numbers, subsonic combustion is necessary to maintain high cycle thermal efficiency while at higher hypersonic Mach numbers, supersonic combustion is required to avoid the high static temperatures which would result in dissociation of the working fluid. To accomplish this with a singular geometry, the DMSJ is designed such that it can operate in a subsonic combustion mode at lower Mach numbers, a dual-mode utilizing both subsonic and supersonic combustion at Mach numbers from approximately 4-5, and a supersonic mode for higher hypersonic flight Mach numbers.

Since the testing of scramjet engines in a flight setting is often prohibitively costly, great effort has been made to simulate the hypersonic flight environment in ground-based test facilities. Unfortunately no single ground test facility can accurately simulate the entire hypersonic flight envelope. Combustion-heated test facilities leave combustion products, or vitiates, in the test gas which impact ignition as well as the thermodynamics and chemical kinetics of combustion. Storage-heated blowdown facilities can supply clean, heated air for extended periods of time but are generally limited to flight Mach numbers of about 6 (Mitani, 1995). Direct-connect facilities can simulate higher Mach number flight conditions if adequate total pressure is available but do not account for the 
effects of an inlet which is required to capture freestream air and process it to the proper pressure and temperature in a real airbreathing propulsion system (Van Wie, 2000). In order to obtain the high flight enthalpies of hypersonic flight the test gas is often heated by the passage of a shock wave. Such a facility avoids combustion-generated contaminants in the test gas as well as fundamental heating and mass flow limits on blowdown type facilities. Test time, however, is often on the order of milliseconds. Since a short test time raises questions regarding flow establishment and a vitiated test gas has been shown to affect combustion through various mechanisms, it is important to understand how supersonic and dual-mode combustion are influenced by these effects.

The Short Duration Propulsion Test and Evaluation (SDPTE) Program was designed to quantify and understand the effects of a contaminated test gas as well as a short test gas flow duration on the performance and operation of a dual-mode scramjet (Goyne et al., 2009a). Ground tests have been carried out in a variety of facilities capable of operating on various time scales and with different levels of contamination in the test gas at a simulated flight Mach number of 5. The work presented here involves the testing of a dual-mode scramjet in the NASA HyPulse facility, a shock-heated hypersonic wind tunnel owned by NASA and operated by ATK-GASL in Ronkonkoma, NY, in support of the SDPTE Program.

\subsubsection{Testing scramjets in impulse facilities}

Despite the limitations on test time, impulse facilities offer a number of benefits for scramjet testing not realized in other types of ground-based wind tunnels. Shock-heated facilities often have the ability to simulate a wide range of flight Mach numbers and flight dynamic pressures. NASA's HyPulse facility can simulate Mach numbers from 4 
to 25 at dynamic pressures of interest for airbreathing engine testing past Mach 15 (Chue et al., 2002). This capability provides the ability to test a model at a wide range of flight Mach numbers and dynamic pressures without variation in boundary conditions, such as wall temperature or freestream turbulence, that could result if a different facility was used to test at additional flight conditions. Also, since a wide variety of flight conditions are available in a single facility, only one model is necessary and fewer facility integration problems need resolution. These facts alone can significantly decrease the cost of a test program which spans a wide range of flight conditions.

The impulsive heat load presented by a pulse facility offers several further advantages for hypersonic airbreathing engine testing. The short-duration of the heat load in an impulse facility results in the model retaining a nearly constant temperature throughout the test. This is advantageous for several reasons. The impulsive nature of the heat load provides a well-defined thermal boundary condition, often lacking in experiments, which is useful if the test results are used to validate computational models. This constanttemperature model exhibits little to no thermal deformation which simplifies the integration of windows for optical measurements. It also relieves the need for active cooling within a scramjet model. This simultaneously decreases the complexity of the test article and reduces design and fabrication costs. Finally, a constant temperature model makes possible high-fidelity heat flux measurements difficult or impossible in long duration facilities. While testing a DMSJ is possible in a blowdown facility at Mach numbers near 5, there are therefore significant advantages to testing in an impulse facility if stable combustion can be obtained. This is especially true if tests are planned at higher Mach numbers for the same engine geometry. 
The short test time presented by impulse facilities has implications on the establishment of steady flow through the scramjet flowpath. These effects have been extensively examined (eg. Jacobs et al. 1990 and Holden 1971). Guidelines have been determined for the nondimensional establishment time, $G$, for various flow features likely found in a scramjet. This nondimensional establishment time is defined as the time required for the flow feature to reach steady state times a characteristic velocity divided by a characteristic length. The flow structures investigated by Jacobs et al., (1990) were a laminar boundary layer $(G=3)$, a turbulent boundary layer $(G=2)$, a base recirculation region $(G=28)$, and a recompression shock $(G=140)$. Of these features studied, all will reach steady state well within the test time of this study with the longest, the internal flowpath boundary layer, having a conservatively estimated establishment time of $2.2 \mathrm{~ms}$ (Jacobs et al., 1990). The establishment of a precombustion shock train, characteristic of dual-mode combustion within a scramjet, however, has not been explicitly studied in this manner and its establishment time is not well characterized. It is expected that the establishment time of a precombustion shock train is greater than that of the flow structures studied by Jacobs et al. (1990) because there is dynamic feedback between the separation and resulting shock structure in the isolator and the pressure rise generated by combustion downstream in the combustor.

It has also been shown that some inlets with high contraction ratios are easier to start in an impulse facility than in a steady facility (Gurylev and Mamet'yev, 1978). In this light, the ability of an inlet to start in an impulse facility may not be indicative of its general starting characteristics in a steady facility or in a flight environment. The SDPTE inlet, though, has been designed to be self starting under all conditions. The cowl 
sidewalls are swept at 30 degrees, allowing spillage at the corners of the air scoop, and the internal contraction is kept below the Kantrowitz limit (Kantrowitz and Donaldson, 1945) ensuring that it self-starting and self-restarting. Since steady flow is maintained through an impulse facility for only a short period of time, special high-frequency instrumentation must be specified. The movement of test gas over the model must also be considered. It is common for pressure data in impulse facilities to be time-shifted to account for the time it takes for test gas to flow over the model, because this time is of comparable magnitude to that of the entire test. Despite these difficulties, shock-heated facilities remain attractive for testing scramjets with a clean test gas at higher Mach numbers. These advantages can be realized for DMSJ testing by extending this testing capability to lower Mach numbers than those traditionally simulated in impulse facilities.

Many scramjets have been tested in shock tunnels, although none have exhibited dual-mode combustion. The NASA HyPulse facility was used in a detonation-driven reflected shock tunnel mode to carry out the Mach 7, 10, and 15 components of the Hyper-X ground testing campaign (Bakos et al., 1999 and Rogers et al., 2001). Supersonic combustion of hydrogen fuel was demonstrated for all 3 Mach numbers at various conditions. The T4 free-piston driven shock tunnel was used to take measurements in support of the HyShot program at a freestream Mach number of 6.5 (Paull et al., 2000). Stable supersonic combustion was demonstrated for approximately $2.5 \mathrm{~ms}$ at various conditions although actual combustion data has been obscured in the open literature. Most recently, a generic scramjet utilizing a cavity flameholder was tested in the T3 free-piston shock tunnel using various combustor inlet and fuel flow conditions. Steady supersonic combustion was achieved at combustor Mach numbers 
between 3.71 and 3.97 (Jeong et al., 2008). The HyShot II scramjet was also tested in the High Enthalpy Shock Tunnel Göttingen, HEG, of the German Aerospace Center, DLR (Schramm et al., 2008) in support of the LAPCAT Program (Steelant, 2008). Supersonic combustion was achieved and qualitatively matched that of the HyShot II flight experiment (Smart et al., 2006).

Despite several successful scramjet tests in impulse facilities, nowhere in the literature is the successful operation of a dual-mode scramjet reported. This is partially due to the fact that the flight regime required for dual-mode scramjet operation can often be simulated in blowdown facilities. For test programs where a dual-mode scramjet is also tested at higher Mach numbers unattainable in blowdown facilities, the ability to test the same model in the same facility in a different operating regime is still very valuable.

\subsubsection{Objectives}

For the reasons stated above, it is of interest to explore testing a DMSJ operating in the dual-mode regime in a shock tunnel. The objectives of this work are to:

1. Test a DMSJ in an impulse facility with both supersonic and dual-mode combustion.

2. Analyze the test data to determine if steady DMSJ operation in the dual-mode regime was achieved and determine if testing a DMSJ in the dual-mode regime is feasible in an impulse facility.

3. If possible, estimate the nondimensional establishment time for any precombustion shock train observed in the tests from objective 1.

Following is a description of the experimental facility, test article, test conditions, and the fuel and ignition systems. The results of the test follow as well as a short discussion 
and several concluding remarks.

\subsection{Experiments}

A dual-mode scramjet was tested in the NASA HyPulse facility in support of the SDPTE program. Two scramjet flowpaths, A and B, were tested side by side at various conditions. Only flowpath A will be considered here because it was designed and developed at the University of Virginia and has been the subject of long duration testing at UVa (Goyne et al., 2007).

\subsubsection{Facility}

When configured as a Reflected Shock Tunnel (RST), HyPulse is capable of simulating flight Mach numbers from 4 to 12 . This is the desired configuration for Mach numbers below 12 because test time is maximized. The RST mode of HyPulse is utilized for these tests. For Mach numbers from 12-20 where a higher stagnation pressure and enthalpy is required, HyPulse can be configured as a Shock Expansion Tunnel (SET). The test gas in HyPulse is clean, dry air.

In RST mode, the test gas is heated by a forward-moving shock and its reflection off the end wall of the shock tube. This shock-heated air serves exactly the same purpose as air in the plenum, or low subsonic portion, of a supersonic nozzle. While very high flight enthalpies can be obtained by heating the test gas in this manner, the resulting test time is often on the order of 3-9 milliseconds depending on the desired test conditions.

In the RST mode, the shock tube section is filled with the test gas at a pressure usually lower than atmospheric while the driver gas section is filled with high-pressure helium. The test is initiated by bursting the double diaphragm separating the driven and driver gas. This generates a shock which travels through the test gas, which is held in 
place by a thin Mylar film installed at the nozzle's throat. The shock breaks the thin Mylar film upon arrival and the test gas is accelerated through the nozzle, over the test article, and into the dump chamber. As discussed later, the resulting steady test time for these experiments is taken from $4.2-6 \mathrm{~ms}$.

\subsubsection{Test article}

A detailed description of the test article is given in the previous chapter. Instrumentation locations for Flowpath A are shown schematically in Figure 3.1. While the vast majority of pressure measurements are taken on the bodyside (fuel injector) wall centerline, several are mounted on sidewalls to allow for the assessment of flow uniformity over various cross sections along the flowpath.

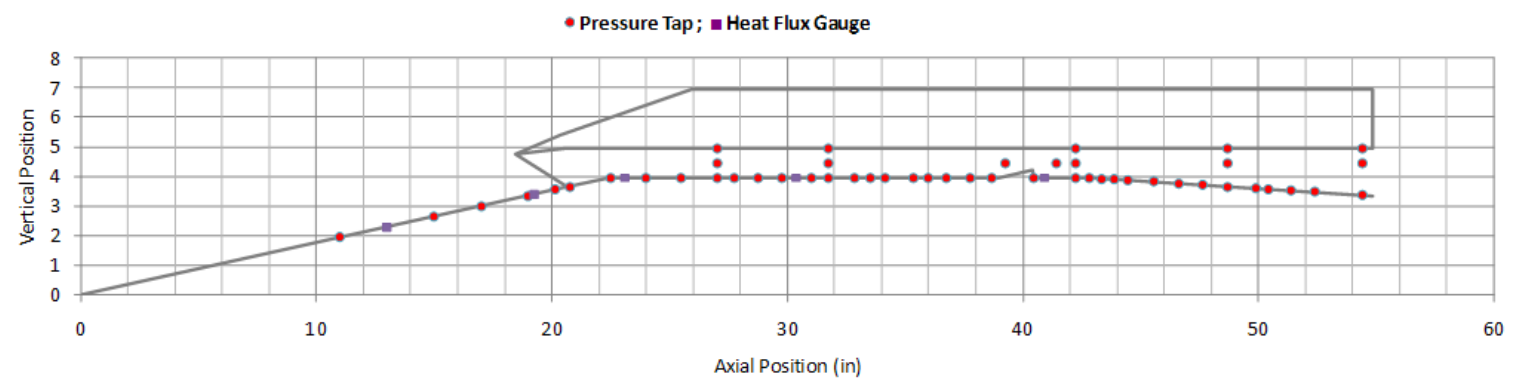

Figure 3.1: SDPTE HyPulse test article instrumentation locations.

\subsubsection{Test Conditions}

The NASA HyPulse facility was configured to match the conditions seen at the isolator entrance with those anticipated in flight. Testing for another program at ATKGASL showed that the pebble bed air heater for TBIV, a storage-heated blowdown facility also used for SDPTE testing, would likely be unable to maintain a full Mach 5.0 enthalpy simulation $\left(T_{t}=2230 \mathrm{deg}\right.$. $\left.R\right)$ for the required test time. As such, the ground test simulated Mach number was reduced from 5.0 to $4.8\left(T_{t}=2089\right.$ deg. $\left.R\right)$ keeping the 
total pressure the same. It was assumed that this change in enthalpy did not significantly alter the operation of the scramjet. HyPulse test conditions for a dry-air Mach 4.8 flight simulation are detailed in Table 2-3. Facility calibration and model installation are detailed in the previous chapter.

\subsubsection{Fuel System}

A Ludwieg tube (Warmbrod, 1969) supplies fuel to the fuel plenum for each injection site on the engine through a fast-acting Marotta ${ }^{\circledR}$ model MV100 solenoid valve. Fuel mass flow delivered by each of the plenums is determined by assuming a choked orifice with an experimentally determined discharge coefficient. The solenoid valve was triggered by the pressure rise measured at an upstream pressure tap. The optimal pressure tap location was determined for each condition based on the expected shock speed, the opening time of the valve ( $2 \mathrm{~ms})$, and the time required for the fuel plenum to fill which was itself dependent upon the type of fuel and the size of the plenum. Unpublished data from the Mach 10 Hyper-X tests in the HyPulse facility indicated that approximately $6 \mathrm{~ms}$ were required for the hydrogen delivery to reach steady state after the solenoid valve was actuated. As such, initiation of hydrogen delivery was triggered approximately $6 \mathrm{~ms}$ before ignition was initiated.

Fuel plenum total pressure during the time of interest was relatively constant and did not vary by more than $5 \%$ during the test time. Figure 3.2 shows a plot of fuel plenum total pressure vs. time where red vertical lines indicate the approximate test time. For a choked orifice, as was the case in this study, fuel mass flow is proportional to the pressure upstream of the orifice. Therefore a relatively constant plenum total pressure indicates a relatively constant mass flow of fuel to the engine. 


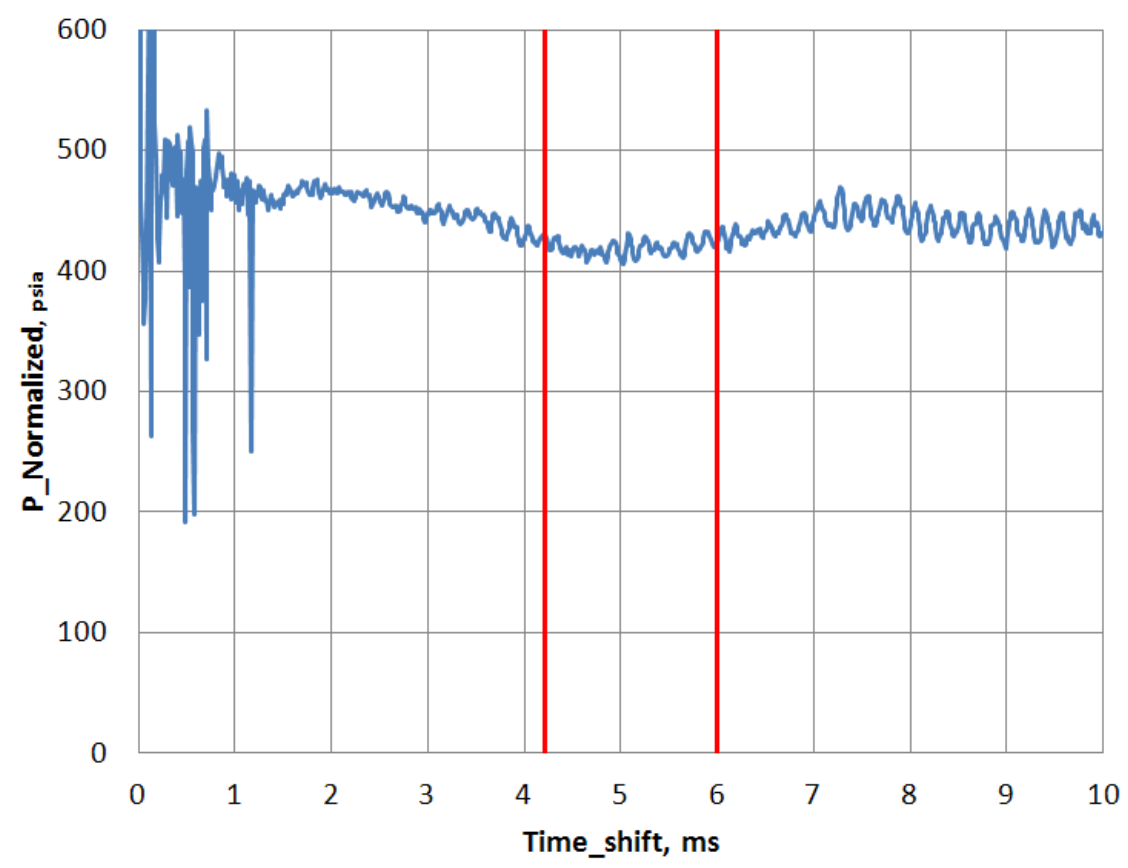

Figure 3.2: Fuel plenum pressure vs. time.

\subsubsection{Ignition system}

Since the static temperature near the fuel injector is below the autoignition temperature for hydrogen, an ignition system was necessary to initiate combustion within the scramjet. This is a direct result of attempting to test a DMSJ near Mach 5 enthalpy. $\mathrm{A} \mathrm{H}_{2}-\mathrm{O}_{2}$ detonation pulse igniter was designed for this purpose. The detonation tube was 12 inches long and had an outer diameter of 0.5 inches. It was filled to 25 psia with premixed hydrogen and oxygen and was ignited with a spark plug at one end. The detonation wave ruptures a thin Mylar diaphragm at the other end of the tube, allowing the hot combustion products to be released into the engine flowpath behind the base of the 10 degree, unswept ramp fuel injector, which was 0.25 inches tall and 0.5 inches wide. This ignitor was unable to produce hydrogen ignition in flowpath A for all test conditions even when $\mathrm{H}_{2}-\mathrm{O}_{2}$ fill pressure was increased to 75 psia and the hot gas 
mixture was vented entirely to flowpath A. This was the fill pressure utilized for all engine tests reported here using this configuration.

It was theorized that a large percentage of the energy in the detonation gas was lost when venting through the igniter choke point and to conduction to the tubing wall. Therefore, the static temperature of the detonation gas decreased as the gas was expanded into the flowpath through the igniter port. To increase the igniter pulse energy, a 12 inch long, 0.5 inch diameter tube filled with 20/80 silane/hydrogen mixture by mole was inserted between the $\mathrm{H}_{2}-\mathrm{O}_{2}$ detonation tube and the igniter injection port. The two tubes were separated by a thin Mylar diaphragm. This essentially created a small detonation shock tube where the silane/hydrogen mixture acted as the driven gas and the $\mathrm{H}_{2}-\mathrm{O}_{2}$ mixture acted as the driver gas. The hot silane/hydrogen mixture entered the flowpath at the base of the fuel injector and autoignited, producing a high static temperature and free radical concentration locally near the base of the fuel injector, and aided in hydrogen ignition within the engine. Fill pressure for both the silane/hydrogen and $\mathrm{H}_{2}-\mathrm{O}_{2}$ mixtures were 75 psia. Despite the significant additional energy added to the flowpath, this configuration also failed to produce hydrogen ignition in flowpath A. This indicates that the problem was instead an inability of the flowpath to flamehold with hydrogen fuel and not deficiency in the ignition system.

Since the flowpath was unable to flamehold after ignition using pure hydrogen fuel, a 20/80 silane/hydrogen mixture by mole was used. The autoignition temperature for this fuel is below the static temperature in the flowpath and autoignited without the use of the ignition system.

Approved for public release; distribution is unlimited. AEDC PA 2012-083 


\subsubsection{Nozzle starting process and test time determination}

It is important to determine the time required for the facility nozzle to start in order to accurately assess experimental results obtained in an impulse facility. This process has been studied extensively since the introduction of impulse facilities (e.g. Smith, 1966). When the diaphragm just upstream of the nozzle plenum is ruptured, a primary shock forms, travels upstream, and processes the stagnant air contained within the facility nozzle. The primary shock and the downstream moving flow behind it decelerates due to the divergence of the nozzle walls and produces a secondary shock which moves upstream relative to the primary shock but still travels downstream in the lab reference frame due to the high velocity of the fluid processed by the primary shock. Depending on the initial pressure of the fluid within the nozzle, the nozzle is considered started either when the unsteady expansion at the throat (for low initial pressure) or when the secondary shock (for high initial pressure) is expelled from the nozzle (Smith, 1966). When the ratio of the pitot pressure measured at the nozzle exit and the time-shifted, measured plenum pressure reaches a steady state, it is assumed that the nozzle starting process is complete.

Once the nozzle has completely started, and transients enter the model, it is the starting time of the model itself which determines the beginning of the test time. By calculating the establishment time of each flow feature expected within the scramjet, the starting time for the internal flowpath can be estimated. The flow feature which took the longest to start was the internal boundary layer which exhibits a starting time of $2.2 \mathrm{~ms}$ (Jacobs et al., 1990). Here the velocity at the inlet throat was used as the characteristic velocity and the length of the model was used for the characteristic length for the above 
calculation of the required starting time. The start of the test time is taken as the sum of the nozzle starting time and the flowpath starting time. For these tests, that value is 4.2 ms.

The end of the test time is determined either by the first of either the arrival of driver gas contamination or an unacceptable drop in pressure, taken here as $10 \%$. This occurs at $6 \mathrm{~ms}$ for this test which is before the arrival of the helium driver gas. Thus, the test time is taken as 4.2-6.0 ms. Figure 3.3 shows the stagnation pressure measured in the nozzle plenum as a function of time indicating where the vertical line indicates where the pressure has dropped by $10 \%$. Figure 3.4 shows the ratio of the pitot pressure and the time-shifted, measured plenum pressure with test events indicated by vertical lines. While the beginning of the driver gas/driven gas interface does not arrive until approximately $13 \mathrm{~ms}$ with full driver gas contamination arriving at $16 \mathrm{~ms}$, conditions after $6 \mathrm{~ms}$ are changing too rapidly to make meaningful conclusions about test data taken after this point.

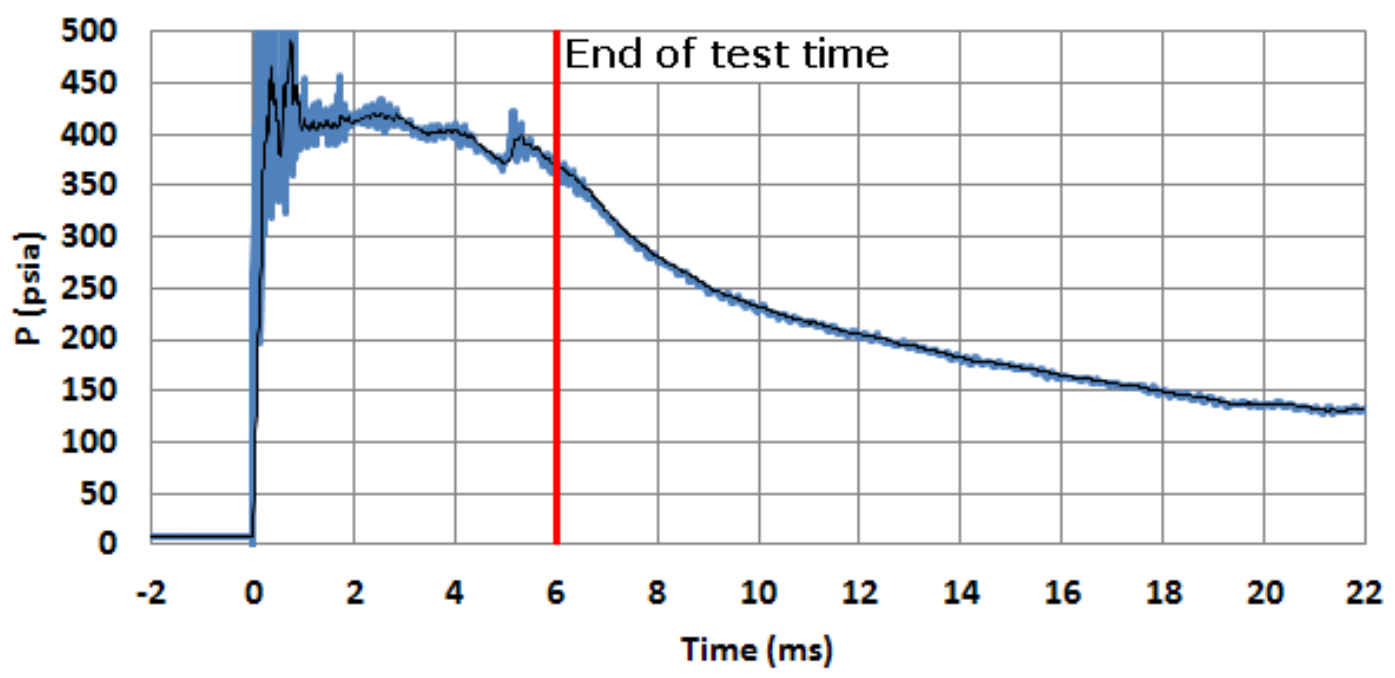

Figure 3.3: Average stagnation pressure vs. time. 


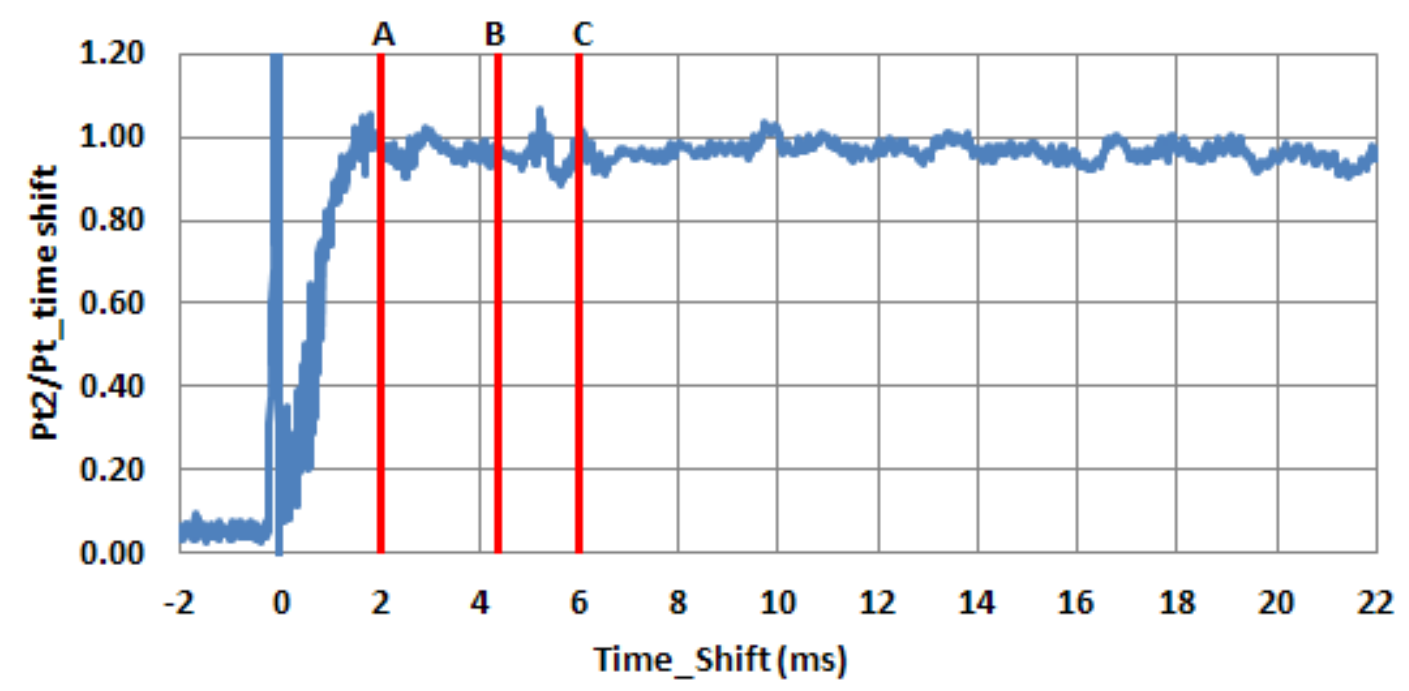

Figure 3.4: Ratio of time shifted static pressure at nozzle exit plenum pressure. A) Nozzle started, B) scramjet flow features started, beginning of test time, and C) end of test time.

\subsection{Results}

A total of 9 engine tests were performed. 7 tests utilized pure hydrogen fuel at various equivalence ratios from 0.31 to 0.72 . Successful ignition with pure hydrogen fuel was never obtained. Of these 7 tests, ignition of flowpath A was not attempted twice. For these two tests all ignitor effluent was routed to flowpath B. Two tests were performed utilizing a 20/80 silane/hydrogen mixture by mole. In these two tests, the fuel autoignited and combustion was successfully obtained. A summary of the fueling and ignition characteristics for each test is given in Table 3-1. The equivalence ratio quoted is based on actual mass flow of fuel as calculated through the choked orifice and the predicted mass-flow through the engine scaled to the time shifted, measured total pressure. Since the available instrumentation was not sufficient to measure the mass 
capture of the engine, the actual equivalence ratio is likely greater than the value quoted in Table 3-1. This deviation is discussed further below. The real-time experimental measurement of air mass flow through a scramjet is an active area of research at the time of writing.

Table 3-1: Summary of flowpath A fueling and ignition.

\begin{tabular}{|c|c|c|c|c|}
\hline $\begin{array}{c}\text { Test } \\
\text { number }\end{array}$ & Fuel type & $\begin{array}{c}\text { Calculated } \\
\text { ER }\end{array}$ & Igniter Configuration & $\begin{array}{c}\text { Ignition } \\
\text { Result }\end{array}$ \\
\hline 1 & Hydrogen & 0.67 & None & None \\
\hline 2 & Hydrogen & 0.73 & H2-O2 to both engines & None \\
\hline 3 & $20 / 80$ Silane/Hydrogen & 0.72 & None & Autoignition \\
\hline 4 & Hydrogen & 0.68 & H2-O2 to engine A only & None \\
\hline 5 & Hydrogen & 0.51 & $\begin{array}{c}20 / 80 \text { silane/hydrogen }+\mathrm{H} 2-\mathrm{O} 2 \\
\text { to both engines }\end{array}$ & None \\
\hline 6 & Hydrogen & 0.31 & None & None \\
\hline 7 & Hydrogen & 0.32 & $\begin{array}{c}20 / 80 \text { silane/hydrogen }+\mathrm{H} 2-\mathrm{O} 2 \\
\text { to both engines }\end{array}$ & None \\
\hline 8 & Hydrogen & 0.64 & $\begin{array}{r}20 / 80 \text { silane/hydrogen }+\mathrm{H} 2-\mathrm{O} 2 \\
\text { to both engines }\end{array}$ & None \\
\hline 9 & $20 / 80$ Silane/Hydrogen & 0.33 & None & Autoignition \\
\hline
\end{tabular}

Figure 3.5 shows the body-side pressure traces with time for test number 1 where ignition was not attempted. This result is qualitatively and quantitatively similar to all other tests (tests 2, 4, 5, 6, 7, and 8) where ignition was not obtained. As expected, the peak pressure is seen just downstream of the fuel injector. Figure 3.6 and Figure 3.7 show the body-side pressure traces for tests 3 and 9 respectively where a 20/80 silane/hydrogen fuel mixture was used and the fuel autoignited. In test 3, with an equivalence ratio of 0.72 , a precombustion shock train can be seen as well as combustion in the aft part of the combustor. In test 9 , with an equivalence ratio of 0.33 , combustion is seen in the aft part of the combustor with no precombustion shock train. The peak pressure in both tests 3 and 9 occurs in the same axial location. The flowpath height shown in the following two figures is not to scale. 


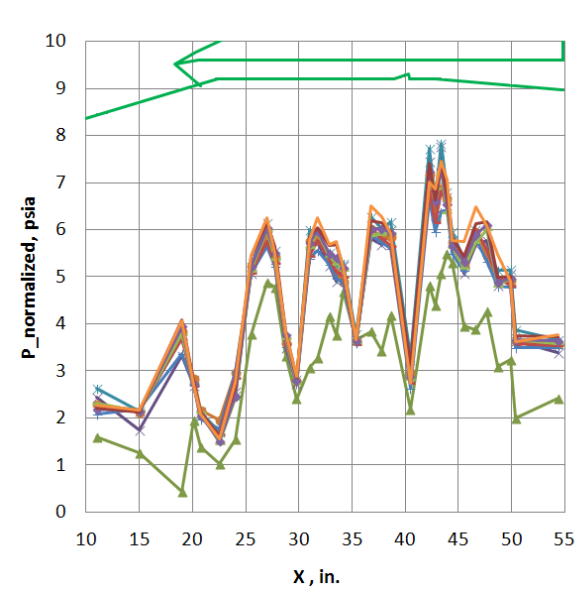

a.

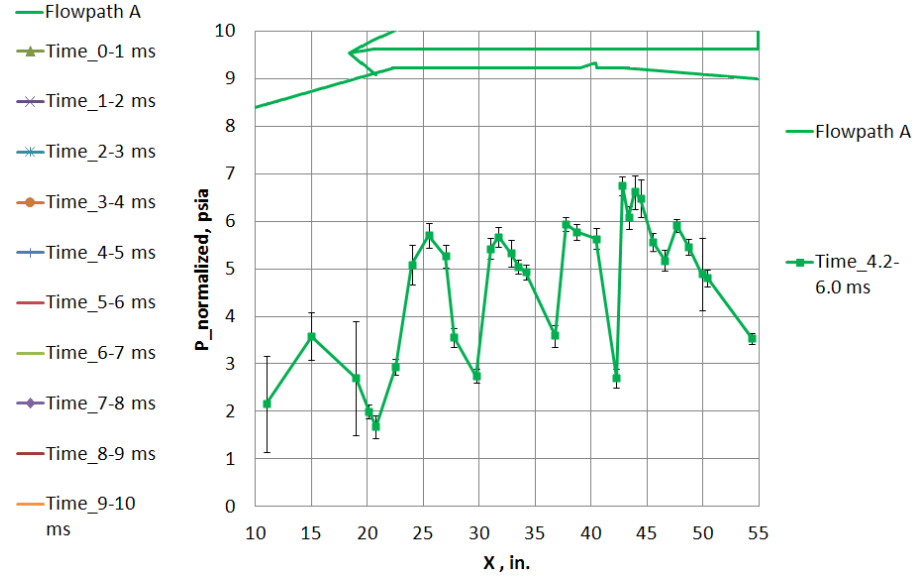

b.

Figure 3.5: Pressure traces for test 1 at a) 0-10 ms, and b) average pressure through test time (2-6ms). Error bars are 1 standard deviation.

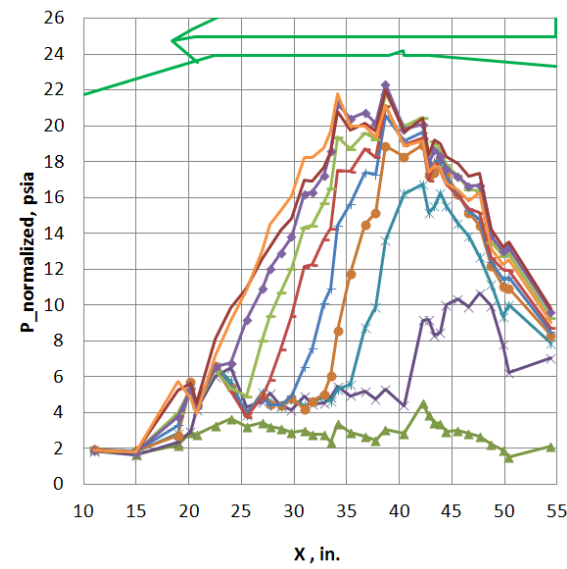

a.
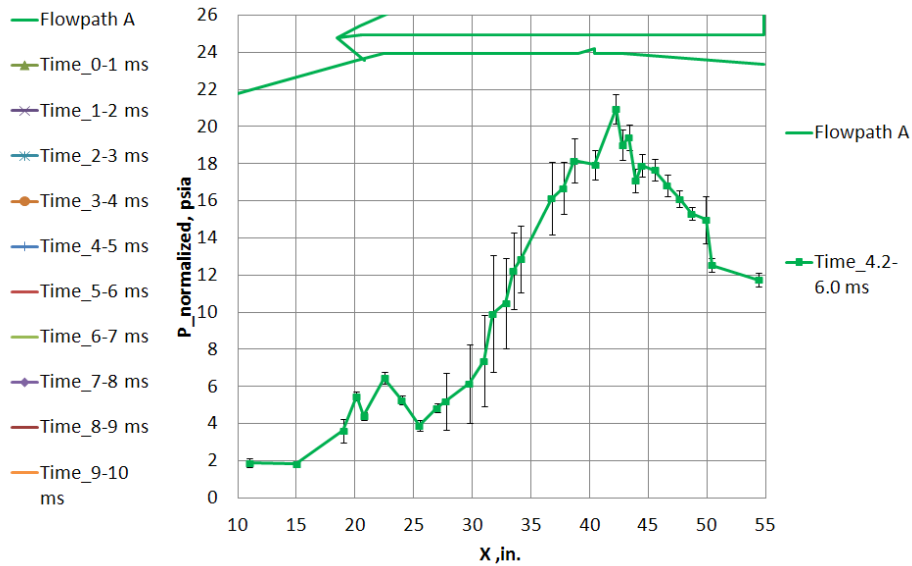

b.

Figure 3.6: Pressure traces for test 3 at a) 0-10 $\mathrm{ms}$, and b) average pressure through test time (2-6ms). Error bars are 1 standard deviation. 


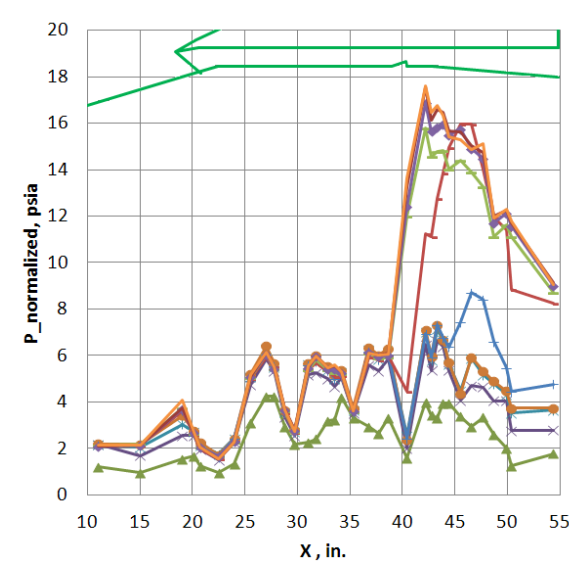

a.

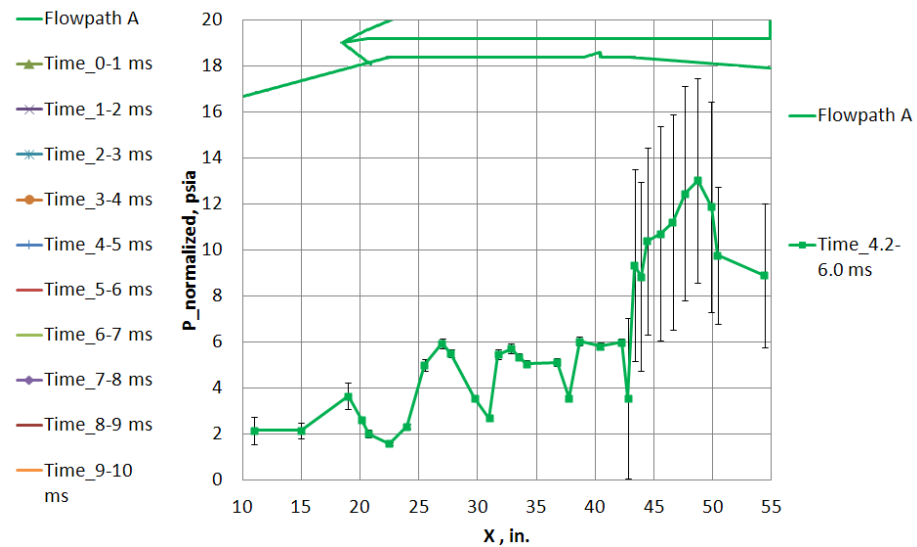

b.

Figure 3.7: Pressure traces for test 9 at a) 0-10 ms, and b) average pressure through test time (2-6ms). Error bars are 1 standard deviation.

\subsection{Discussion}

Several interesting phenomena can be observed in the above figures. An unexpected pressure rise is consistently seen on the forebody at 19 inches. This is indicative of a partial unstart which is likely caused by a shock-induced separation on the forebody as discussed extensively in the previous chapter. As such, mass capture is likely lower than expected. Since the equivalence ratio is calculated using a mass capture determined through CFD, where no separation was observed, the actual equivalence ratio within the engine may be higher than reported. Since there was no quantitatively measured mass capture through the inlet, the actual test equivalence ratio cannot be determined through available measurements. The equivalence ratios quoted in Table 3-1 act as lower bounds because a partial unstart necessarily decreases the ability of the inlet to capture air. Calculations based on 1D analysis of flow over a triangular separation bubble, similar to that described in the 'Discussion' section of the previous chapter, show that for a 10 degree triangular separation on the forebody, the decrease in mass capture results in an 
equivalence ratio that is $9 \%$ higher than the values reported. It is also important to remember that equivalence ratio is increasing after $6 \mathrm{~ms}$ due to the fact that the facility total pressure, and thus static pressure of the air captured by the inlet decays through the remainder of the test.

This partial unstart is seen in every test whether ignition was achieved or not. Since the precombustion shock train reached the entrance of the inlet for test 3 , further increasing the severity of the inlet unstart, an increase in actual test equivalence ratio after $8 \mathrm{~ms}$ is likely greater than in other tests. Again, since engine mass capture cannot be quantified given the available instrumentation, we cannot draw conclusions regarding the extent of the equivalence ratio inflation that results. At the time of this writing, the real-time measurement of engine air mass capture is an area of active research and a suitable solution has not yet been found.

Figure 3.5 shows body-side pressure traces for test 1, where the fuel did not ignite. Autoignition of pure hydrogen is not expected at the conditions within the scramjet flowpaths according to Huber et al. (1979). This is consistent with the more recent findings of Sung et al. (1999) who extended this work to higher total pressures. While it has been shown that at an isolator entrance Mach number of 2 this flowpath and flameholder in a direct-connect configuration at the UVaSCF can support steady combustion at Mach 5 enthalpy when the scramjet is ignited with an external ignition source (Goyne et al., 2001, Rockwell et al., 2011, and Haw et al., 2011), this behavior was not observed in these tests.

It is possible that flowpath wall temperatures play a large role in the ability of the scramjet flowpath to remain lit after ignition. Since the heat load in HyPulse is of a short 
duration, the model walls remains at approximately room temperature $(\sim 540 \mathrm{R})$. While the walls in the UVaSCF are cooled at steady-state, the area directly downstream of the base of the ramp fuel injector glows red hot. This indicates a local temperature in excess of 1800 degrees R (CRC, 2003). Unpublished IR pyrometer measurements taken in the UVaSCF confirm this. Disregarding the high local temperatures at the base of the ramp, these results are consistent with CFD results obtained by Engblom et al. (2011) on the same flowpath configuration. In these simulations, combustion was numerically initiated by temporarily decreasing the activation energy of key reactions by a factor of 10 . Stable combustion with pure hydrogen was obtained for all cases where a wall temperature of $800 \mathrm{deg}$. R was used and ignition was numerically induced. Combustion ceased when values for activation energies were returned to their normal values for all simulations utilizing a constant wall temperature of $530 \mathrm{deg}$. R. These were the only two wall temperatures used in these simulations.

The experiments show that no ignition source was needed for the autoignition of the 20/80 silane/hydrogen fuel blend which was used for each test where steady combustion was obtained in flowpath A. The fact that the silane/hydrogen fuel mixture autoignited is not surprising because its autoignition temperature at atmospheric pressure is approximately 527 deg. R. ( $293 \mathrm{~K}$ ) as compared to hydrogen which has an autoignition temperature of 1,456 deg. $\mathrm{R}(809 \mathrm{~K})$ at the same pressure (CRC, 2003).

A precombustion shock train can clearly be seen for test 3 in Figure 3.6. Its leading edge continues to move upstream until it encounters the inlet where it stabilized for the remainder of the test. This is significant because the establishment time for a precombustion shock train is currently unknown. In fact, it has been disputed whether or 
not a precombustion shock train could establish within the short test times available in impulse facilities. The fact that the shock train anchored on the inlet entrance indicates that either the isolator length is inadequate for the pressure rise in the combustor despite the fact that the isolator design was consistent with Waltrup and Billig (1973) (See Goyne et al., 2009b). Since the relationship set forth by Waltrup and Billig (1973) (See also Billig, 1993) was developed based on data from circular ducts, its applicability to the rectangular SDPTE isolator is questionable. Further investigation by Stockbridge (1989) on co-annular ducts indicated that for a given pressure ratio, momentum thickness, Reynolds number, and inflow Mach number, the shock train in this geometry is longer than that in a round duct for the same characteristic length. Extending this trend further, it is likely that for a given pressure ratio a two-dimensional shock train in a rectangular duct would form over an even longer distance for a given pressure rise. Experimental evidence from the tests presented here indicates that a longer isolator length is required for the conditions tested here and is consistent with the above argument.

It is also possible that the decreasing mass flow, and thus increasing equivalence ratio, during the test time caused the upstream movement of the shock train leading edge. Figure 3.8 shows the time histories of the normalized pressures measured at taps located at a point far upstream on the forebody, a point within the developing separation bubble on the forebody, and a point within the inlet. Normalized pressure is almost perfectly constant at the most upstream pressure tap on the forebody. In contrast, normalized pressure at $x=19$ inches (within the separation) increases by over $60 \%$ during the test period indicating that the strength of the separation is growing throughout the test. Since normalized pressure at $\mathrm{x}=22.5$ inches stays relatively constant during the test period at 
approximately 6.5 psia and the total pressure decreases during the test period by roughly $10 \%$, absolute static pressure during the test time at $\mathrm{x}=22.5$ inches also decreases by roughly $10 \%$. It is unclear whether the decreasing mass flow to the engine as a result of the separation is responsible for the upstream movement of the shock train or if this movement is due to the fact that this flow feature has not reached steady state.

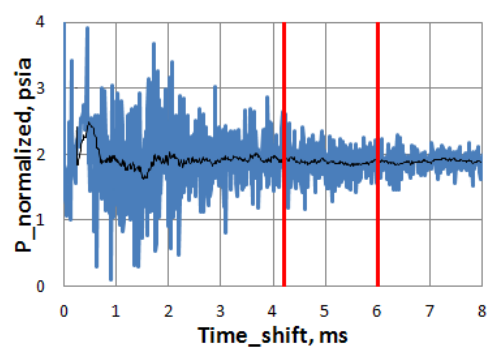

a.

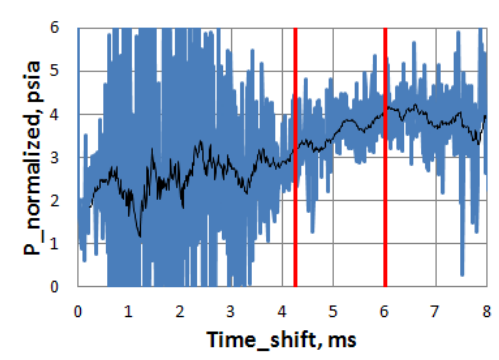

b.

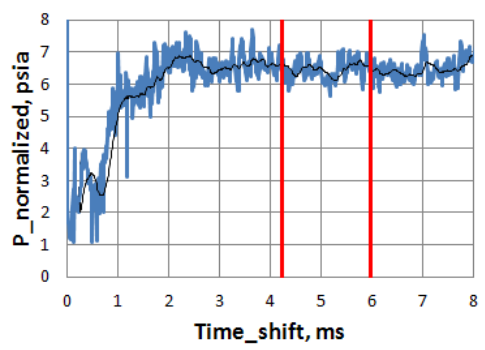

c.

Figure 3.8: Test pressure traces with time for the pressure taps at a) $x=11.0$ inches, b) $x=19.0$ inches, and c) $x=22.5$ inches.

No precombustion shock train is shown for the lower ER for test 9 in Figure 3.7, indicating purely supersonic combustion. The peak pressure occurs at the same axial location as in test 3 but is $27 \%$ lower in magnitude. Tests 3 (dual-mode combustion) and 9 (supersonic combustion) demonstrate the two different modes of operation of a DMSJ. These tests leave open the possibility that a DMSJ can be tested at conditions for which the amount of subsonic combustion is small and the steady-state shock train length is small. It likely that a shock train which has a large steady-state length will take longer to establish because shock train formation is a dynamic feedback process where the structure of the shock train and the nature of the combustion process are dependent upon one another. It is possible that for a lower equivalence ratio than that in test 3 , where the shock train would necessarily be shorter, that a steady precombustion shock train could 
fully develop within the test time. As such, these experiments cannot conclusively determine whether or not a DMSJ can be effectively operated in the dual-mode regime in an impulse facility despite the fact that a stable precombustion shock train was not established in these tests. More testing is required to determine the extent to which a DMSJ can be tested in an impulse facility, if any, and to understand the transient nature of precombustion shock train formation.

\subsection{Conclusion}

A dual-mode scramjet whose flowpath was designed after that installed in the UVaSCF was tested in a shock-heated, hypersonic wind tunnel. This test took place in a freejet configuration where a forebody and inlet processed the freestream flow before it entered the isolator. While demonstrated in the UVaSCF at a lower Mach number, ignition and flameholding were not possible with pure hydrogen engine fuel in HyPulse. It is believed that a low wall temperature throughout the test contributed to the inability of this flowpath to flamehold with pure hydrogen. This could be investigated in future studies by installing an artificially heated plate at the base of the fuel injector in HyPulse or a cooled section in the UVaSCF. When a 20/80 blend of silane/hydrogen fuel was used, however, the mixture autoignited and both dual-mode and supersonic combustion were observed, at high and low corresponding engine ER's $(0.72,0.33)$.

It is possible that the equivalence ratios tested were in fact higher than expected. This is due to a partial unstart of the inlet resulting from a shock-induced boundary layer separation on the forebody. While it was not possible to experimentally determine the actual equivalence ratio, 1D calculations indicate that the difference between the reported and actual values was approximately $9 \%$. Incorporation of a boundary layer trip as 
described in the previous chapter would likely eliminate this separation and much of the resulting uncertainty in engine mass capture.

Despite these difficulties, this is the first time in the open literature that dual-mode scramjet operation has been demonstrated in an impulse facility. The precombustion shock train is pushed forward through the isolator and anchors on the inlet after the test period as the total and static pressure, and thus mass flow through the engine decay. While steady operation in the dual-mode regime during the test time was not achieved, these test results to do not preclude that possibility for different conditions. The operation of a DMSJ in the supersonic combustion regime was also demonstrated. This study shows the possibility of testing a DMSJ at lower flight enthalpies into the dualmode regime. Benefits of this capability include the ability to take heat flux measurements in this regime, simpler and cheaper model construction, easier integration of optical access to the flowpath for application of advanced diagnostic techniques, and the ability to test a single model over the wide variety of flight conditions often possible in impulse facilities.

At the time of this writing, a new nozzle is under construction for the UVaSCF which will simulate the higher average isolator entrance Mach number of the SDPTE freejet test articles. Previous direct-connect tests have been conducted at an isolator entrance Mach number of 2.0. While the UVaSCF will be unable to match the total pressure capabilities of the HyPulse tests presented here, these tests will shed additional light onto the operation of this flowpath over a variety of conditions. These tests also open the possibility of further investigation the role of wall temperature on the ability of the flowpath to flamehold.

Approved for public release; distribution is unlimited. AEDC PA 2012-083 
Since blowdown facilities are commonly capable of simulating the flight conditions characteristic of dual mode scramjet operation, they are usually the facility of choice when testing scramjets designed to operate in the dual-mode regime. Testing scramjets in impulse facilities, however, allows a simpler, uncooled, and thus cheaper, model to be constructed. Further, the enhanced ability to make high-fidelity heat flux measurements and integrate optical access for advanced diagnostics to engines tested in an impulse facility makes testing in this manner particularly attractive for studies involving the validation or verification of computational models. If the test program in question requires testing over a wide range of Mach numbers, the higher of which may only be attainable in an impulse facility, the ability to test a scramjet operating in the dual-mode regime in an impulse facility is very valuable. This study was inconclusive in determining whether or not the testing of a DMSJ in the dual-mode regime is possible in an impulse facility. It remains possible that testing of a DMSJ is possible for conditions where there is only a small amount of subsonic combustion taking place and the shocktrain length is not excessive. More testing, however, is required to determine these limits. 


\section{Chapter 4: Dispersion and dispersion reduction}

\subsection{Introduction}

The development of hypersonic airbreathing engines has traditionally relied heavily on ground-based testing methods. While these tests are very useful, many suffer from test gas vitiation, poor flow quality, poorly matched boundary conditions, or short flow duration. With this in mind, the Short Duration Propulsion Test and Evaluation (SDPTE) Program (Goyne et al., 2009a) has been developed with the aim of examining the influence of ground test facilities on scramjet performance and operation. As part of this program, a future flight test of two dual-mode scramjet flowpaths is planned in order to generate a database for comparison with ground test data. This comparison is considered particularly valuable because flights performed in atmospheric air do not suffer from the limitations of ground-based facilities described above. Testing in three facilities is planned in order to isolate the effects of test flow duration and facility vitiation. One test article will be tested in the University of Virginia's supersonic combustion tunnel, which is an electrically heated, direct connect facility and can run continuously (Goyne et al., 2007). A freejet model will be tested in ATK-GASL's Test Bay IV blowdown tunnel. This facility can operate in both vitiated and non-vitiated modes below Mach 5 and has a run-time up to two minutes depending on the flow rate (Roffe et al., 1997). A second freejet model was tested in NASA's HyPulse facility as previously described. By comparing the ground test data across facilities with that of flight, more accurate estimates of flight performance can be made in the future by taking into account the effects of ground test flow duration and vitiation. 
The planned flight experiment for the SDPTE Program will be conducted in a captive boost mode using an unguided, spin-stabilized, Terrier Improved-Orion sounding rocket that is launched from the NASA Wallops Flight Facility. This vehicle will accelerate the scramjet to the required test conditions at which point the flowpaths will be ignited and combustion data will be recorded. Due to the inherent uncertainties associated with the launch of such a rocket, the actual trajectory that the rocket will follow can only be estimated to within certain degrees of confidence. These uncertainties arise because of differences in modeled and actual day of flight winds, launch dynamics, rocket burn rate and thrust, thrust misalignment, weight, and inaccurate estimates of vehicle drag, among others. The level of dispersion, however, from the nominal predicted trajectory can be estimated using stochastic computer simulations. This dispersion is very important because the flight Mach number and altitude affect the scramjet operating pressures and temperatures. While dispersion in freestream conditions may not be important for many sounding rocket flights, such as those for astronomical or terrestrial observations, an unsuccessful scramjet test can result if flow quantities deviate significantly from what is expected. It is also imperative that the conditions in flight match those seen in ground testing such that meaningful comparisons can be made.

There have been several scramjet tests in recent history that adopted the use of unguided, spin-stabilized sounding rockets, many of which experienced varying degrees of dispersion in test conditions. For example, HyShot was a flight test program aimed at demonstrating scramjet flight and validating the use of short duration ground test facilities for supersonic combustion studies above a freestream Mach number of 7.5. The maximum test Mach number for the HyShot 2 experiment exceeded the pre-flight 
prediction by 0.4 (Smart et al., 2006). Fortunately, the scramjet design was robust enough to accommodate this dispersion and the flight was successful. Other flight tests have seen greater trajectory dispersion. FASTT was a program aimed at demonstrating the operation of a hydrocarbon-fueled scramjet-powered vehicle (Foelsche et al., 2006). Two unpowered surrogate flights (named SPV1 and SPV2) were flown prior to a powered scramjet flight (named FFV1). The insertion Mach number for the SPV1 surrogate flight, at the beginning of the test time, was 0.81 less than the Mach 5.64 that was expected. Insertion altitude was also 11,300 feet $(3,444 \mathrm{~m})$ less than the 63,800 feet $(19,446 \mathrm{~m})$ expected which corresponds to a $72 \%$ increase in static pressure. For the engine test flight, FFV1, the insertion altitude was $13.5 \%$ lower than expected and Mach number was $1.2 \%$ higher than expected. This resulted in a $63 \%$ deviation in dynamic pressure from the expected value (Foelsche et al., 2006). Again, this program was successful, partially in this case due to the use of automated, on-board fuel control. The variation in pressure and Mach number seen in these Terrier Improved-Orion sounding rocket flights, however, is unacceptable for the SDPTE scramjet design for which strict Mach number and dynamic pressure requirements have been developed.

The success of the single planned SDPTE flight is critically dependent upon the ability of the launch vehicle to pass near the design test condition. A simple blowdown fuel system designed to deliver a nearly constant fuel flow rate will be used to reduce program costs. For a predetermined fuel mass flow rate, if the air mass capture is greater than expected, the resulting equivalence ratio will be lower than expected and a lean blow-out can occur (Muruganandam et al., 2002). Conversely, if the air mass capture is lower than expected, the resulting equivalence ratio will be higher than expected and 
engine unstart can occur (Wang et al., 2010). It is also important that the freestream test conditions are within those able to be simulated by the ground test facilities so that meaningful conclusions regarding the effects of the facility can be made from the resulting data sets. While the actual flight vehicle will be spinning at approximately 5 $\mathrm{Hz}$, the forward velocity at the test conditions is so great that the rotational velocity will not affect the operation or mass capture of the engine.

Multiple options exist for reducing dispersion in the trajectories of sounding rockets. Guided rocket systems utilize thrust vectoring and/or actively controlled aerodynamic surfaces to change the direction of travel. Control surfaces or attitude control jets can also be added to the payload to influence the flight of the vehicle. Any active control of the vehicle's flight, however, is accompanied by a significant increase in project complexity and cost. The method presented here allows the vehicle to satisfy the scramjet test Mach number and dynamic pressure requirements while preserving the economy of utilizing an unguided sounding rocket to accelerate the scramjet to operating conditions. This is achieved by modifying the interstage time delay of the sounding rocket during the flight based on the level of trajectory dispersion experienced up until that point. Such a technique is relatively simple and cost effective to implement and has not been previously reported in the literature.

This chapter continues by briefly describing the SDPTE flight vehicle payload, launch vehicle configuration, the nominal trajectory, and its development using GEM (NASA, 1991), a six degree of freedom trajectory simulation program. A Monte Carlo analysis was performed about the nominal trajectory to quantify the likely dispersion in metrics of interest for a hypersonic airbreathing engine test and to provide a basis for this 
dispersion reduction technique. For each Monte-Carlo trajectory, the optimal second stage ignition time was found such that the vehicle passed through the target test Mach number and dynamic pressure concurrently. This optimal second stage ignition time and corresponding test time were related to the vehicle's Mach number and altitude at a time during the interstage coast. In order to test the method, a second Monte Carlo analysis was then performed, this time using the relationships derived a priori for the optimal second stage ignition time and test time. This resulted in a significant increase in the likelihood of a successful scramjet test. The results of this analysis are presented with a discussion of their implications for a hypersonic airbreathing engine test. This dissertation chapter has been previously published by Smayda and Goyne (2012).

\subsection{Flight vehicle and nominal trajectory design}

\subsubsection{Vehicle Design}

The SDPTE flight vehicle payload was designed to house two instrumented scramjet flowpaths oriented on opposing sides of a wedge forebody, as well as all supporting subsystems. A model of the launch vehicle was developed by building on aerodynamic data from the FASTT scramjet test, which utilized a similar payload design and suppressed ballistic trajectory (Foelsche et al., 2006). Booster data typically used by the NASA Sounding Rocket Operations Contract (NSROC) was also used.

The vehicle consists of the four sections detailed in Figure 4.1: the Terrier Mk. 70 first stage booster, the Improved Orion second stage booster, the payload, and the shroud. The shroud protects the self-starting inlet from the high aerodynamic and thermal loads of launch. The payload houses two opposing scramjet flowpaths, with slightly varying geometry, as well as avionics, telemetry, and a hydrogen fuel delivery system. Since the 
drag on the shrouded payload was shown to be nearly identical to that on the payload with an exposed scramjet inlet using MISSILE DATCOM (Blake, 1998), the vehicle model assumes a shrouded payload throughout the entire trajectory for simplicity.

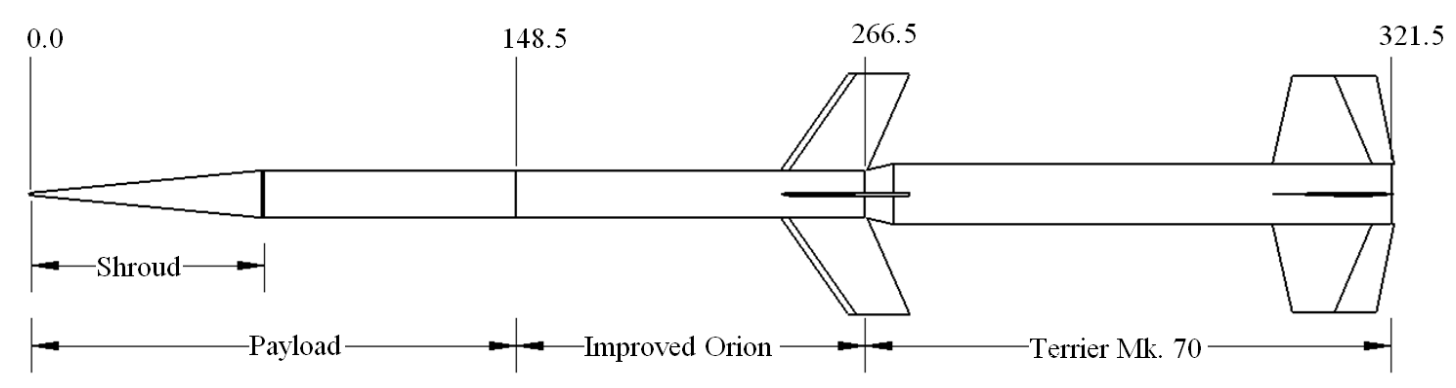

Figure 4.1: A schematic of the SDPTE launch vehicle model. (dimensions in inches) Reprinted with permission of the American Institute of Aeronautics and Astronautics.

\subsubsection{Nominal trajectory design}

The nominal trajectory was designed in parallel with the scramjet inlet such that conditions at the entrance to the scramjet isolator are similar to those seen in ground testing. For this reason, a suppressed ballistic trajectory was chosen with a launch elevation angle near 50 degrees. A more common sounding rocket objective, such as one for astronomical observations or atmospheric measurements, is to propel a payload to a desired altitude. Such a flight would utilize a launch elevation angle much closer to 90 degrees (NASA, 2005). Figure 4.2(a) shows Mach number and altitude as functions of time for the nominal trajectory, which satisfies the test conditions of Mach 5 and a dynamic pressure of $1,500 \mathrm{psf}(71.82 \mathrm{kPa})$. This nominal trajectory also satisfies the secondary trajectory design objective which is an approximately constant dynamic pressure with respect to time $(\mathrm{dq} / \mathrm{dt}=0)$ when the primary test conditions are met. Figure 4.2(b) shows the predicted Mach number and dynamic pressure near the test 
window. After first stage burnout, the first stage booster is separated from the vehicle. The vehicle coasts for approximately 30 seconds while altitude increases and elevation angle decreases. The second stage booster then ignites. During the second-stage burn, the vehicle approaches the required test conditions. The shroud is jettisoned, exposing the scramjet inlets and allowing atmospheric air to flow through the scramjet flowpaths. Combustion is initiated while temperature and pressure data are continuously relayed back to the ground for subsequent analysis. The primary experiment ends at the time of the second stage burnout. A secondary experiment then takes place as both Mach number and dynamic pressure decay. The secondary experiment, which was required to accommodate the lower operating pressures of the University of Virginia's supersonic combustion facility, concludes when the dynamic pressure reaches $1,000 \mathrm{psf}(47.88 \mathrm{kPa})$. The trajectory was chosen with the aim of minimizing dispersion in freestream conditions during the test window as well as integrated thermal loads on the vehicle. Since dispersion in Mach number, altitude, and thus dynamic pressure increases throughout the flight, positioning the test window as early as possible minimizes the dispersion in both Mach number and dynamic pressure during the expected test window. Positioning the test window as early as possible in the flight also minimizes integrated aerodynamic heating, which increases monotonically with time. 


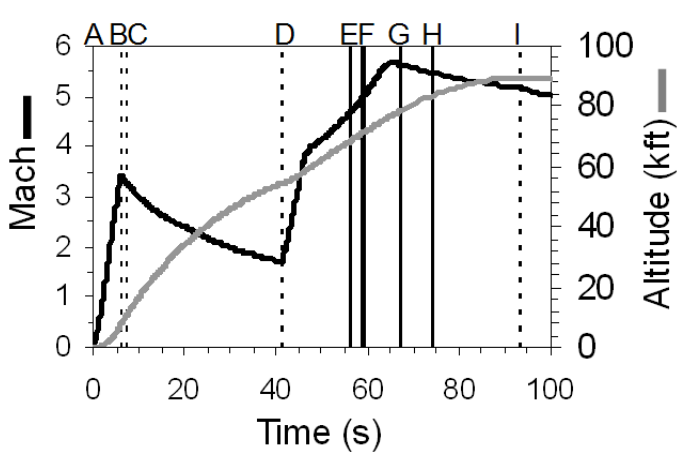

a.

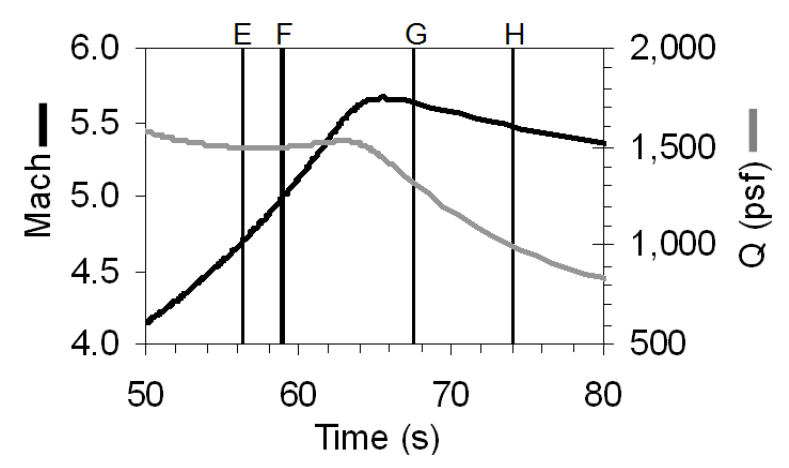

b.

Figure 4.2: Nominal trajectory a) Mach number and altitude vs. time and b) Mach number and dynamic pressure vs. time within test window. A) First stage ignition, B) First stage burnout, C) Stage separation, D) Second stage ignition, E)

Deploy shroud, begin primary experiment, F) Nominal test point, G) Second stage burnout, primary experiment end, $H$ ) Dynamic pressure reaches 1,000 psf, secondary experiment end, and I) Apogee. Reprinted with permission of the American Institute of Aeronautics and Astronautics.

\subsection{Dispersion}

With a nominal trajectory in hand, dispersion about that trajectory can be determined. Dispersion of sounding rocket trajectories is typically estimated using a Monte Carlo analysis technique. Monte Carlo analysis is a statistical tool that is used to relate predicted independent parameter variations to the performance of the system. Applicable model inputs are varied independently and randomly within estimated uncertainty bounds for each run. When many simulations are performed, each with a unique set of randomly varied contributors, a more realistic model of system performance is developed than if only one input variable, or set of variables, was varied at a time. This is because random variations in input uncertainties can interact with each other in unexpected and potentially detrimental manner. Such an analysis was performed for the Hyper-X Program to simulate the dynamics of the X-43A vehicle (Baumann et al., 2007).

The contributors used for this Monte Carlo analysis are based on those historically 
used by NSROC to determine dispersion in apogee altitude and impact location. The standard contributors are launch elevation angle $(\mathrm{QE})$, payload weight, thrust multiplier, thrust misalignment, center of gravity offset, fin misalignment, wind, drag coefficient multiplier, initial pitch rate, and the launch azimuth. Some quantities, such as thrust and drag coefficients, are multiplied by a non-dimensional "multiplier" which when changed allows the contributor to be varied by a percentage instead of an absolute value. Nominal values and 3- $\sigma$ ranges are shown below in Table 4-1. For the present analysis, a higher than standard magnitude and uncertainty range for the initial pitching rate (rail tip-off) and vehicle drag was used as a result of the post-flight trajectory analysis performed for the FASTT Program. The resulting dispersion in the Mach number and dynamic pressure is shown in Figure 4.3 for a 5,000 run Monte Carlo simulation. This level of simulation was chosen such that the number of runs necessary for statistical convergence could be identified and a lower number of runs could be adopted in latter analyses that were more computationally intensive. This number, 1000, was determined by finding the number of runs necessary for both average values of Mach number and altitude and their standard deviations to reach within $2 \%$ of their final value. Conveniently, this was also the number used by NSROC in their dispersion analyses.

Table 4-1: Monte Carlo dispersion contributors and ranges.

\begin{tabular}{|l|l|l|l|l|}
\hline Stage & Contributor & Nominal Value & $\mathbf{3 - \sigma}$ Range $(+/-)$ & Units \\
\hline 1 & QE & 50.4 & 0.1 & $\mathrm{deg}$ \\
\hline 1 & Payload weight & 503.0 & 30.0 & $\mathrm{lbs}$ \\
\hline 1 & Thrust multiplier & 1.0157 & 0.03 & - \\
\hline 1 & Thrust misalignment & 0.0 & 0.2 & $\mathrm{deg}$ \\
\hline 1 & CG offset & 0.0 & 0.0167 & $\mathrm{ft}$ \\
\hline 1 & Fin misalignment & 0.0 & 0.000349 & $\mathrm{deg}$ \\
\hline 1 & Wind & 0.0 & 7.5 & $\mathrm{ft} / \mathrm{s}$ \\
\hline 1 & Drag coefficient multiplier & -1.0 & 0.3 & - \\
\hline 1 & Rail tip-off & -3.0 & 3.0 & $\mathrm{deg} / \mathrm{s}$ \\
\hline 1 & Azimuth & 107.0 & 0.1 & $\mathrm{deg}$ \\
\hline 2 & Thrust misalignment & 0.0 & 0.2 & $\mathrm{deg}$ \\
\hline
\end{tabular}




\begin{tabular}{|l|l|l|l|l|}
2 & CG offset & 0.0 & 0.0192 & $\mathrm{ft}$ \\
\hline 2 & Fin misalignment & 0.0 & 0.00349 & $\mathrm{deg}$ \\
\hline 2 & Drag coefficient multiplier & -1.3 & 0.3 & - \\
\hline
\end{tabular}

Approximately $68 \%$ of trajectories fall within one standard deviation, $95 \%$ within two standard deviations, and 99.5\% within three standard deviations. For both Mach number and dynamic pressure, dispersion increases throughout the trajectory, as can be seen in the figure. During the second stage burn, thrust is much greater than drag. Since the thrust of the boosters is known to a much higher degree of precision than the drag coefficient, dispersion is limited during the boost phases. After the second stage burn at point " $\mathrm{H}$ " in Figure 4.3, drag is the main force on the vehicle, so the effect of the drag coefficient's larger variation is more important to the trajectories for the remainder of the flight. Also, at this point, dynamic pressure can vary by over a factor of two. This also significantly increases the uncertainty in the drag on the vehicle because the drag is determined both by the drag coefficient and the dynamic pressure. These two factors combine to create the large increase in dispersion observed after the second stage burn. The observed increase of dispersion with time validates the decision to design the nominal trajectory with the test window as early in the trajectory as possible. 


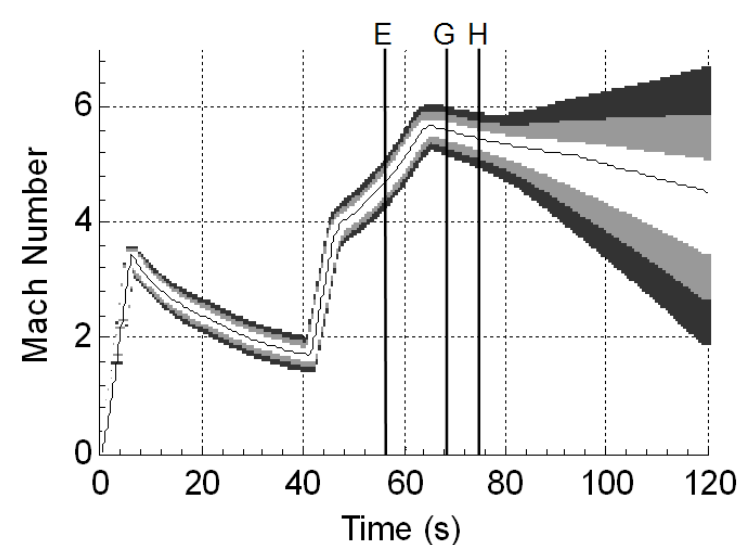

a.

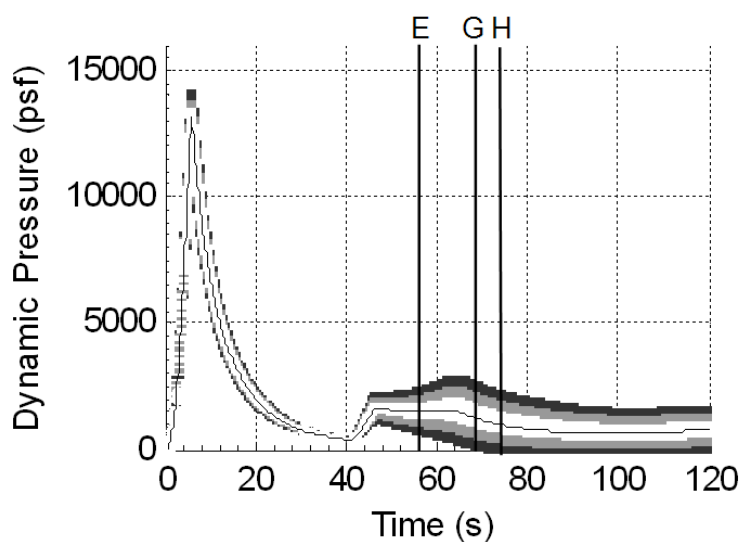

b.

Figure 4.3: a) Mach number vs. time +/- 1, 2, and 3 standard deviations, and b) Dynamic pressure vs. time $+/-1,2$, and 3 standard deviations. Primary test window is from 56.4 seconds $(E)$ to 57.5 seconds $(G)$ and secondary test window is from 67.5 to 74.0 seconds $(\mathrm{H})$, as indicated by vertical bars. Reprinted with permission of the American Institute of Aeronautics and Astronautics.

The dispersion in the Mach number and dynamic pressure during the test window and at the nominal test time is particularly important because these quantities affect the operation of the scramjet inlet and flowpaths. Given the performance characteristics of the boosters and the nominal trajectory for this flight, it is nearly certain that the vehicle will pass through the design Mach number of 5.0 during the sustained burn phase of the second stage burn as no trajectories in this Monte Carlo analysis failed to do this. However, achieving the design dynamic pressure at this Mach number means that the vehicle must pass through Mach 5 at the proper altitude since the static pressure is determined by the altitude and dynamic pressure is given by $q=(\gamma / 2) P M^{2}$, where $q$ is the dynamic pressure, $\gamma$ is the ratio of specific heats, $P$ is the static pressure, and $M$ is the Mach number. There is also uncertainty in the time at which the vehicle passes through a given Mach number. This is important because payload events, such as shroud deployment, will be determined by a preprogrammed timer for this program. For 
instance, if the shroud deployment time is set based on the nominal trajectory and in flight the Mach number is less than expected at this time (or equivalently, the vehicle passes through the expected Mach number at a later time in the trajectory) the inlet may not operate as expected. Computational fluid dynamics studies indicated a lower Mach number limit for which all inlet shocks remain attached and the inlet remains started. For this study, scramjet flowpath geometry and ground test facility limitations determined the upper and lower dynamic pressure and upper Mach number limits for a successful experiment. Based on these considerations, the success criteria developed included lower and upper Mach number limits of 4.7 and 5.3, respectively. The lower and upper dynamic pressure limits were 1,109 and 1,873 psf (53.10 and $89.68 \mathrm{kPa}$ ), respectively. Other success criteria derived from further scramjet operability concerns could be incorporated into this analysis, but for simplicity, were not considered here.

\subsection{Method for reduction of dispersion}

Given the fact that only one flight test is planned for the SDPTE program, it is important that every measure is taken to increase the likelihood of a successful test. Without actively controlling the launch vehicle, one of the only ways to change the freestream conditions at the expected test time is to vary the second stage ignition time (SSIT) and alter the expected test time appropriately. A relationship was found here between the state of the vehicle at a time during the interstage coast and the second stage ignition time required to achieve a desired flight Mach number at the altitude consistent with a given dynamic pressure.

A 1,000 run Monte Carlo simulation was performed using the vehicle model and dispersion contributors discussed above in order to establish this relationship. This 
number of runs was deemed optimal as statistical convergence was obtained and incorporating more runs would have been computationally prohibitive as each trajectory is later iterated upon in order to determine the best second stage ignition time. Each run was comprised of one trajectory which incorporated its own distinct set of randomly varied input contributors. For each trajectory, the second stage ignition time was iterated upon until the trajectory passed within $3 \mathrm{psf}(0.143 \mathrm{kPa})$ of the design dynamic pressure at a Mach number of 5.0. For $0.2 \%$ of the trajectories, altering the second stage ignition time to attain the design dynamic pressure precluded the vehicle passing through a Mach number of 5.0. For these trajectories, the second stage ignition time was adjusted to bring the dynamic pressure as close to $1,500 \mathrm{psf}(71.82 \mathrm{kPa})$ as possible without preventing the vehicle from achieving the design Mach number. Since second stage ignition time was adjusted to achieve the desired test conditions, the time at which we expect these conditions to occur must also be adjusted. Therefore the time at which the test conditions were achieved was extracted in addition to the second stage ignition time required to achieve the proper test conditions.

For each trajectory, the vehicle's state was observed at a flight time of 27.0 seconds. This time was chosen to be as late as was feasible such that the vehicle has as much time as possible to stray from the nominal trajectory giving the largest possible variation in measured Mach number and altitude. This observation time, however, cannot be made so late that it is after the earliest optimal second stage ignition time. The earliest optimal second stage ignition time was found to be 30.0 seconds. Three seconds was deemed a conservative estimate for the time needed to take the measurements required to calculate the vehicle's state, calculate the vehicle's state, determine the optimal second stage 
ignition time, and ignite the second stage booster.

To determine the relationship between the optimal second stage ignition times and the Mach numbers and altitudes observed at 27.0 seconds, a third order polynomial surface was linearly regressed to fit the extracted optimal second stage ignition time data. Since the second stage ignition time was adjusted to achieve the desired test conditions, the time at which we expect these test conditions to occur must also be adjusted. Similar to the relationship for the optimal second stage ignition time, a third order polynomial surface was fit to the optimal test time data. The $\mathrm{R}^{2}$ values for the optimal second stage ignition time and optimal test time surfaces were 0.961 and 0.653 respectively. The lower certainty in the optimal test time has different implications for different mission profiles. For the mission considered here, the mass flow of fuel is nearly constant, so if the test condition is reached slightly earlier or later than predicted, combustor fueling would still be expected at the same mass flow rate. Assuming the correct SSIT has been selected, the vehicle will still pass through the correct Mach number at the correct altitude, and thus dynamic pressure. Figure 4.4 shows the second stage ignition time (SSIT) and optimal test time (OTT) relationships for various altitude ranges. The solid lines are lines of constant altitude corresponding to the upper and lower limits in altitude measured at $\mathrm{t}=27.0$ seconds from which the data points were selected.

Approved for public release; distribution is unlimited. AEDC PA 2012-083 


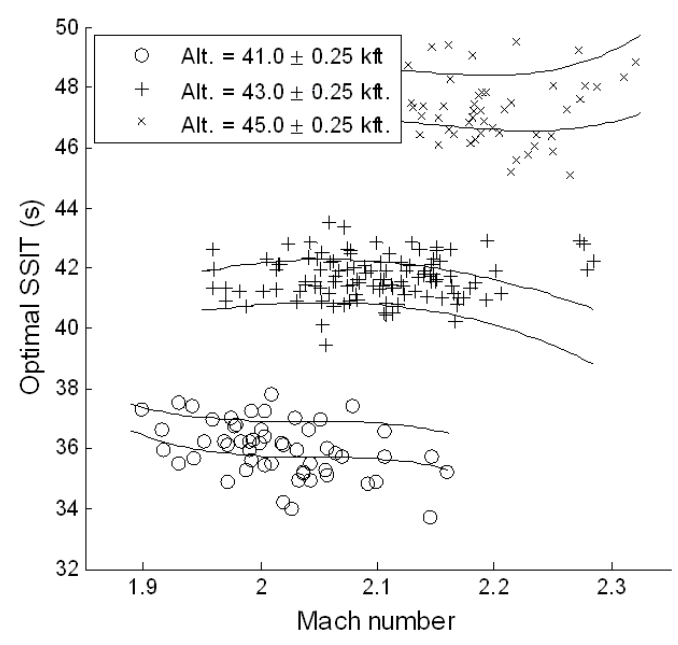

a.

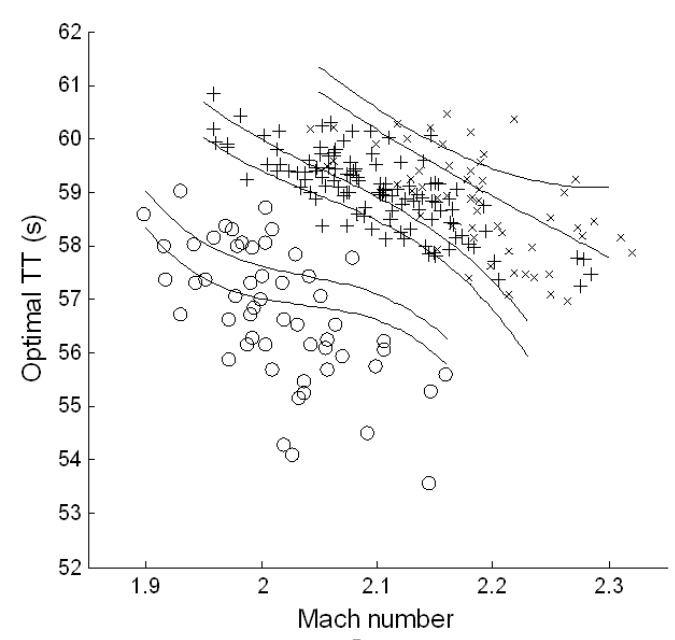

b.

Figure 4.4: Relationship between a) optimal second stage ignition time and b) optimal test time and the Mach number and altitude measured at $t=27.0$ seconds. The curves represent the polynomial regression at the limits of the $+/$ $0.25 \mathrm{kft}$ range for each nominal altitude. Reprinted with permission of the American Institute of Aeronautics and Astronautics.

Once the relationship between optimal second state ignition time and test time with Mach number and altitude was determined, a new 1,000 run Monte Carlo analysis was performed to test the dispersion reduction approach. This analysis used a new set of contributors for each trajectory but adopted the determined relationships to calculate the second stage ignition time and the expected test time based on the observed altitude and Mach number at 27.0 seconds. A new analysis was required because the original Monte Carlo runs were used as the basis for the relationships and it would not be an independent test of the effectiveness of the dispersion reduction approach to reuse the original trajectories. While the base values and 3- $\sigma$ ranges for the contributors were the same, the actual random values that the contributors took on for each Monte Carlo trajectory were different. Since these new trajectories utilize the optimal second stage ignition and test time maps, which were determined a priori, they give an accurate prediction of the dispersion that results when utilizing the dispersion reduction method. 


\subsection{Results}

The results from the Monte Carlo analysis, which utilized the computed maps to determine the second stage ignition and test times, are presented here. The likelihood of a successful test was significantly increased by use of this method. It is useful to plot the dynamic pressure and Mach number at the expected test time for each trajectory and compare against the program specific success criteria discussed above. For the uncorrected trajectories, the expected test time is the time when the nominal trajectory passes through Mach 5.0. This is equivalent to initiating the test time in flight via a timer that was originally set using the nominal trajectory as a guide. For the corrected trajectories, the expected test time is that determined from the optimal test time relationship described above. Figure 4.5 shows this plot with success criteria cast into dynamic pressure and Mach number limits, indicated by the black box. Without dispersion reduction, $71.0 \%$ of trajectories fall within the success criteria. Using the method for reducing dispersion, $99.3 \%$ of trajectories fall within the success criteria at the anticipated test time. This represents a significant increase in the likelihood of a successful scramjet test. Figure 4.6 shows a histogram of dynamic pressures when the vehicle passes through a Mach number of 5.0. The standard deviation of dynamic pressures without and with dispersion reduction is 389 and $66.0 \mathrm{psf}(18.63$ and $3.16 \mathrm{kPa})$, respectively. Again, this is a significant improvement. 


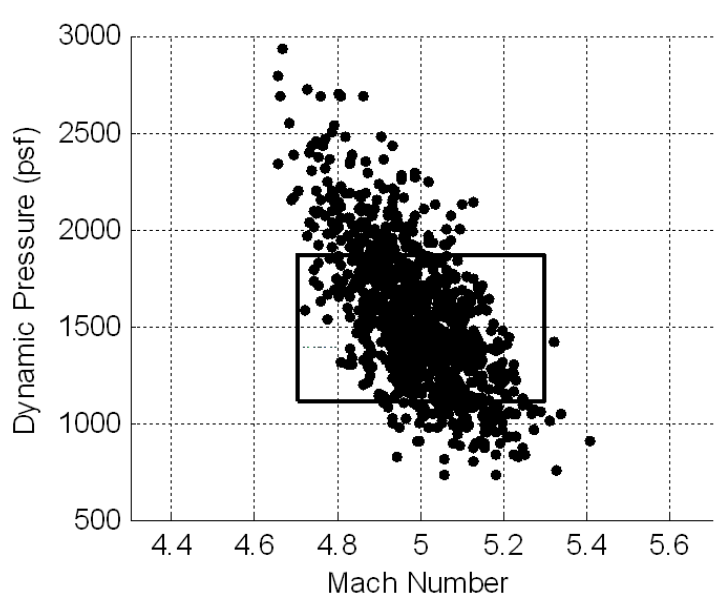

a.

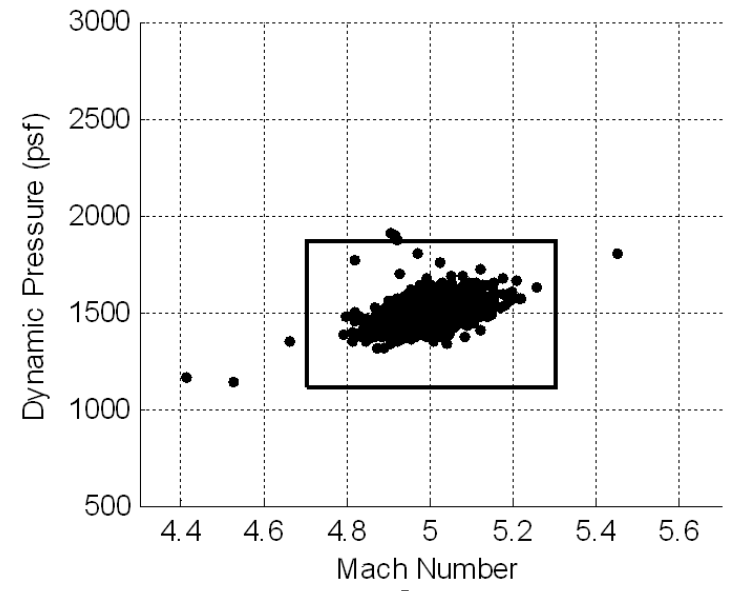

b.

Figure 4.5: a) Dynamic pressure and Mach number for each trajectory without and b) with the application of dispersion reduction method, at the expected test time. Boxes represent success criteria. Reprinted with permission of the American Institute of Aeronautics and Astronautics.

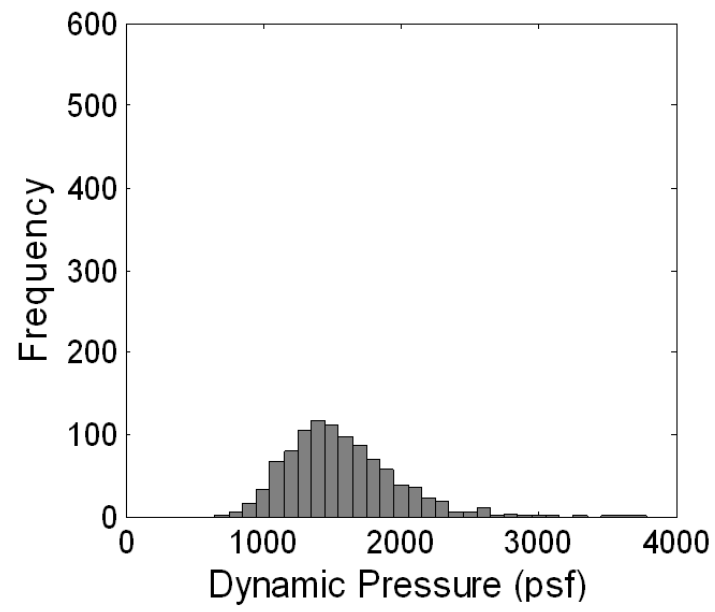

a.

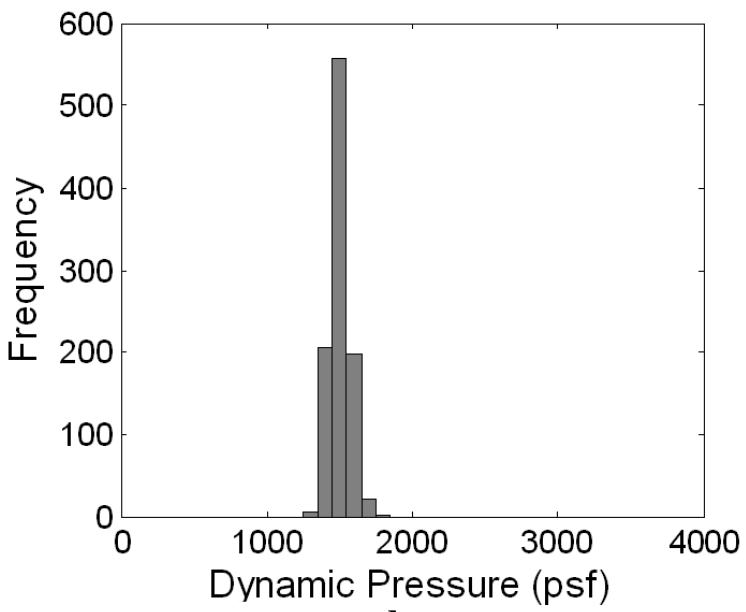

b.

Figure 4.6: Histogram of dynamic pressures at the time the vehicle passes through

Mach 5.0 for trajectories a) without dispersion reduction and b) with dispersion reduction. Reprinted with permission of the American Institute of Aeronautics and Astronautics.

\subsection{Discussion}

The method described here was conceived with the aim of decreasing the dispersion in freestream conditions that the payload and vehicle experience at and near the design 
test point. While successful, utilizing this method has other implications for practical scramjet flight testing. How this method affects the trajectory off the design test point must be also considered as this affects ignition flow conditions of the scramjet and equivalence ratios seen by the scramjet combustor during the test. Range safety must also be considered, as the eventual impact location of the second stage and payload may change. Finally, practical implementation of the dispersion reduction technique should also be considered.

As discussed above, the nominal trajectory incorporates a nearly constant dynamic pressure near the test point. This is possible because the increasing Mach number during the sustained burn phase of the second stage improved-Orion booster is almost exactly balanced by the decreasing static pressure with increasing altitude. Figure 4.7 shows both Mach number and dynamic pressure vs. time for the nominal trajectory as well as trajectories which initially undershoot and overshoot the nominal altitude. These two latter trajectories have been corrected by decreasing and increasing the second stage ignition time, respectively. Since both these trajectories are outliers, it is likely that the correction required, and thus the effects of this correction, will be less than is shown here. The trajectory shown for which the SSIT is 32.9 seconds originally has a Mach number and dynamic pressure of 4.85 and 2,457 psf respectively at the expected test time. The trajectory shown for which the SSIT is 55.2 seconds originally has a Mach number and dynamic pressure of 5.1 and 842 psf respectively at the expected test time. As such, the two sample trajectories in Figure 4.7 both had optimal second stage ignition times over 1.7 standard deviations away from that of the nominal trajectory. Trajectories that initially undershoot the nominal altitude are corrected back to pass through $\mathrm{M}=5.0$ and $\mathrm{q}$ 
$=1,500$ psf by decreasing the second stage ignition time. For these trajectories, the dynamic pressure is decreasing in time near the test point, and the test point occurs near the end of the sustained burn phase of the second stage booster (test time at $t=56.0 \mathrm{sec}$. for SSIT = 32.9sec). Since the second stage burn takes place at a lower altitude where total drag is higher, the peak Mach number attained is lower than for the nominal trajectory. Conversely, when trajectories that initially overshoot altitude are corrected, second stage ignition time must be delayed. This results in an increasing dynamic pressure around the test point, which occurs closer to the beginning of the sustained burn phase of the second stage booster than for the nominal trajectory (test time at $\mathrm{t}=62.5 \mathrm{sec}$. for SSIT $=55.2 \mathrm{~s}$ ). Since the second stage burn takes place at a higher altitude where there is less total drag, a higher peak Mach number is attained.

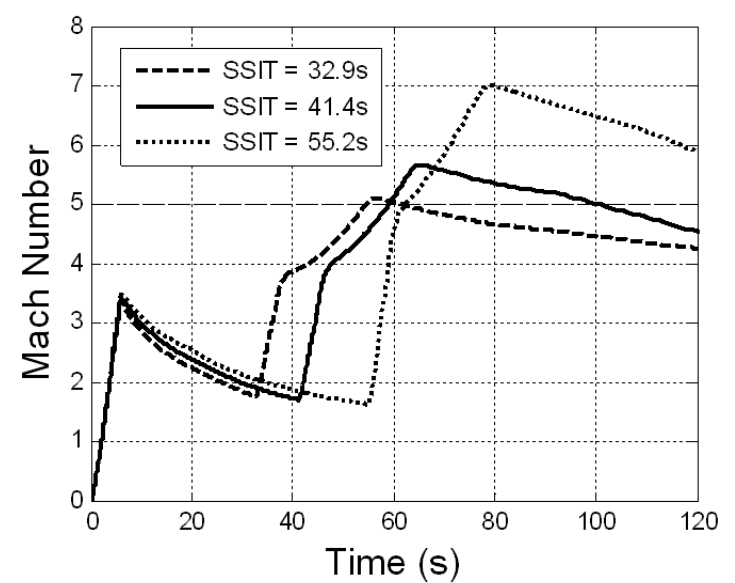

a.

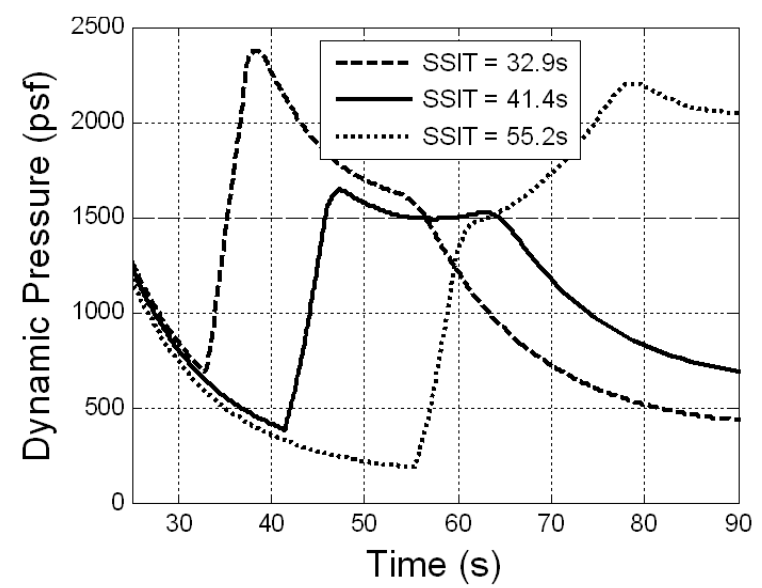

b.

Figure 4.7: a) Mach number vs. time for the nominal trajectory and two with adjusted second stage ignition and test times, and b) Dynamic pressure vs. time near the test window for the nominal trajectory and two with adjusted second stage ignition and test times. Approximate test points are where trajectories cross $M=5.0$ and $q=1500$ psf as indicated by horizontal dashed lines. Reprinted with permission of the American Institute of Aeronautics and Astronautics.

It is also important to consider the effect of trajectory correction on scramjet 
operation. For a trajectory which initially undershoots the desired altitude and is corrected back, a decreasing dynamic pressure in the vicinity of the test point means that before the test point, dynamic pressure will be higher than expected. If the fuel system is designed to provide a nearly constant and predetermined fuel flow rate, as is the case for the SDPTE flight, the equivalence ratio when the scramjet is ignited will be lower than expected and the scramjet may not ignite. For a trajectory which initially overshoots the desired altitude and is corrected back, an increasing dynamic pressure means that the equivalence ratio at light-off will be higher than expected and the inlet could unstart. If it is determined that light-off equivalence ratios are outside predetermined limits for a particular scramjet, then maps of optimal shroud deployment and ignition times as a function of Mach number and altitude measured during the interstage coast may be required. The procedure for determining this relationship would be exactly the same as that for finding the appropriate second stage ignition time and test time. Operability of the scramjet following ignition should also be considered and expected equivalence ratio limits compared against preflight ground test results.

Without understanding the operating limits of the engine under consideration, the effect of altering the second stage ignition time on the amount of useful test time is unknown. Assuming combustion is successfully initiated, the decreasing dynamic pressure of an initial undershoot will result in a lower dynamic pressure after the optimal test time and a higher than expected equivalence ratio during the remainder of the test. As the dynamic pressure drops, the equivalence ratio will increase, eventually leading to an engine unstart. The increasing dynamic pressure of an initial overshoot will result in a higher dynamic pressure after the optimal test time. The lower than expected equivalence 
ratio will lead to a lean blowout if the dynamic pressure becomes too large. If engine operating limits are established before the flight test, the likelihood of an engine unstart or lean blowout can be investigated further before flight testing.

Adjusting the second stage ignition time mid-flight also has implications on the impact location. While impact location is of little consequence for the success of the scramjet test, it is very important for range safety. The effect of this dispersion reduction technique on impact location is non-intuitive. Use of this technique actually decreases the dispersion in impact location and creates a bimodal distribution of impact locations. Figure 4.8 shows the impact locations for all trajectories with and without dispersion reduction. Trajectories which are initially low on altitude and are corrected by decreasing the interstage time delay tend to be clustered near the nominal trajectory and with trajectories which require little correction. Trajectories which are initially high on altitude and are corrected by increasing the interstage time delay are clustered downrange. Total downrange dispersion is decreased by approximately $30 \%$. It is currently unclear why a bimodal distribution of impact locations is observed despite the smooth random variation of individual contributors. As expected, cross-range dispersion is unaffected by use of this technique. As such, it is unlikely that the implementation of this technique will adversely affect range safety.

Approved for public release; distribution is unlimited. AEDC PA 2012-083 


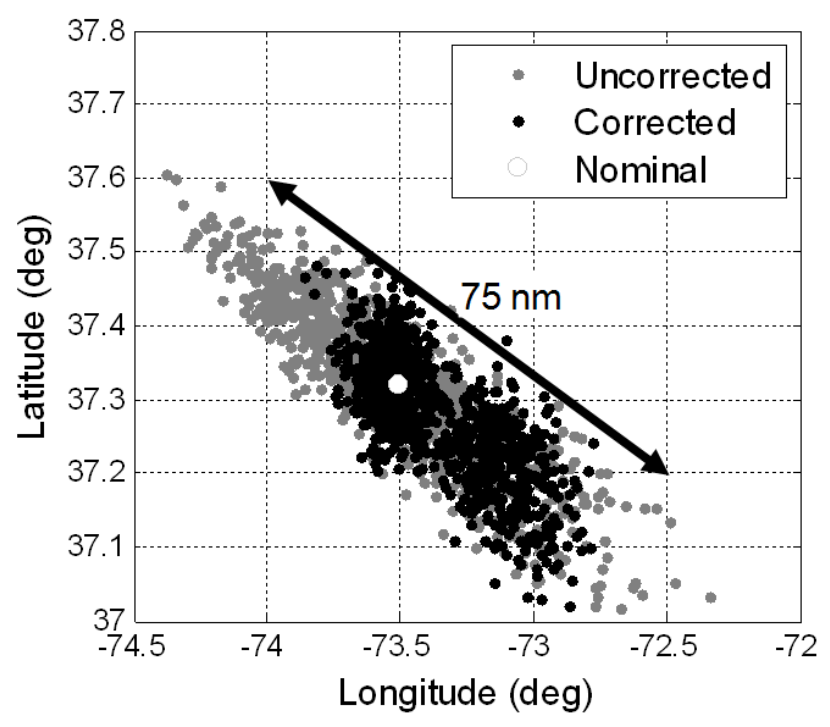

Figure 4.8: Impact location for all trajectories with (corrected) and without (uncorrected) dispersion reduction. Vehicle enters figure from the upper left. Reprinted with permission of the American Institute of Aeronautics and Astronautics.

\subsection{Conclusion}

A novel and inexpensive method for decreasing dispersion for a spin-stabilized, unguided sounding rocket scramjet flight experiment is presented here. Using a Monte Carlo simulation, the confidence with which the nominal trajectory is simulated has been quantified and presented. While not all resulting trajectories are acceptable, it is possible to reduce dispersion in the test conditions by altering the delay between the first stage booster burnout and the second stage booster ignition. This is accomplished by using a statistical relationship between Mach number and altitude, measured during the interstage coast, and the second stage ignition time which allows the vehicle to pass through the desired dynamic pressure at the target Mach number. Altering the second stage ignition time necessitates adjusting the times at which other payload events take place. Since the relationship between the vehicle state during the interstage coast and the optimum timing 
for payload events is generated through trajectory simulations, the fidelity of this relationship is dependent upon the accuracy of the input parameters and modeling of the contributors. While active control of the vehicle may help a test article achieve desired freestream conditions, such systems carry with them additional risk of failure and are expensive to develop and implement. The method for test condition dispersion reduction presented here is an inexpensive way to increase the probability of a successful scramjet test aboard unguided, spin-stabilized sounding rockets without adding significantly to the complexity or cost of the program.

Approved for public release; distribution is unlimited. AEDC PA 2012-083 


\section{Chapter 5: Conclusions}

Simulating the hypersonic flight environment in ground test facilities continues to present a difficult challenge to researchers in the field of hypersonic airbreathing propulsion. Ground-based wind tunnels utilize a variety of heating methods to achieve the high total enthalpies seen in hypersonic flight. Common heating methods include heating the test gas through combustion, passing the test gas through a heat exchanger, heating it through electrical resistance, passing a shock through the test gas, or some combination of the above. For full scale ground testing at hypersonic conditions, combustion heating and shock heating are predominantly used. The former leaves combustion byproducts in the test gas, which can affect the thermodynamics and chemical kinetics of combustion within a scramjet. The latter necessarily implies a short test time which gives rise to questions about the establishment of steady flow through the scramjet.

It is these difficulties which gave rise to the Short Duration Propulsion Test and Evaluation (SDPTE) program, a combination of ground and flight testing aimed at investigating the effects of a contaminated test gas and a short test time on the performance and operation of a dual-mode scramjet (DMSJ). To accomplish this, a dualmode scramjet flowpath was tested in a direct-connect facility which could operate with both a clean test gas and one with combustion byproducts added artificially. This DMSJ flowpath formed the basis for further ground testing in a freejet configuration and a flight test. Further direct-connect testing at the actual flight isolator entrance Mach number will also take place to provide a direct comparison with freejet ground test and flight test data.

For both the freejet tests and the flight experiment, an inlet was designed to process 
the incoming freestream air to the temperature and pressure required for combustion. The DMSJ inlet for flight was designed in conjunction with a nominal vehicle trajectory to allow the full-scale flowpath to be tested at the same conditions as those tested in the UVaSCF. Ultimately the requirement that the conditions at the inlet exit match those tested in the UVaSCF was relaxed in favor of increased inlet operability and reduced flight program risk for the flight experiment.

The chosen inlet was adapted for ground testing and retained critical dimensions while aiding installation in the chosen freejet facilities. This inlet was tested in the NASA HyPulse facility, verifying its performance and operation. It successfully delivered supersonic air to the flowpath, although several aspects of its operation remain unresolved.

Since dual-mode combustion requires a flight Mach number between 4 and 6, freejet testing in this regime is often conducted in a blowdown facility. If higher Mach number tests, which may only be achievable in an impulse facility, are planned for a given engine, significant advantages can be realized by testing a DMSJ in an impulse facility. For these tests in the dual-mode regime, ignition and establishment of steady combustion within DMSJ for hydrogen fuel were never achieved in HyPulse. When a 20/80 silane/hydrogen fuel mixture was used, however, the fuel autoignited resulting in dualmode $(\mathrm{ER}=0.72)$ and supersonic $(\mathrm{ER}=0.33)$ combustion.

The nominal trajectory for the flight vehicle utilized a two-stage launch vehicle. A Terrier Mk. 70 rocket formed the first stage booster while an improved-Orion rocket formed the second. In order to reduce the expected dispersion in test conditions as well as integrated heating loads, the flight experiment was positioned early within the flight 
during the burn of the second stage booster. Still, a Monte Carlo analysis showed that the likelihood of a successful test as defined by program success metrics was only $71 \%$. To increase the likelihood of passing through the required conditions, a method was developed by which the second stage ignition time was varied according to a predetermined relationship between the conditions seen during the interstage coast and the optimal second stage ignition time and test time. This method was tested with an additional Monte Carlo simulation and resulted in a dramatic increase in the success rate.

This chapter continues with findings and a discussion of their contributions to the field of scramjet testing. Suggestions for future work which will extend the ideas and concepts explored in this dissertation are also presented. Finally, some conclusions regarding this work are drawn.

\subsection{Findings}

The findings as related to objectives presented in the introduction of this dissertation are presented here.

\subsubsection{Nominal trajectory and inlet development}

A nominal trajectory was successfully developed and simulated using GEM in conjunction with the aerodynamic design of the inlet for both flight and ground testing. The scramjet test was positioned during the second stage boost to limit dispersion and integrated heating. The nominal test altitude and Mach number correspond to those achievable in ground test facilities available for use in the SDPTE program and give the desired isolator entrance conditions. The inlet geometry was designed in conjunction with the trajectory as the conditions seen at the entrance to the isolator are dependent on both the inlet geometry and the freestream conditions the inlet is exposed to. The flight 
vehicle inlet was designed to fit within strict geometric limitations. Ultimately, a compromise was made between isolator entrance conditions and the ability of the inlet to handle off-design conditions. The inlet for freejet ground testing was designed to be easily integrated into the HyPulse facility while preserving the geometry of the flight inlet.

\subsubsection{Analysis of Mach 5 HyPulse data}

The results of the Mach 5 tests in HyPulse were analyzed to evaluate both the operation of the inlet in a freejet configuration, the operation of the combustor and isolator, as well as the ignition and flameholding characteristics of the scramjet. The inlet did not operate as expected because an unexpected separation occurred on the forebody. Evidence indicates, however, that with a turbulent boundary layer on the forebody, the inlet would in fact operate as expected. While ignition was not achieved with pure hydrogen fuel a silane/hydrogen mix fuel autoignited and the combustor operated as expected. Since the effective ER for the dual-mode case was apparently too high, the precombustion shock train partially unstarted the inlet. Therefore, at present, it is inconclusive as to whether it is possible to test a DMSJ in the dual-mode regime.

\subsubsection{Dispersion and its reduction}

The expected dispersion of the SDPTE flight vehicle was evaluated through a Monte Carlo simulation. Further analysis was performed to understand the effect of this dispersion on the likelihood of a successful scramjet test. Since only one flight is planned, a method was developed and tested to reduce the dispersion in freestream conditions seen by the scramjet by altering the second stage ignition delay. 


\subsection{Contributions}

\subsubsection{Inlet Design}

Each part of the work presented here forms a novel contribution to the field of hypersonic airbreathing propulsion testing. While various aspects of scramjet inlet design have been documented in the literature, the complete detailed aerodynamic design of a specific inlet within stringent geometric restrictions as well as the resulting design tradeoffs have never been documented in the open literature. Further, the SDPTE inlet described here was tested at full scale in an impulse facility providing the opportunity for comparison with predicted performance. This brings full circle the inlet design process for a scramjet test program.

\subsubsection{Freejet testing of a dual-mode scramjet combustor in an}

\section{impulse facility}

While there is significant literature describing scramjet testing at hypervelocity flight Mach numbers greater than 6 in impulse facilities, nowhere is the testing of a dual-mode scramjet described. This may be largely due to the fact that other facilities exist for testing in this flight regime which do not carry with them the difficulties associated with a short test time. As explained in previous chapters, though, testing a dual-mode scramjet in this type of facility offers several advantages not seen in other types of facilities.

Since shock-heated facilities can produce a wide range of flight Mach numbers at dynamic pressures of interest for air-breathing engines, a single test article can be tested over a wide range of test conditions in the same facility. This limits variability from test to test as well as the number of facility integration issues that must be solved. Further, the impulsive heat load on the test article presents a number of advantages as the test 
article remains at nearly constant temperature throughout the test. Active cooling is not required making test articles simpler and cheaper to manufacture. There is no thermal stress within the model aiding in the integration of windows for optical measurements. The constant-temperature model walls also make possible high-fidelity heat flux measurements and provide a well-characterized boundary condition for later comparison with numerical models.

This study is the first demonstration of dual-mode combustion and a precombustion shock train in an impulse facility. This is significant because the establishment time for a shock train has never been determined and it was not clear that a shock train could establish within the short test times characteristic of impulse facilities.

\subsubsection{Dispersion reduction}

Since only one flight experiment is planned for the SDPTE program, every effort should be made to ensure that that flight is successful and the launch vehicle passes through the required Mach number and altitude. This is important because the operation of an airbreathing engine is highly dependent upon the atmospheric conditions it encounters. The idea that an interstage time delay can be altered such that a launch vehicle achieves a desired flight condition has likely been around since the invention of multi-stage rockets. Determining what this optimal interstage time delay should be for an airbreathing engine test a priori, however, has not been done before. Dynamic simulations cannot be run during the flight because the computing power does not currently exist to enable such computations. As such, the second stage ignition time must be determined before the flight or a simple map must be created such that it can be determined with simple arithmetic from data available to the onboard processing unit. 
A statistical relationship between the Mach number and altitude of the flight vehicle at a point during the interstage coast and the optimal second stage ignition time and test time was determined. A Monte Carlo technique was used to evaluate the likelihood of a successful test when this predetermined relationship was used to decide the second stage ignition and test times. The results of this test showed an increase in success rate from $71 \%$ without use of the dispersion reduction technique to over $99 \%$ when it was used. It was also important that this method is inexpensive and preserves the economy of using a spin-stabilized, unguided sounding rocket for scramjet flight testing. Further, this technique avoids an increase in program complexity as it only utilizes hardware already likely to be used for a scramjet flight experiment.

\subsection{Future work}

\subsubsection{Inlet Design}

As was discussed extensively in previous sections, an unexpected separation was observed on the forebody of the SDPTE HyPulse test article. While this separation is characterized through extensive analysis of the pressure data, further study is required to completely understand the nature of this separation and its effect on the operation of the inlet. Flow visualization is an excellent method for doing this and would elucidate the nature of the disturbances seen. Several techniques could be used to this end. Already available in HyPulse is a schlieren system which gives integrated line of sight density gradients throughout the flow. This would confirm the shape and size of the separation seen on the SDPTE forebody.

The HyPulse test article was designed such that a boundary layer trip could be added on the forebody at a later date in the case that such an addition was later deemed 
necessary. While there was significant pressure to rationalize the exclusion of a trip because of its cost, the test results presented here show that a trip is necessary. All evidence indicates that it was the inability of the forebody boundary layer to transition to turbulence that led to a cowl-shock induced separation. Heat flux data would have confirmed the state of the boundary layer along the forebody. It is believed that the heat flux gauges were damaged during installation, which has led to unusable data. Reinstallation of the heat flux gauges for further testing would confirm a laminar boundary layer on the forebody. If the boundary layer was confirmed to be laminar or transitional at the end of the forebody, then this would strongly indicate that it was the interaction of the cowl shock with the forebody boundary layer which caused the pressure spike seen in the test data. In this case, inclusion of the boundary layer trip would ensure a turbulent boundary layer which would not separate. This would confirm that the inlet can operate as designed and would validate its use on the SDPTE flight vehicle.

\subsubsection{Freejet testing of a dual-mode scramjet combustor in an impulse facility}

In order to further investigate the operation of this combustor at the increased isolator Mach number of the flight vehicle, the construction of a new nozzle for the UVaSCF has been funded by $\mathrm{T} \& \mathrm{E} / \mathrm{S} \& \mathrm{~T}$. This will allow a more direct comparison between directconnect tests and those performed in freejet mode. It will also allow further investigation of the ignition characteristics of hydrogen fuel in the combustor at an increased isolator entrance Mach number. While successful ignition of hydrogen has been demonstrated with an isolator entrance Mach number of 2.0 in the UVaSCF, the same cannot be said at higher Mach numbers. It is likely that the wall temperature directly downstream of the 
ramp fuel injector plays an important role in the ability of the configuration to flamehold. This was discussed earlier in the dissertation but could be further investigated by installing a temperature-controlled plate directly downstream of the fuel injector in either facility. In HyPulse, a heated plate could be used to confirm that it is a wall-temperature effect that is preventing flameholding with hydrogen. If flameholding with hydrogen is successfully demonstrated in the UVaSCF at the new condition, installation of a cooled plate downstream of the fuel injector could shed light on the effect of wall temperature within the recirculation region on flameholding and ignition in a steady facility.

\subsubsection{Dispersion and its reduction}

The conceptual design, implementation of the dispersion reduction technique is presented in this dissertation. If one agrees that the Monte Carlo simulation is a valid estimation of the integral over the contributor space, then the testing of this technique has also been presented. The next step is for this technique to be implemented on a flight experiment. Since scramjet flight experiments are so rare, though, it may be some time before this technique is used.

\subsection{Concluding remarks}

This dissertation provides a framework for the design and execution of a scramjet test campaign within the context of the SDPTE program. Work on the design of the inlet and nominal trajectory, testing of the scramjet in HyPulse, and the invention of a novel method for reducing dispersion in test conditions were each enabling components of the SDPTE program. In a broader sense, the SDPTE program will help researchers to understand the effects of test gas vitiation and a short test time, problems common to hypersonic propulsion testing, on the performance and operation of a dual-mode 
scramjet. The resulting increase in understanding of the dual-mode operation of a DMSJ will lead to better predicted operating margins and the potential for reduced safety factors in future systems to be reduced. Since a major source of risk for the flight experiment was remedied with the dispersion reduction technique presented here, it is possible that the experiment will fly at some future date. If this happens, the resulting database combined with SDPTE ground test results will significantly aid in more accurate extrapolation of ground test data to flight performance in the future reducing mission risk and increasing system safety. 


\section{References}

Aerosoft Inc. (2009) “Gasp Version 5.0 Reference Guide,” Blacksburg, VA.

Andrews, E.H., McClinton, C.R., and Pinckney, S.Z. (1971) "Flowfield Starting Characteristics of an Axisymmetric Mixed-Compression Inlet," NASA TM-X2072, January.

Bakos, R.J., Tsai, C.-Y., Rogers, R.C., and Shih, A.T. (1999) "The Mach 10 Component of NASA's Hyper-X Ground Test Program," 14 th International Symposium on Airbreathing Engines, ISABE Paper 99-7216, September.

Baumann, E., Bahm, C., Strovers, B., Beck, R., and Richard, M. (2007) “The X-43A Six Degree of Freedom Monte Carlo Analysis.” NASA/TM-2007-214630, December.

Berry, S., Karyebeigi, K., Wurster, K., and Bittner, R. (2008) "Boundary Layer Transition on the X-43," $38^{\text {th }}$ Fluid Dynamics Conference and Exhibit, Seattle, WA, AIAA Paper 2008-3736, June.

Berry, S.A., and Horvath, T.J. (2008) "Discrete-Roughness Transition for Hypersonic Flight Vehicles," Journal of Spacecraft and Rockets, Vol. 45, No. 2.

Berry, S., Nowak, R.J., and Horvath, T.J. (2004) "Boundary Layer Control for Hypersonic Airbreathing Vehicles," $34^{\text {th }}$ Fluid Dynamics Conference and Exhibit, Portland, OR, AIAA Paper 2004-2246, June.

Berry, S., DiFulvio, M., and Kowalkowski, M. (2000) "Forced Boundary Layer Transition on X-43 (Hyper-X) in NASA LaRC 20-inch Mach 6 Air Tunnel," Hyper-X Technical Note, NASA, NASA-TM-2000-210316.

Billig, F.S. (1995) “Supersonic Combustion Ramjet Missile," Journal of Propulsion and Power, Vol. 11, No. 6. 
Billig, F.S. (1993) "Research on Supersonic Combustion," Journal of Propulsion and Power, Vol. 9, No. 4.

Billig, F.S., and Van Wie, D.M. (1987) "Efficiency Parameters for Inlets Operating at Hypersonic Speed," 1987 International Society of Airbreathing Engines Symposium, ISABE Paper 87-7047, June.

Blake, W.B. (1998) “MISSILE DATCOM User's Manual - 1997 Fortran 90 Revision,” Air Force Research Laboratory, AFRL-VA-WP-TR-1998-3009.

Cary, A.M. Jr. and Bertram, M.H. (1974) "Engineering Prediction of Turbulent Skin Friction and Heat Transfer in High-Speed Flow," NASA TN D7507.

Chen, F.J., Malik, M.R., and Beckwith, I.E. (1989) "Boundary-Layer Transition on a Cone and Flat Plate at Mach 3.5," AIAA Journal, Vol. 27, No. 6.

Chue, R.S.M., Tsai, C.Y., Bakos, R.J., Erdos, J.I., and Rogers, R.C. (2002) 'NASA's HYPULSE Facility at GASL-A Dual Mode, Dual Driver, Reflected Shock/ Expansion Tunnel," In Advanced Hypersonic Test Facilities. Chap. 3, pp 29-72; Edited by F. K. Lu \& D. E. Marren; Progress In Astronautics \& Aeronautics Vol. 198.

Cockrell, C.E., Auslender, A.J., Guy, R.W., McClinton, C.R., and Welsch, S.S. (2002) “Technology Roadmap for Dual-Mode Scramjet Propulsion to Support SpaceAccess Vision Vehicle Development," AIAA/AAAF $11^{\text {th }}$ International Space Planes and Hypersonic Systems and Technology Conference, AIAA Paper 20025188 , September.

Cozart, A.B., Holland, S.D., Trexler, C.A., and Perkins, J.N. (1992) "Leading Edge Sweep Effects in Generic Three-Dimensional Sidewall Compression Scramjet Inlets," $30^{\text {th }}$ Aerospace Sciences Meeting, AIAA Paper 92-0674, January.

Curran, E.T., and Bergsten, M.B. (1964) "Inlet Efficiency Parameters for Supersonic Combustion Ramjet Engines,” APL-TDR-64-61, June. 
CRC (2003) "CRC Handbook of Chemistry and Physics” $84^{\text {th }}$ ed., Boca Raton, FL.

Davies, W.R., and Bernstein, L. (1969) "Heat transfer and transition to turbulence in the shock-induced boundary layer on a semi-infinite flat plate," Journal of Fluid Mechanics, Vol. 36, No. 1.

Delerey, J. (1988) "Shock-Shock and Shock-Wave/Boundary-Layer Interactions in Hypersonic Flows," AGARD-FDP-VKI Special Course on Aerothermodynamics of Hypersonic Vehicles, May.

Emami, S., Trexler, C.A., Auslander, A.H., and Weidner, J.P. (1995) "Experimental Investigation of Inlet-Combustor Isolators for a Dual-Mode Scramjet at a Mach Number of 4," NASA-TP-3502, May.

Engblom, W., Bellamkonda, G., and Georgiadis, N. (2011) "Wind-US Support to SDPTE Program," Final Report to Arnold Engineering Development Center, August.

Foelsche, R.O., Beckel, S.A., Betti, A.A., Wurst, G.T., Charletta, R.A., and Bakos, R.J. (2006) "Flight Results from a Program to Develop a Freeflight Atmospheric Scramjet Test Technique." 14th AIAA/AHI Space Planes and Hypersonic Systems and Technologies Conference, AIAA Paper 2006-8119, November.

Fry, R.S., (2004) “A Century of Ramjet Propulsion Technology Evolution,” Journal of Propulsion and Power, Vol. 20, No. 1.

Gaffney, R.L., Jr., and Cutler, A.D. (2005) “CFD Modeling Needs And What Makes A Good Supersonic Combustion Validation Experiment," JANNAF CS/APS/PSHS/MSS Joint Meeting, June.

Goldberg, T.J., and Hefner, J.J. (1970) “Starting Criterion for Hypersonic Inlets,” Journal of Aircraft, Vol. 7 No. 3.

Goyne, C.P., Cresci, D., and Fetterhoff, T.P. (2009a) "Short Duration Propulsion Test and Evaluation (Hy-V) Program," 16th AIAA/DLR/DGLR International Space 
Planes and Hypersonic Systems and Technologies Conference, AIAA Paper 2009-7296, October.

Goyne, C.P., Rockwell, R.D., Untaroiu, A., Smayda, M.G., Sklar, A., and Cresci, D. (2009b) "Dual-Mode Flowpath Design for the SDPTE (Hy-V) Program," JANNAF 43td CS $/ 31^{\text {st }} A P S / 25^{\text {th }}$ PSHS Joint Meeting, JANNAF Paper 785, December.

Goyne, C.P., Krauss, R.H., McDaniel, J.C. and Whitehurst, W.B. (2007) "Test Gas Vitiation Effects in a Dual-mode Scramjet Combustor," Journal of Propulsion and Power, Vol. 23, No. 3.

Goyne, C.P., Hall, C.D., O’Brien, W.F., and Schetz, J.A. (2006) “The Hy-V Scramjet Flight Experiment," $14^{\text {th }}$ AIAA/AHI Space Planes and hypersonic Systems and Technologies Conference, AIAA Paper 2006-7901, November.

Goyne, C.P., McDaniel, J.C., Quagliaroli, T.M., Krauss, R.J., and Day, S.W. (2001) "Dual-Mode Combustion of Hydrogen in a Mach 5, Continuous-Flow Facility," Journal of Propulsion and Power, Vol. 17, No. 6.

Gurylev, V.G., and Mamet'yev, Yu.A. (1978) "Effect of Cooling of the Central Body on Start-Up Separation of the Flow at the Intake and the Throttling Characteristics of Air Scoops at Supersonic and Hypervelocity Velocities," Fluid Mechanics Soviet Research, Vol. 7, No. 3.

Guy, R.W., Rogers, R.C., Pulster, R.L., Rock, K.E., and Diskin, G.S. () "The NASA Langley Scramjet Test Complex," $32^{\text {nd }}$ ASME, SAE, and ASEE, Joint Propulsion Conference and Exhibit, AIAA Paper 96-3243, July.

Hank, J., Murphy, J., and Mutzman, R. (2008) "The X-51A Scramjet Engine Flight Demonstration Program," $15^{\text {th }}$ AIAA International Space Planes and Hypersonic Systems and Technologies Conference, AIAA Paper 2008-2540, April.

Harsha, P.T., Keel, L.C., Castrogiovanni, A., and Sherrill, R.T. (2005) "X-43A Vehicle Design and Manufacture," AIAA/CIRA $13^{\text {th }}$ International Space Planes and Approved for public release; distribution is unlimited. AEDC PA 2012-083 
Hypersonics Systems and Technologies Conference, AIAA Paper 2005-3334, May.

Haw, W.L., Goyne, C.P., Rockwell, R.D., Krauss, R.H., and McDaniel, J.C. (2011) "Experimental Study of Vitiation Effects on Scramjet Mode Transition," Journal of Propulsion and Power, Vol. 27, No. 2.

Heiser, W.H., and Pratt, D.T., with Daley, D.H., and Mehta, U.B. (1994) "Hypersonic Airbreathing Propulsion," American Institute of Aeronautics and Astronautics, Inc., Washington, DC.

Holden, M.S. (1971) "Establishment time of laminar separated flows," AIAA Journal, Vol. 9, No. 11.

Holland, S.D., Woods, W.C., and Engelund, W.C. (2001) "Hyper-X Research Vehicle Experimental Aerodynamics Test Program Overview," Journal of Spacecraft and Rockets, Vol. 38, No. 6.

Holland, S., and Perkins, J. (1990) "Mach 6 Test of Two Generic Three-Dimensional Sidewall Compression Scramjet Inlets in Tetraflouromethane," $28^{\text {th }}$ Aerospace Sciences Meeting, AIAA Paper 90-0530, January.

Huber, P.W., Schexnayder, C.J., and McClinton, C.R. (1979) "Criteria for Self-Ignition of Supersonic Hydrogen-Air Mixtures," NASA TP-1457, August.

Jacobs, P.A., Rogers, R.C., Weidner, E.H., and Bittner, R.D. (1990) "Flow Establishment in a Generic Scramjet Combustor," NASA ICASE Report 90-77, October.

Jeong, E., O’Byrne, S., Jeung, I-S., and Houwing, A.F.P (2008) "Investigation fo Supersonic Combustion with Angled Injection in a Cavity-Based Combustor," Journal of Propulsion and Power, Vol. 24, No. 6.

Kantrowitz, A., and Donaldson, C. (1945) "Preliminary Investigation of Supersonic Diffusers," NACA WRL-713, May. 
Keenan, J.H., and Kaye, J. (1948) “Gas Tables,” Wiley.

Korkegi, R.H. (1975) "Comparison of Shock-Induced Two- and Three-Dimensional Incipient Turbulent Separation," AIAA Journal, Vol. 13, No. 4.

Liu, J.S. (2001) "Monte Carlo strategies in scientific computing," Springer-Verlag, New York, NY.

Lu, F.K., and Marren, D.E. (2002) "Principles of Hypersonic Test Facility Development," In Advanced Hypersonic Test Facilities. Chap. 2, pp 17-27; Edited by F. K. Lu \& D. E. Marren; Progress In Astronautics \& Aeronautics Vol. 198.

Marshall, L.A., Corpening, G.P., and Sherrill, R. (2005) “A Chief Engineer's View of the NASA X-43A Scramjet Flight Test," AIAA/CIRA $13^{\text {th }}$ International Space Planes and Hypersonics Systems and Technologies Conference, AIAA Paper 2005-3332, May.

McClinton, C.R., Holland, S.D., Rock, K.E., Engelund, W.C., Voland, R.T., Huebner, L.D., and Rogers, R.C. (1998) "Hyper-X Wind Tunnel Program," $36^{\text {th }}$ Aerospace Sciences Meeting and Exhibit, AIAA Paper 1998-0553, January.

McDaniel, J.C., Chelliah, H., Goyne, C.P., Edwards, J.R., Givi, P., and Cutler, A.D. (2009) "US National Center for Hypersonic Combined Cycle Propulsion: An Overview," $16^{\text {th }}$ AIAA/DLR/DGLR International Space Planes and Hypersonic Systems and Technologies Conference, AIAA Paper 2009-7280, October.

McGregor, R.J., Molder, S., and Paisley, T.W. (1992) "Hypersonic Inlet Flow Starting in the Ryerson/University of Toronto gun Tunnel," Investigations in the Fluid Dynamics of Scramjet Inlets, Ryerson Polytechnical University and University of Toronto, Canada, July.

McLafferty, G.J., (1955) "A Generalized Approach to the Definition of Average Flow Quantities in Non-Uniform Streams," United Aircraft, Research Department Report SR-13534-9, December.

Approved for public release; distribution is unlimited. AEDC PA 2012-083 
Messersmith, N., and Castro, J.H. (2003) "Future High Mach Propulsion," AIAA/ICAS International Air and Space Symposium and Exposition: The Next 100 Years, AIAA Paper 2003-2613, July.

Miller, C.G., III (1990) “Langley Hypersonic Aerodynamic/Aerothermodynamic Testing Capabilities - Present and Future," $16^{\text {th }}$ Aerodynamic Ground Testing Conference, AIAA Paper 90-1376, June.

Molder, S., McGregor, R.J., and Paisley, T.W. (1992) "A Comparison of Three Hypersonic Air Inlets," Investigations in the Fluid Dynamics of Scramjet Inlets, Ryerson Polytechnical University and University of Toronto, Canada, July.

Molder, S., and Szpiro, E.J. (1966) "Busemann Inlet for Hypersonic Speeds," Journal of Spacecraft, Vol. 3, No. 8.

Muruganandam, T.M., Nair, S., Neumeier, Y., Lieuwen, T., and Seitzman, J.M. (2002) "Optical and Acoustic Sensing of Lean Blowout Precursors." 38th AIAA/ ASME/ SAE/ ASEE Joint Propulsion Conference and Exhibit, AIAA Paper 2002-3732, July.

NASA (2005) "NASA Sounding Rocket Program Handbook", NASA Sounding Rockets Program Office Suborbital and Special Orbital Projects Directorate, 810-HBSRP, NASA Goddard Space Flight Center, Wallops Flight Facility, Wallops Island, VA, June.

NASA (1991) “GEM Trajectory Simulation Program Users Guide," NASA Wallops Flight Facility, October.

NAVWEPS (1964) "Handbook of Supersonic Aerodynamics, Section 17: Ducts, Nozzles, and Diffusers," Bureau of Naval Weapons, Department of the Navy, January.

Pate, S.R., and Schueler, C.J. (1969) "Radiated Aerodynamic Noise Effects on Boundary Layer Transition in Supersonic and Hypersonic Wind tunnels," AIAA Journal, Vol. 7, No. 3.

Approved for public release; distribution is unlimited. AEDC PA 2012-083 
Paull, A., Frost, M., and Alesi, H. (2000) "HyShot-T4 Supersonic Combustion Experiments," Report for NAG-1-2113.

Penaranda, F.E., and Freda, M.S., (1985) “Aeronautical Facilities Catalogue, Vol. 1 Wind Tunnels," NASA-RP-1132, January.

Pirrello, C.J., Hardin, R.D., Heckart, M.V., and Brown, K.R. (1971) “An Inventory of Aeronautical Ground Research Facilities. Volume 1 - Wind Tunnels," Prepared by McDonnell Aircraft Co., NASA-CR-1874, November.

Pope, S.B. (2000) “Turbulent Flows,” Cambridge University Press.

Rockwell, R.D., Goyne, C.P., Haw, W.L., Krauss, R.H., McDaniel, J.C., and Trefny, C.J. (2011) "Experimental Study of Test-Medium Vitiation Effects on Dual-Mode Scramjet Performance," Journal of Propulsion and Power, Vol. 27, No. 5.

Roffe, G., Bakos, R., Erdos, J., and Swartwout, W. (1997) “The Propulsion Test Complex at GASL.” XIII International Symposium on Air Breathing Engines, ISABE Paper 97-7096, September.

Rogers, R.C., Shih, A.T., Tsai, C.-Y., Foelsche, R.O. (2001) "Scramjet Tests in a Shock Tunnel at Flight Mach 7, 10, and 15 Conditions," $37^{\text {th }}$ AIAA/ASME/SAE/ASEE Joint Propulsion Conference and Exhibit, AIAA Paper 2001-3241, July.

Roudakov, A.S., Semenov, V.L., and Hicks, J.W. (1998) "Recent Flight Test Results of the Joint CIAM-NASA Mach 6.5 Scramjet Flight Program,” NASA/TP-1998206548, April.

Schneider, S.P. (2001) "Effects of High-Speed tunnel Noise on Laminar-Turbulent Transition," Journal of Spacecraft and Rockets, Vol. 38, No. 3.

Schramm, J.M., Karl, S., Hannemann, K., and Steelant, J. (2008) "Ground Testing of the HyShot II Scramjet Configuration in HEG," $15^{\text {th }}$ AIAA International Space Planes and Hypersonic Systems and Technologies Conference, AIAA Paper 2008-2547, April.

Approved for public release; distribution is unlimited. AEDC PA 2012-083 
Smart, M.K. (2010) “Scramjet Inlets," AVT-185 RTO AVT/VKI Lecture Series, Genèse, Belgium, September.

Smart, M.K. (2007) "Scramjets," AFT-150 RTO AVT/VKI Lecture Series, Genèse, Belgium, March.

Smart, M.K., Hass, N.E., and Paull, A. (2006) "Flight Data Analysis of the HyShot 2 Scramjet Flight Experiment," AIAA Journal, Vol. 44, No. 10.

Smart, M.K. (1999) "Design of Three-Dimensional Hypersonic Inlets with Rectangularto-Elliptical Shape Transition,” Journal of Propulsion and Power, Vol. 15, No. 3.

Smayda, M.G., and Goyne, C.P. (2012) "Dispersion Reduction for a Sounding Rocket Scramjet Flight Experiment," Journal of Spacecraft and Rockets, Vol. 49, No. 3.

Smayda, M.G., Vogel, P.D., Schultz, I.A., Hanson, R.K., Foelsche, R., Cresci, D., and Goyne, C.P. (2012) "Hypervelocity Testing of a Dual-Mode Scramjet," $50^{\text {th }}$ Aerospace Sciences Meeting, AIAA Paper 2012-0481, January.

Steelant, J. (2008) “Achievements Obtained for Sustained Hypersonic Flight within the LAPCAT project," $15^{\text {th }}$ AIAA International Space Planes and hypersonic Systems and Technologies Conference, AIAA Paper 2008-2578, April.

Stockbridge, R.D. (1989) "Experimental Investigation of Shock Wave/Boundary Layer Interactions in an Annular Duct," Journal of Propulsion and Power, Vol. 5, No. 3.

Stollery, J.L. (1967) "Heat transfer at hypersonic speeds - a survey of recent and current experiments in the Imperial College hypersonic gun tunnel," Aerodynamics Department, Imperial College.

Sung, C.J., Li, J.G., Yu, G., and Law, C.K. (1999) "Chemical Kinetics and Self-Ignition in a Model Supersonic Hydrogen-Air Combustor," AIAA Journal, Vol. 37, No. 2. 
Thisted, R.A. (1988) "Elements of Statistical Computing," Chapman and Hall, New York, NY.

Tsai, C-.Y., and Bakos, R.J. (1998) "Shock-tunnel flow visualization with a high-speed schlieren and laser holographic interferometry system," $20^{\text {th }}$ Advanced Measurement and Ground Testing Technology Conference, AIAA Paper 19982700, June.

United States Government Printing Office (USGPO) (1976) "U.S. Standard Atmosphere," Washington, D.C.

Van Wie, D.M. (2000) “Scramjet Inlets,” In Scramjet Propulsion. Chap. 7, pp 447-511; Edited by E.T. Curran and SNB Murthy; Progress In Astronautics \& Aeronautics Vol 189.

Van Wie, D.M., and Ault, D.A. (1996) "Internal Flowfield Characteristics of a TwoDimensional Inlet at Mach 10,” Journal of Propulsion and Power, Vol. 12, No. 1.

Van Wie, D.M., Kwok, F.T., and Walsh, R.F. (1996) "Starting Characteristics of Supersonic Inlets," $32^{\text {nd }} A S M E$, SAE, and ASEE, Joint Propulsion Conference and Exhibit, AIAA Paper 96-2914, July.

Waltrup, P.J., Billig, F.S., and Stockbridge, R.D. (1982) "Engine Sizing and Integration Requirements for Hypersonic Airbreathing Missile Applications," AGARD-CP307, No. 8, March.

Waltrup, P.J. and Billig, F.S. (1973) "Prediction of Precombustion Wall Pressure Distributions in Scramjet Engines," Journal of Spacecraft and Rockets, Vol. 10, No. 9.

Wang, Q., Duraisamy, K., Alonso, J.J., and Iaccarino, G. (2010) "Risk Assessment of Scramjet Unstart Using Adjoint-Based Sampling Methods," 51st AIAA/ ASME/ ASCE/ AHS/ ASC Structures, Structural Dynamics, and Materials Conference, AIAA-2010-2921, April.

Approved for public release; distribution is unlimited. AEDC PA 2012-083 
Warmbrod, J.D. (1969) “A Theoretical and Experimental Study of Unsteady Flow Processes in a Ludwieg Tube Wind Tunnel," NASA TN D-5469, November.

White, Frank M. (2006) "Viscous Fluid Flow," $3^{\text {rd }}$ ed., McGraw Hill, New York, NY. 


\section{Appendix A: Traditional Evaluation of Inlets}

Many performance metrics have been explored in the existing literature to describe the performance of supersonic and hypersonic inlets. Van Wie (2000) provides an excellent summary of various performance metrics commonly used when evaluating inlets. Since the flowpath considered here is designed for operation in the dual-mode regime at a flight Mach number near 5, the ideal gas assumption remains reasonable and the effects of vibrational excitation, dissociation, and ionization have been largely ignored for the design of this inlet. This gives closed form solutions to many performance metrics reported in the literature if inviscid and adiabatic flow is assumed.

The amount of compression or contraction of an inlet can be expressed in many ways but is often reported as a ratio of the area of the captured freestream streamtube to the area of the inlet throat (minimum area). For the purposes of this section and following the conventions of (Van Wie, 2000), let us call the undisturbed freestream state upstream of any external compression, station 0 , the point at which internal contraction begins, station 2, and the throat station 4. Station 4' refers to the conditions downstream of any precombustion shock train that may develop in the isolator. These stations and areas are illustrated in Figure A.1 for a simple 2D scramjet inlet. If $A_{0}$ is the area of the freestream streamtube captured by the inlet and $A_{i}$ is the projected frontal area of the inlet, the mass flow through the inlet can be characterized by its contraction ratio, $A_{0} / A_{i}$. The compression ratio, $P_{4} / P_{0}$, then describes the rise in static pressure over the inlet. It has been suggested that these two metrics, the contraction and compression ratios, should be the primary means for evaluating an inlet's operation. (Billig and Van Wie, 1987) Given the state at station 0 , these two parameters, and the heat loss between stations 0 and 4 , 
stream-thrust-averaged conditions (McLafferty, 1955) at the inlet throat can be calculated.

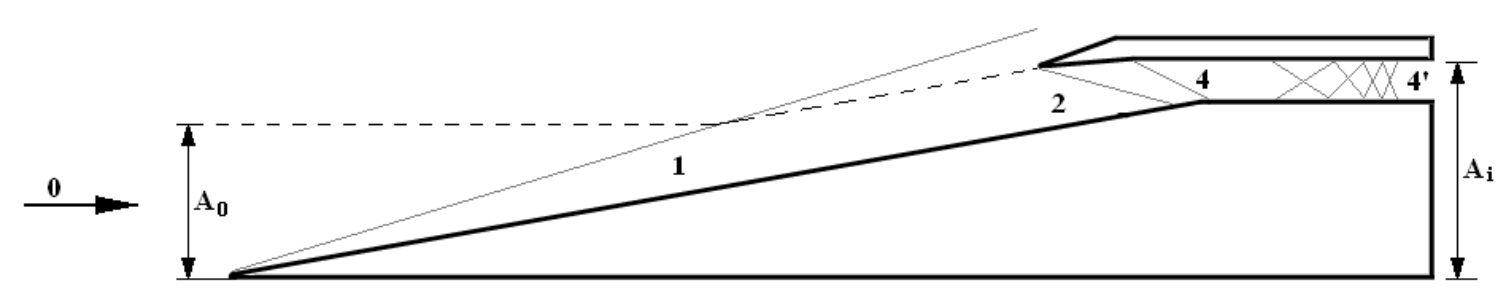

Figure A.1: Simple 2D scramjet inlet schematic (SDPTE inlet).

Various efficiency parameters have been reported in the literature. The most notable are the kinetic energy efficiency, given in Equation A-1:

$\eta_{K E}=\frac{h_{t 4}-h\left(P_{0}, s_{4}\right)}{h_{t 0}-h_{0}}$

where $h_{t}$ is the total enthalpy, $\mathrm{h}$ is the static enthalpy, and $\mathrm{P}$ is the static pressure, the adiabatic kinetic energy efficiency, which does not take heat loss into account and is given in Equation A-2:

$\eta_{K E_{A D}}=\frac{h_{t 0}-h\left(P_{0}, s_{4}\right)}{h_{t 0}-h_{0}}$,

the total pressure recovery, given in Equation A-3:

$\eta_{P t}=\frac{P_{t 4}}{P_{t 0}}$

the effectiveness or thermodynamic efficiency, $\eta_{\mathrm{TH}}$, the dimensionless entropy rise, $\Delta \mathrm{s} / R$, and the compression efficiency, $\eta_{\mathrm{B}}$. For a perfect gas, the kinetic energy efficiency can be calculated as:

$\eta_{K E}=\frac{2}{(\gamma-1) M_{0}^{2}}\left(\frac{T_{t 4}}{T_{t 0}}\right)\left[1+\frac{\gamma-1}{2} M_{0}^{2}-\left(\frac{P_{t 0}}{P_{t 4}}\right)^{\frac{\gamma}{\gamma-1}}\right]$. 
The adiabatic kinetic energy efficiency is commonly used instead of the kinetic energy efficiency and is often estimated as:

$\eta_{K E_{A D}}=1-0.4\left(1-\frac{M_{4}}{M_{0}}\right)^{4}$,

an empirical relation developed by (Waltrup et al., 1982). See Billig and Van Wie (1987) and Curran and Bergsten (1964) for a review of these efficiency metrics as well as others and their calculation. For situations such as that considered here, (supersonic or low hypersonic flight Mach numbers), the total pressure recovery and kinetic energy efficiency are most used. For higher Mach numbers, kinetic energy efficiency is often used exclusively. Since each efficiency parameter has a slightly different physical meaning, no single parameter can completely describe the operation of an inlet. 


\section{Appendix B: Additional Mach 5 flight CFD results}

Table B-1: Mach 5 flight CFD inflow conditions and predicted mass capture.

\begin{tabular}{|l|l|l|l|}
\hline Altitude (ft) & $\mathbf{6 6 , 2 3 5}$ & $\mathbf{7 1 , 2 8 0}$ & $\mathbf{7 4 , 1 4 0}$ \\
\hline Mach No. & 4.46 & 5.00 & 5.40 \\
\hline Ps (kPa) & 5.315 & 4.175 & 3.644 \\
\hline Ts $(\mathbf{K})$ & 216.8 & 218.4 & 219.3 \\
\hline Predicted total Mass Capture (kg/s) & 0.2066 & 0.1965 & 0.1944 \\
\hline
\end{tabular}

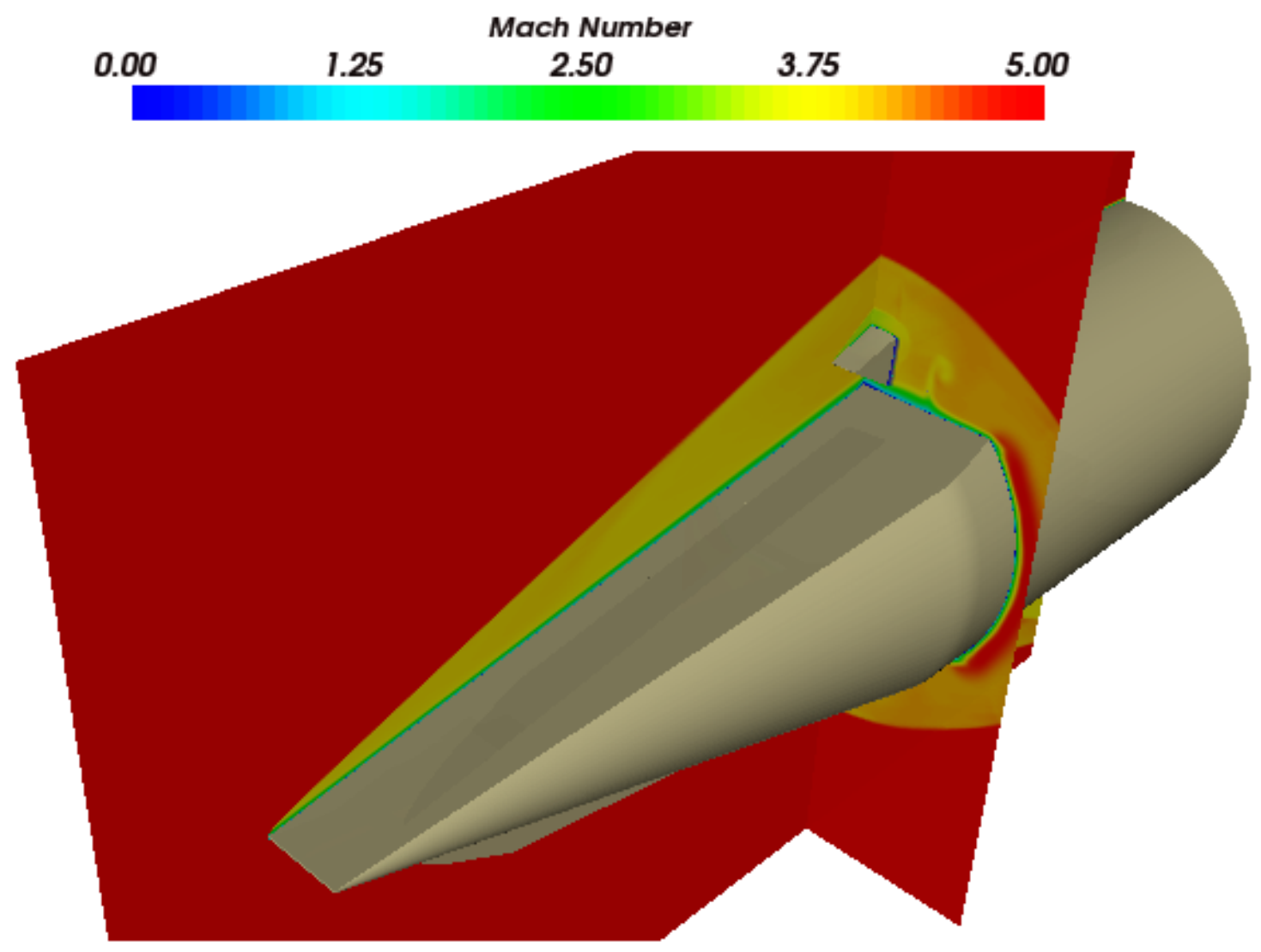

Figure B.1: Isometric view of Mach number contours. 


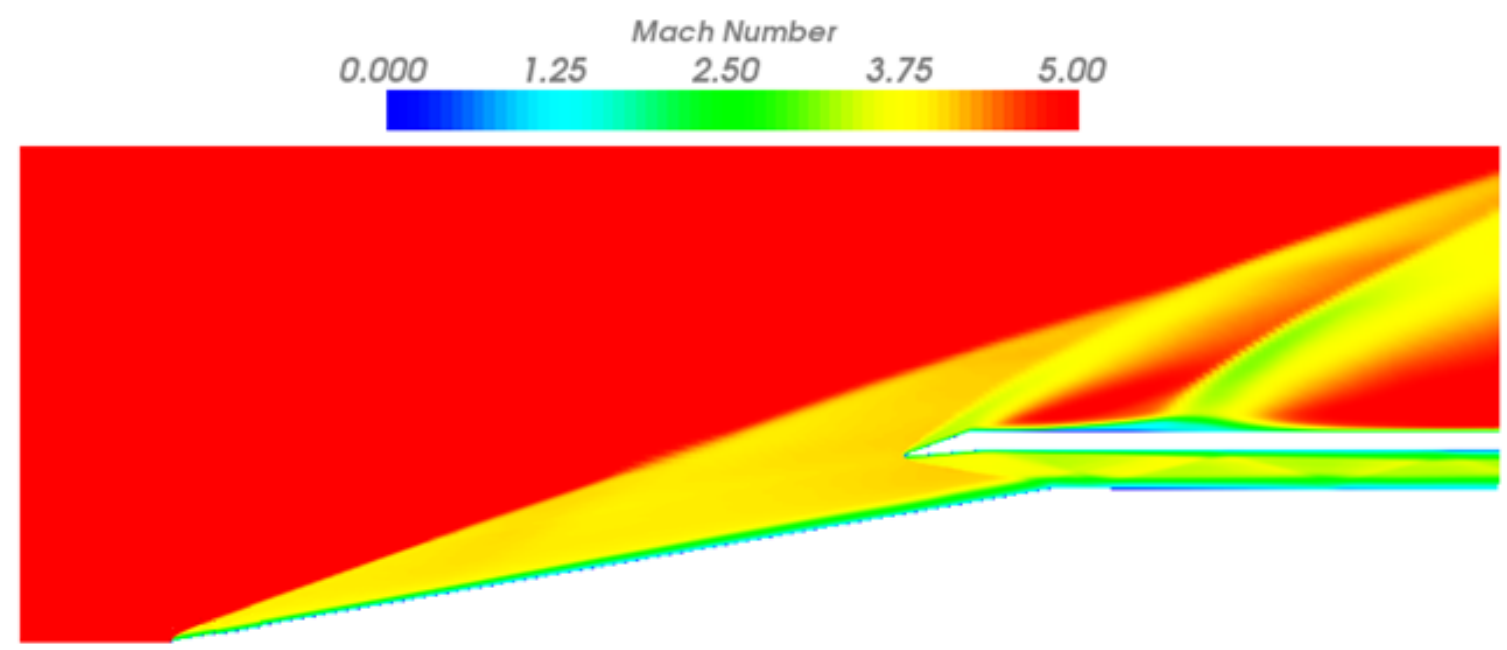

Figure B.2: Mach number contour on center plane.

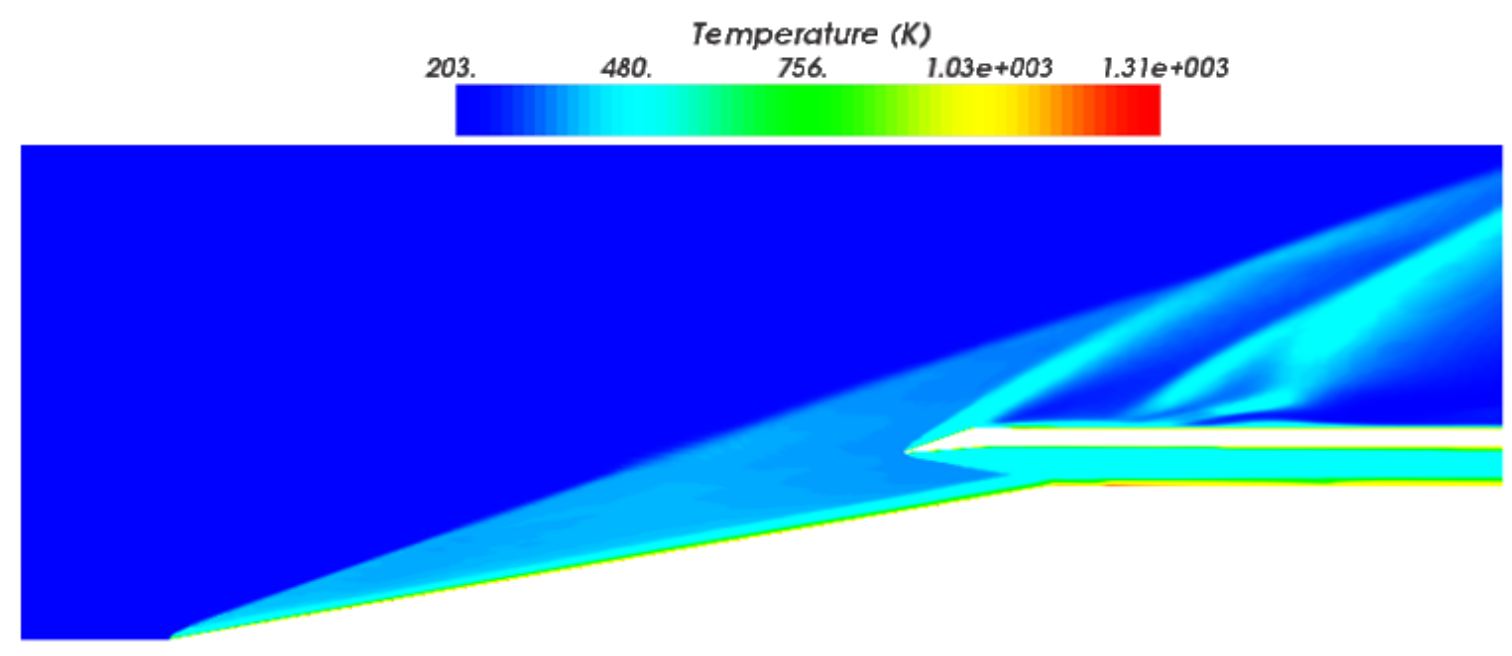

Figure B.3: Temperature contour on center plane. 


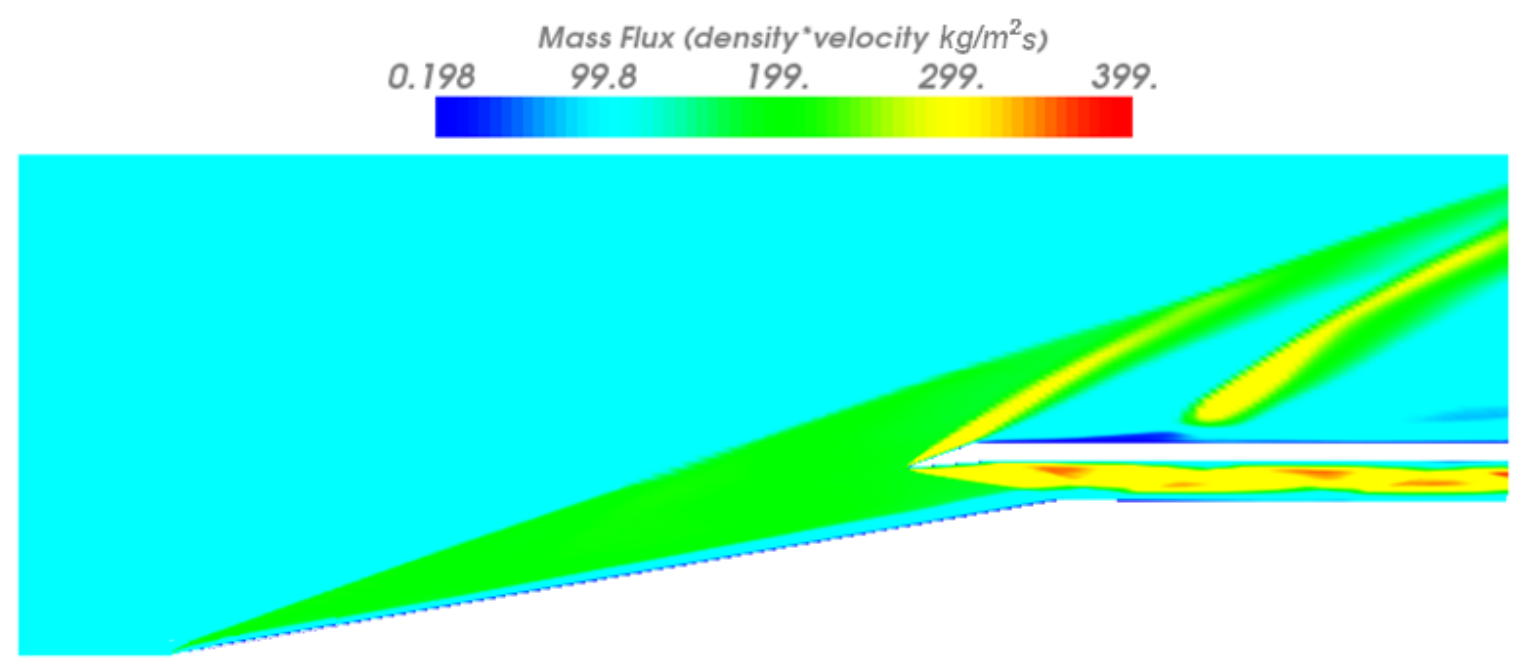

Figure B.4: Mass flux density contour on center plane 


\section{Appendix C: Additional HyPulse inlet results}

\section{$\underline{\text { Test I18 }}$}

In test I18 the realized total pressure and temperature were higher than expected. The stainless steel diaphragm used was from a new batch and was too strong. In order to properly rupture it, a higher driver pressure was required. This resulted in a higher shock speed and the higher than expected total pressure and temperature. The cowl shocks began moving forward around $10 \mathrm{~ms}$ signaling the presence of driver gas contaminating the test gas. The pressure rise at $\mathrm{x}=19$ inches on Flowpath A suggests the possible presence of a small boundary layer separation which is seen in all subsequent tests. The low pressure seen at 19 inches from $0-1 \mathrm{~ms}$ was not seen in any other tests. The forebody disturbance seen upstream of the Flowpath A inlet stabilizes from 2-6 ms and then grows from 6-12 ms. This growth seen for all tests and is likely due to the decreasing Reynolds number with decreasing total pressure, making the boundary layer less turbulent and increasing the strength of the separation. Flowpath B shows an elevated pressure at $\mathrm{x}=$ 11 inches but operates as expected behind this point. It is not known what is caused this steady disturbance. 


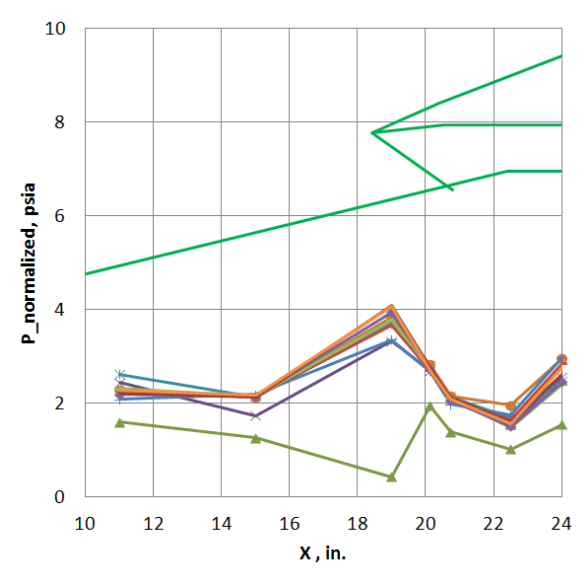

a.
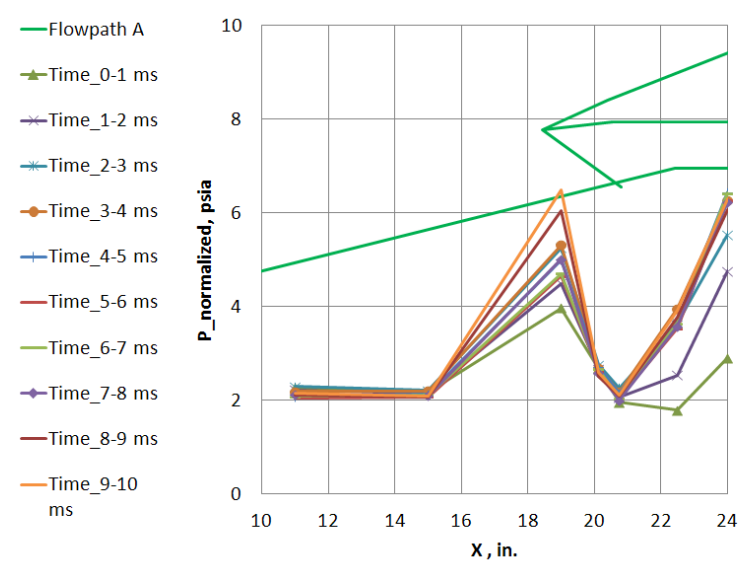

-Flowpath A

-Time_10-11 ms
- Time_11-12

ms

ms
* Time_12-13 $\mathrm{ms}$

$\rightarrow-$ Time_13-14 ms
- Time_14-15 —Time 15 -16 $\mathrm{ms}$

—Time_16-17 ms
$\rightarrow$ Time 17-18 ms ${ }_{\text {Time_18-19 }}$ ms —Time_19-20 ms

Figure C.1: Test I18 inlet pressure traces for flowpath A for a) 0-10 ms and b) 10$20 \mathrm{~ms}$.

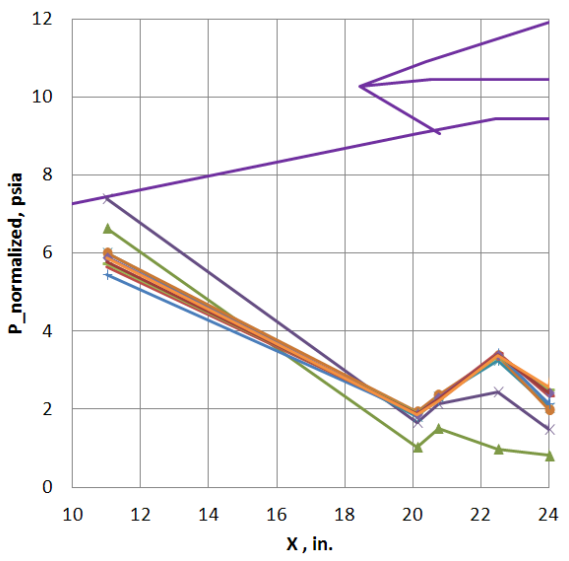

a.
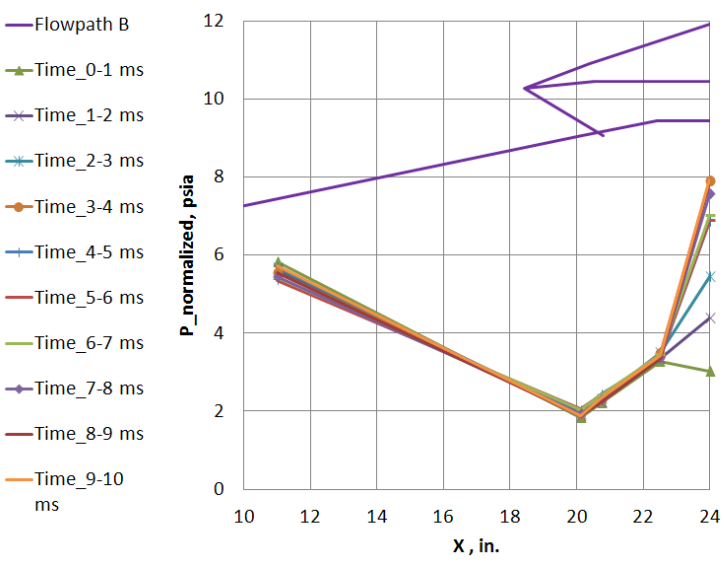

b.

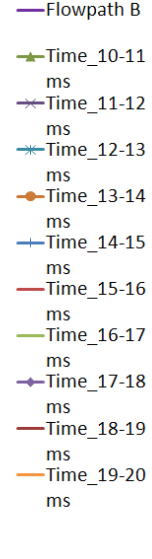

Figure C.2: Test I18 inlet pressure traces for flowpath $B$ for a) 0-10 $\mathrm{ms}$ and b) 10$20 \mathrm{~ms}$.

\section{$\underline{\text { Test I19 }}$}

Test I19 used a similar diaphragm which was scored slightly deeper than for test I18. Unfortunately it was still too strong and resulted in higher than a higher than expected shock speed and thus total pressure and temperature. Still, the results of Test I19 are very similar to other tests. Again, cowl shock movement indicated the arrival of the helium. 
Here this movement occurs at approximately $13 \mathrm{~ms}$. The same flow features for the Flowpath A inlet are shown here as in the previous test. The disturbance at 11 inches in front of flowpath B is of a much lesser magnitude. This behavior is also seen in test I26. Qualitative behavior is the same as Test I18.

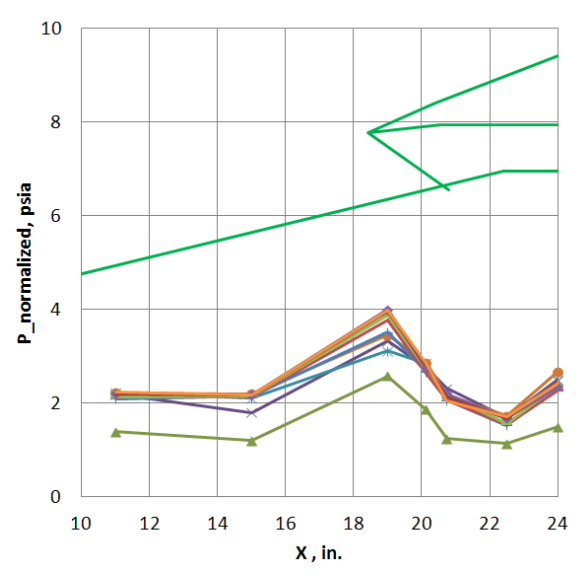

a.

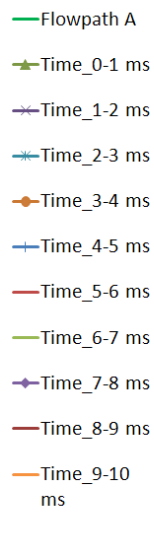

a.

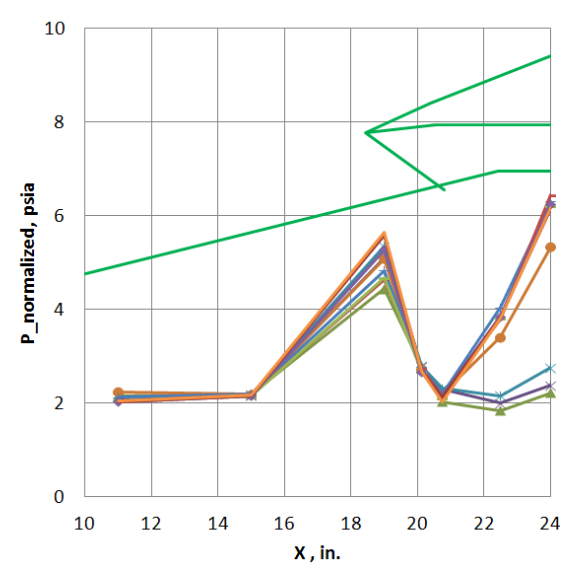

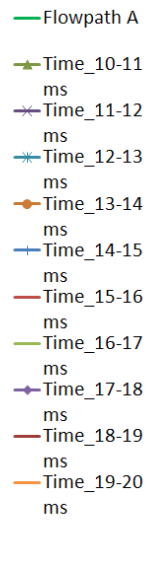

b.

Figure C.3: Test I19 inlet pressure traces for flowpath A for a) 0-10 ms and b) 10$20 \mathrm{~ms}$.

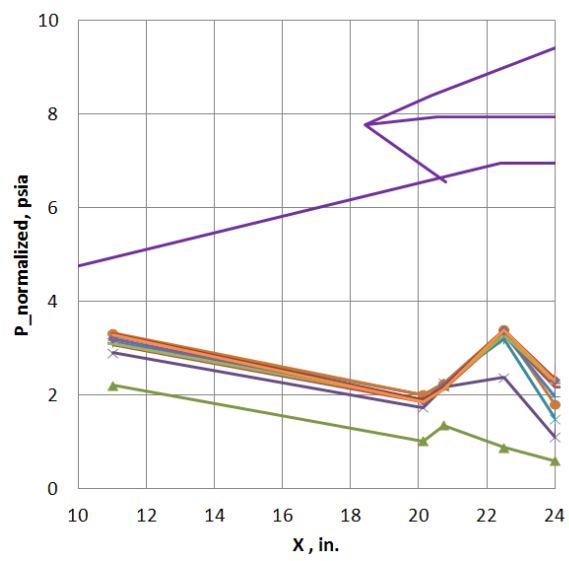

a.

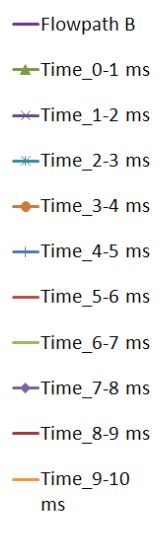

s.

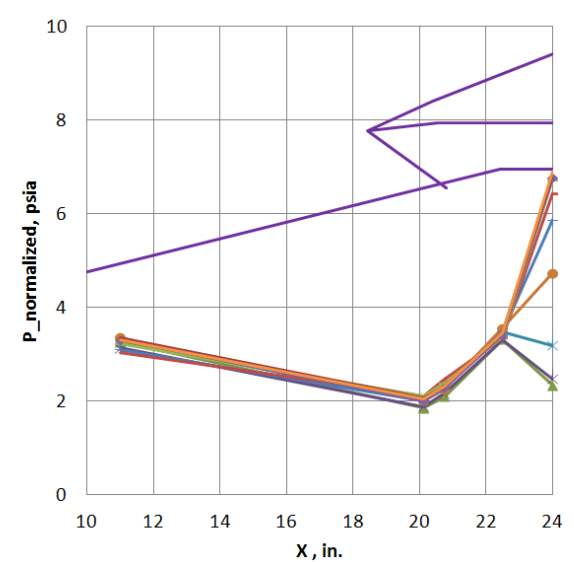

b.

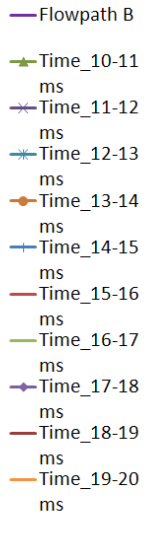

-Time_10-11 ms
$*$ Time_11-12 ms $\underset{\substack{\mathrm{ms} \\ \sim} \text {-Time_13-14 }}{-}$ $\begin{aligned} & \text { ms } \\ \text {-Time_14-15 } & \end{aligned}$ ms ms $\rightarrow$ ms $\rightarrow$ Time_17-18 $\rightarrow$ Time_17-18 —Time_18-19 $\begin{aligned} & \text { ms } \\ \text { - Time_19-20 } & \text { ms }\end{aligned}$

Figure C.4: Test I19 inlet pressure traces for flowpath B for a) 0-10 ms and b) 10$20 \mathrm{~ms}$.

Approved for public release; distribution is unlimited. AEDC PA 2012-083 


\section{$\underline{\text { Test I20 }}$}

Ignition was obtained in flowpath A for test I20 and stable dual-mode combustion follows along with a characteristic precombustion shock train. The precombustion shock train itself does not move past $\mathrm{x}=24$ until $8 \mathrm{~ms}$, but its effect is felt through the boundary layer, increasing the strength of the separation on the forebody. The resulting pressure rise on the forebody from this disturbance is higher than for other cases when no precombustion shock train develops. For flowpath B, no forebody disturbance is seen at 11 inches. This is the only test for which this is the case.

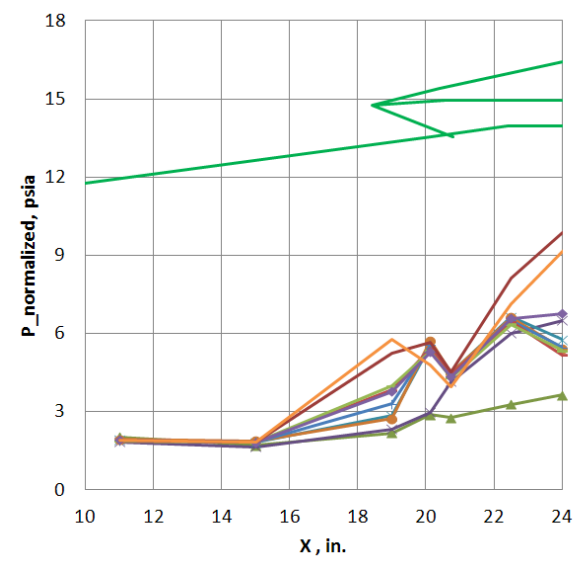

a.

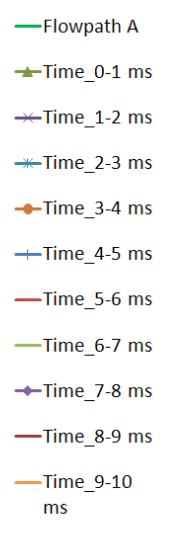

$$
\text { . }
$$




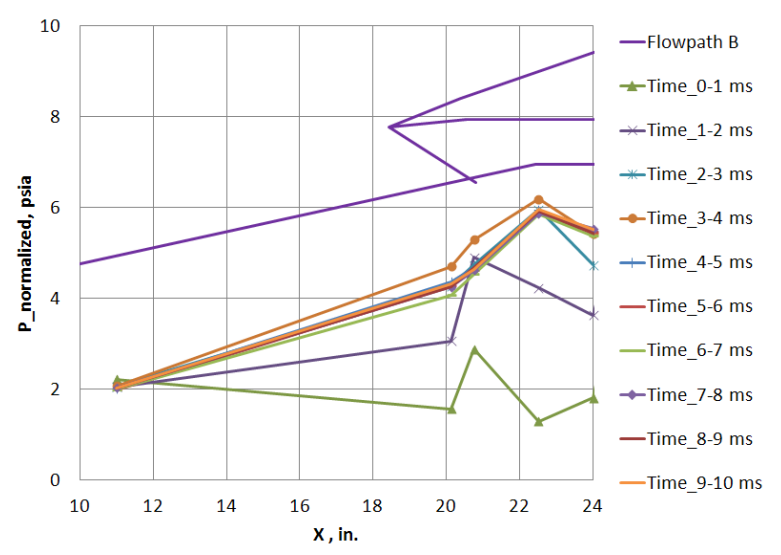

a.

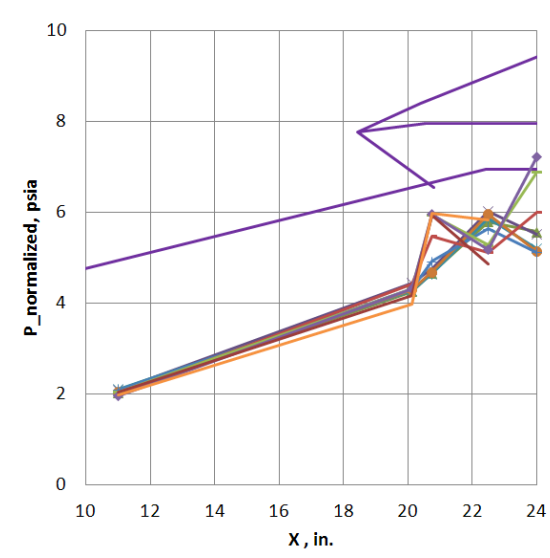

—Flowpath B - Time_10-11 ms
- Time_11-12 ms $m s$
- Time $13-14$ $\mathrm{ms}$
- Time_14-15 ms $14-15$ ms $16-17$ ms $\rightarrow \rightarrow$ Time_17-18 ms —Time_18-19 —Time_19-20 b.

Figure C.6: Test I20 inlet pressure traces for flowpath B for a) 0-10 ms and b) 10$20 \mathrm{~ms}$.

\section{$\underline{\text { Test I21 }}$}

This test shows features similar to most other tests. Helium driver gas contamination is indicated by shock movement around $14 \mathrm{~ms}$. For Flowpath A, the forebody disturbance develops, as in other tests, suggesting boundary layer separation on the forebody. The strength of the disturbance seen upstream of Flowpath B grows significantly more during the end of this test than in other tests. 


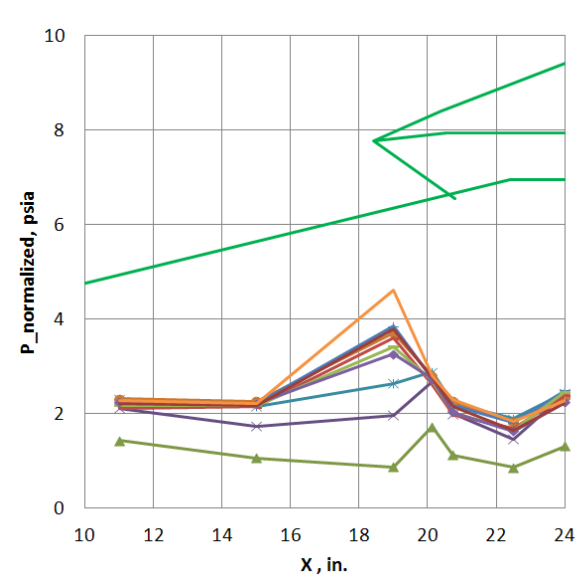

a.

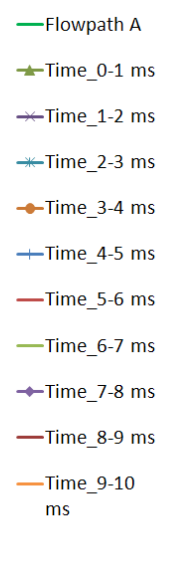

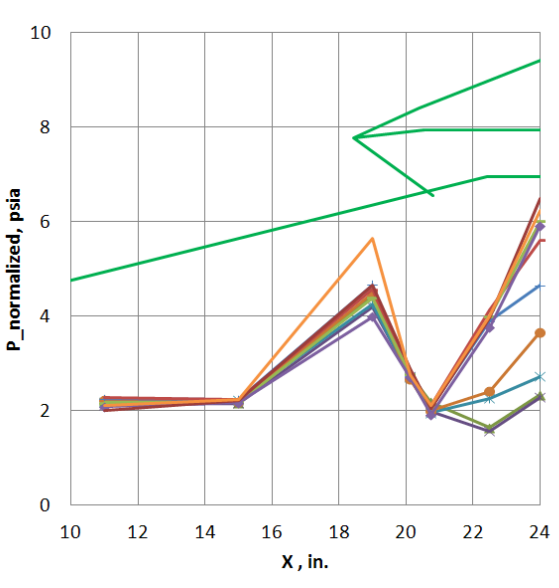

-Flowpath A

-Time_10-11

ms

ms
- Time_11-12
-

ms

* Time_12-13

$\underset{\rightarrow-\text { Time_13-14 }}{\text { ms }}$

ms
- Time_14-15

—Time 15-16

ms

-Tims

$\underset{\rightarrow-\text { Time_17-18 }}{\text { ms }}$

$\rightarrow$ ms $-17-18$

一 Time_18-19

$\mathrm{ms}$
- Time_19-20

Figure C.7: Test 121 inlet pressure traces for flowpath A for a) 0-10 ms and b) 10$20 \mathrm{~ms}$.

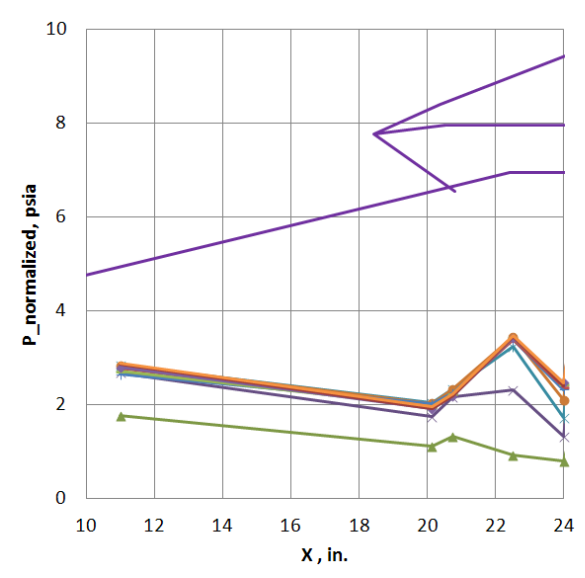

a.
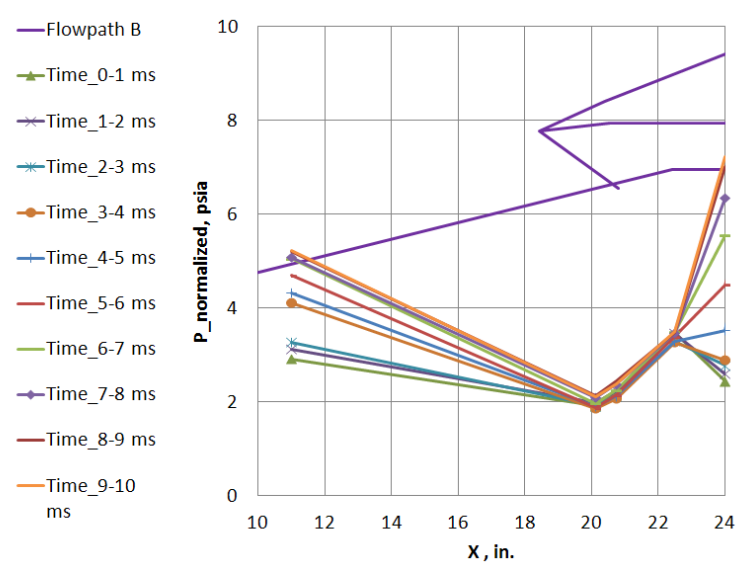

b.

Figure C.8: Test I21 inlet pressure traces for flowpath B for a) 0-10 ms and b) 10$20 \mathrm{~ms}$.

\section{$\underline{\text { Test I22 }}$}

This test shows features similar to most other tests. Helium driver gas contamination is indicated by shock movement around $12 \mathrm{~ms}$. For Flowpath A, the forebody disturbance develops, as in other tests, suggesting boundary layer separation on the forebody. The disturbance seen at 11 inches for Flowpath B is steady, but increases in 
strength right at the end of the test. This behavior is also seen in test I24.

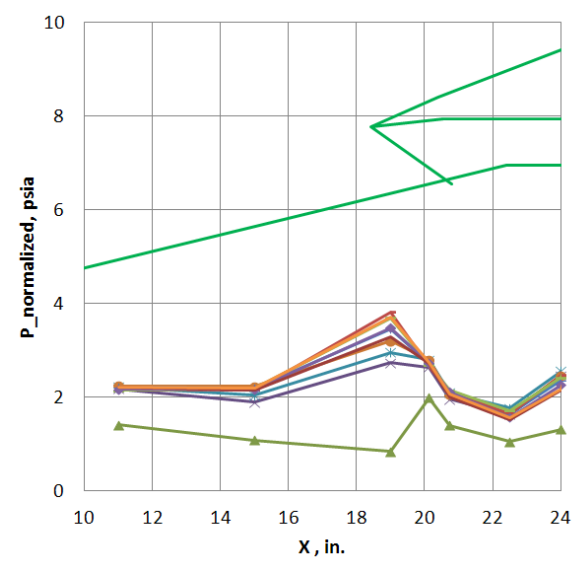

a.
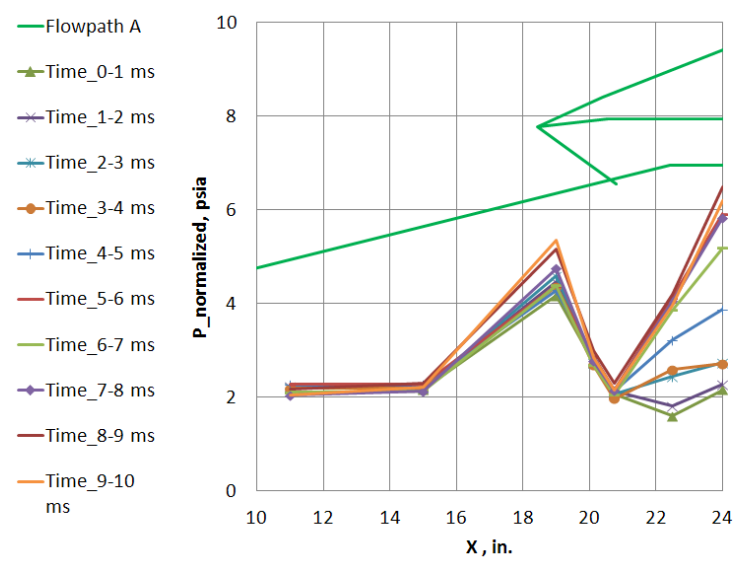

b.
—Flowpath A

-Time_10-11 ms
- Time_11-12

ms $\mathrm{ms}$

$\rightarrow-$ Time_13-14 ms
- Time_14-15 ms

-Time_15-16 ms
-Time_16-17

ms
$\rightarrow-T i m e \_17-18$ ms -Time_18-19 —Time_19-20 $\mathrm{ms}$

Figure C.9: Test I22 inlet pressure traces for flowpath A for a) 0-10 ms and b) 10$20 \mathrm{~ms}$.

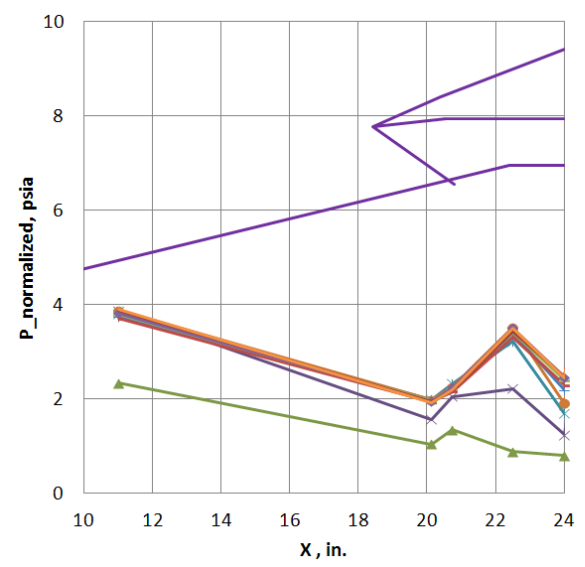

a.
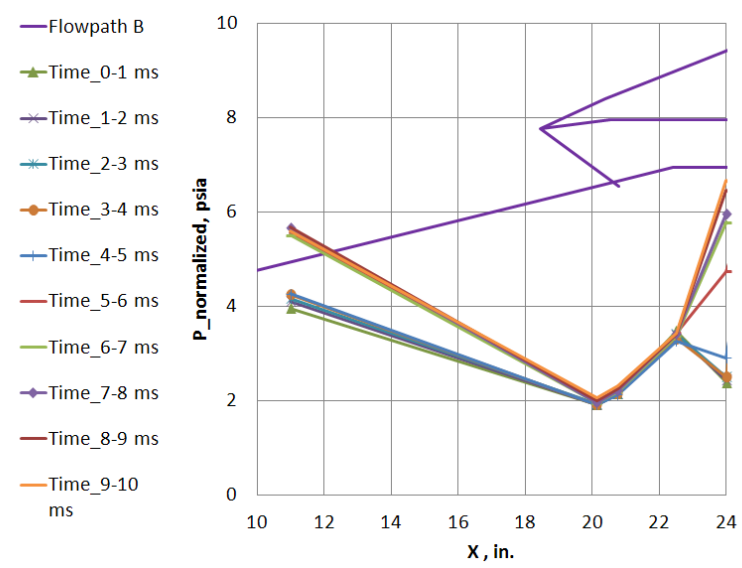

b.

Figure C.10: Test 122 inlet pressure traces for flowpath B for a) 0-10 ms and b) 10$20 \mathrm{~ms}$.

\section{$\underline{\text { Test I23 }}$}

This test shows features similar to most other tests. Helium driver gas contamination is indicated by shock movement around $11 \mathrm{~ms}$. The forebody disturbance develops, as in other tests, suggesting boundary layer separation on the forebody. Flowpath B inlet 
behavior is qualitatively similar to that in Test I21.

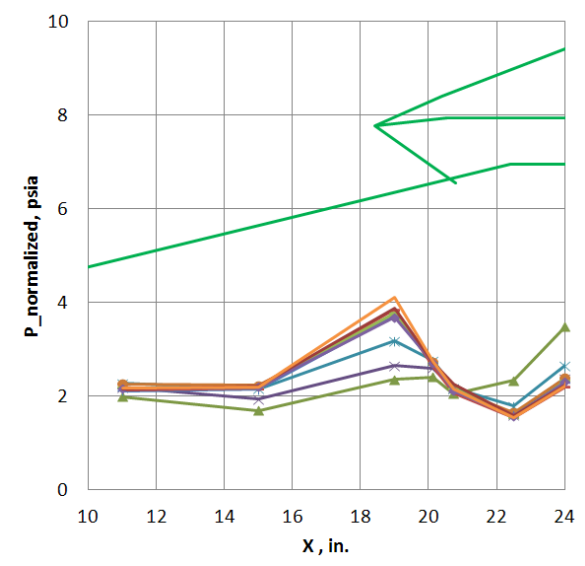

a.

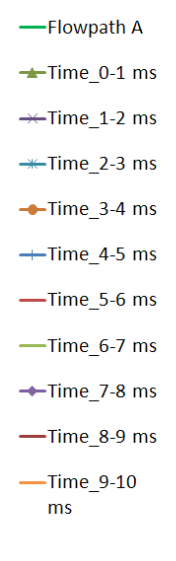

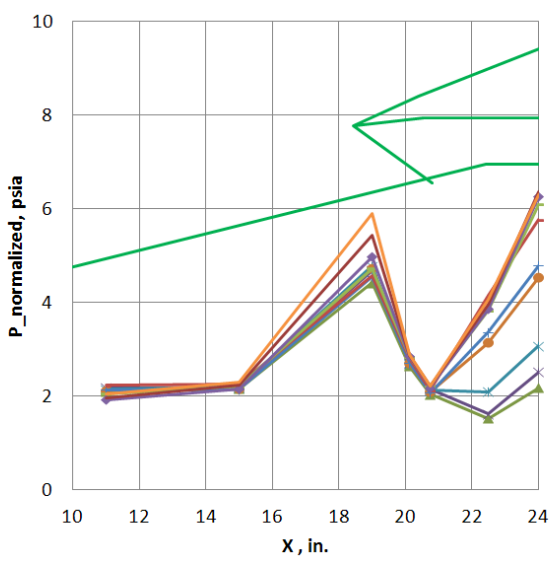

b.

—Flowpath A

-Time_10-11 $\mathrm{ms}$ *Time_11-12

ms
*Time_12-13

ms

-Time_13-14

$\begin{aligned} & \text { ms } \\ \text { - Time_14-15 } & \end{aligned}$

ms

ms

$16-17$

ms
$\rightarrow$ Time_17-18

$\rightarrow$ Time

ms

$\mathrm{ms}$

_Time_19-20

Figure C.11: Test I23 inlet pressure traces for flowpath A for a) 0-10 ms and b) 1020ms.

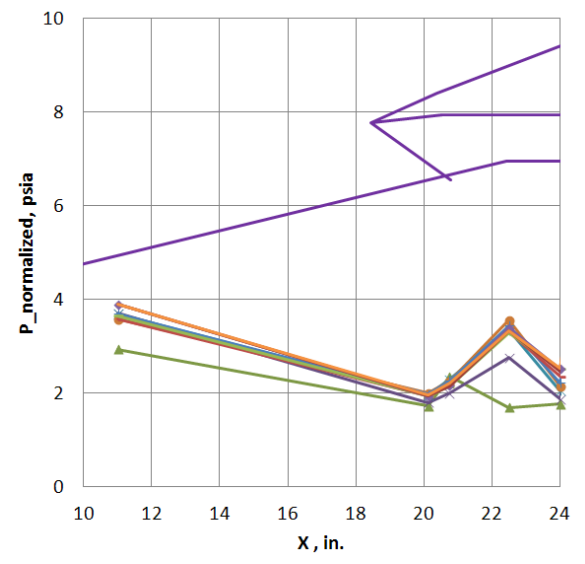

a.
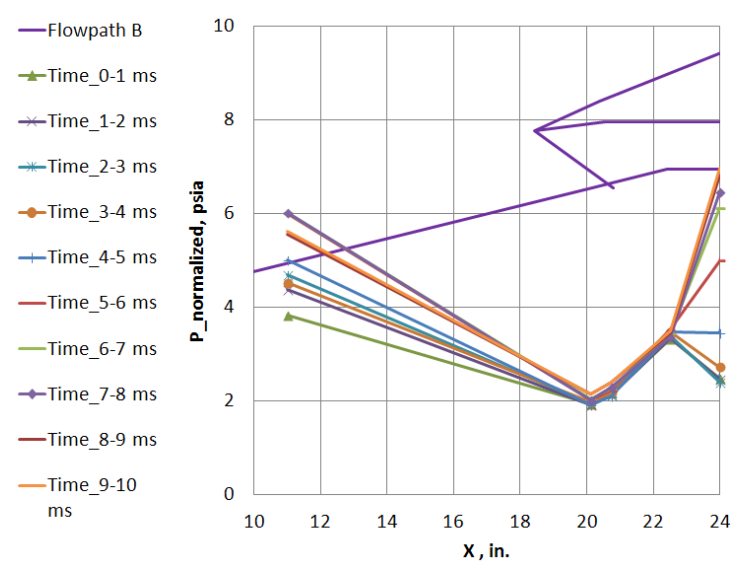

b.

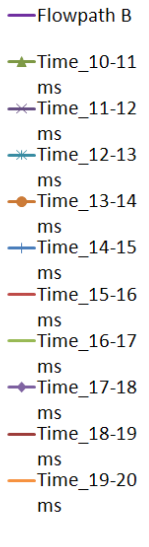

Figure C.12: Test 123 inlet pressure traces for flowpath $B$ for a) $0-10 \mathrm{~ms}$ and b) 10 $20 \mathrm{~ms}$.

\section{$\underline{\text { Test I24 }}$}

This test shows features similar to most other tests. Helium driver gas contamination is indicated by shock movement around $12 \mathrm{~ms}$. The forebody disturbance develops, as in other tests, suggesting boundary layer separation on the forebody. The disturbance seen 
at 11 inches for Flowpath B stabilizes and then grows at the end of the test time. This is qualitatively similar to its behavior in test I22.

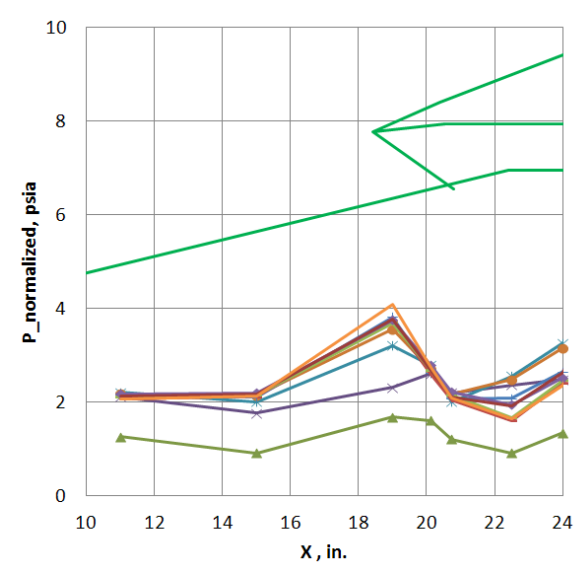

a.

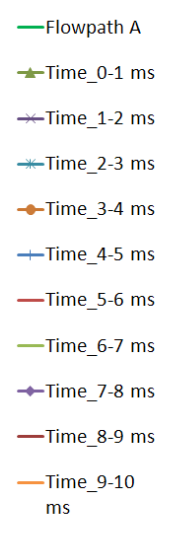

a.

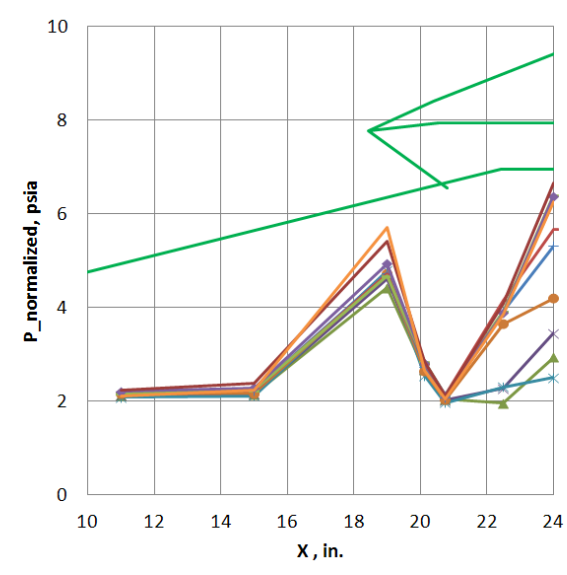

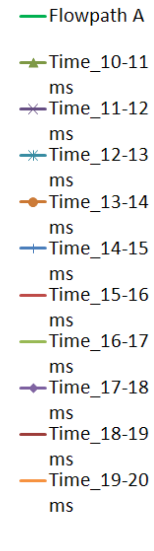

b.

Figure C.13: Test I24 inlet pressure traces for flowpath A for a) 0-10 ms and b) 1020ms.

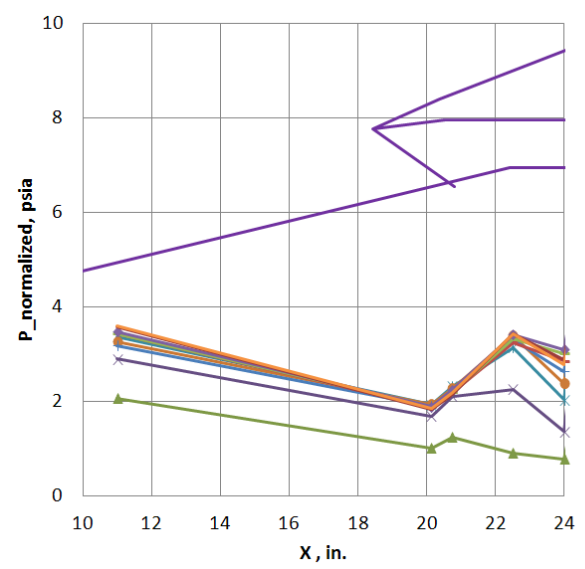

a.
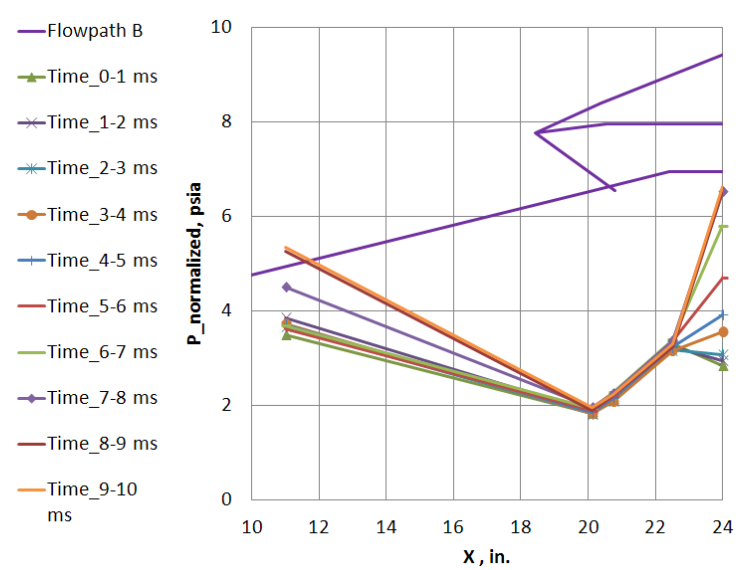

b.

—Flowpath B

-Time_10-11 ms
-Time_11-12 ms
* Time_12-13 $\underset{- \text { Time_13-14 }}{\mathrm{ms}}$ $\begin{aligned} & \text { ms } \\ & \text { - Time_14-15 }\end{aligned}$ ms —Time_15-16 ms -Time_16-17 ms
$\rightarrow$ Time_17-18 ms ms

Figure C.14: Test 124 inlet pressure traces for flowpath B for a) 0-10 ms and b) 1020ms.

\section{$\underline{\text { Test I26 }}$}

This test shows features similar to most other tests. Helium driver gas contamination is indicated by shock movement around $14 \mathrm{~ms}$. The forebody disturbance develops for 
Flowpath A, as in other tests, suggesting boundary layer separation on the forebody. Flowpath B inlet operation is qualitatively similar to that in test I19.
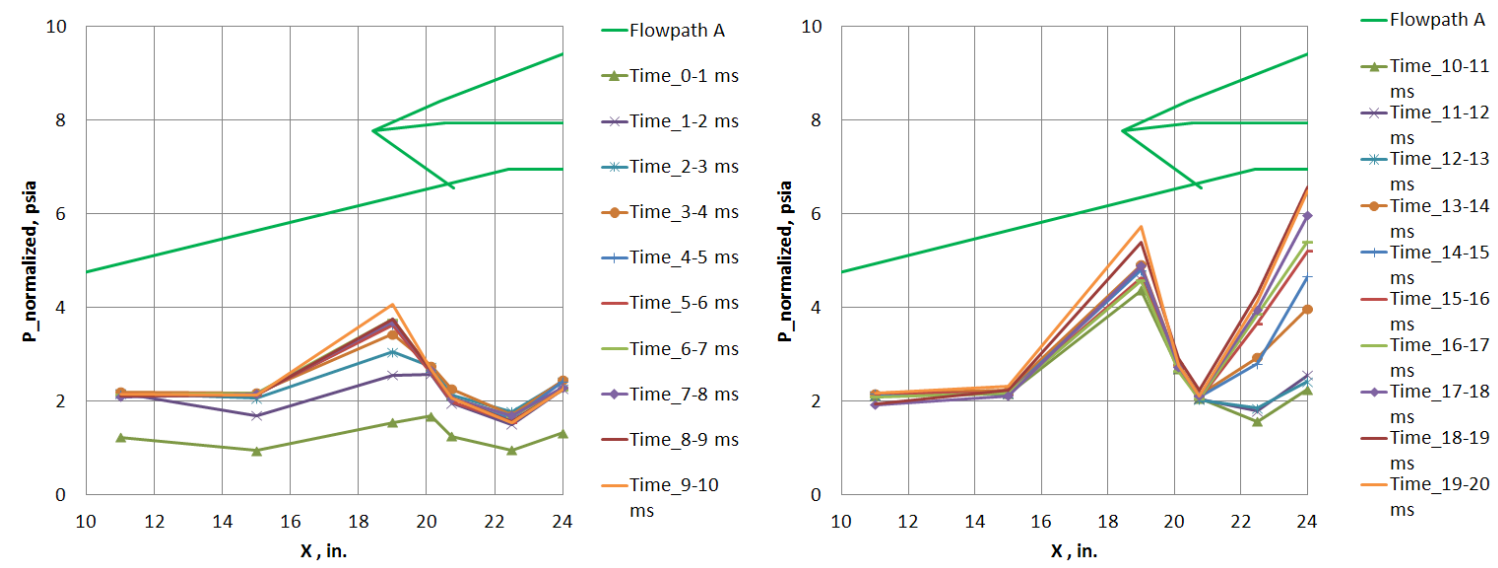

Figure C.15: Test 126 inlet pressure traces for flowpath A for a) 0-10 ms and b) 10$20 \mathrm{~ms}$.
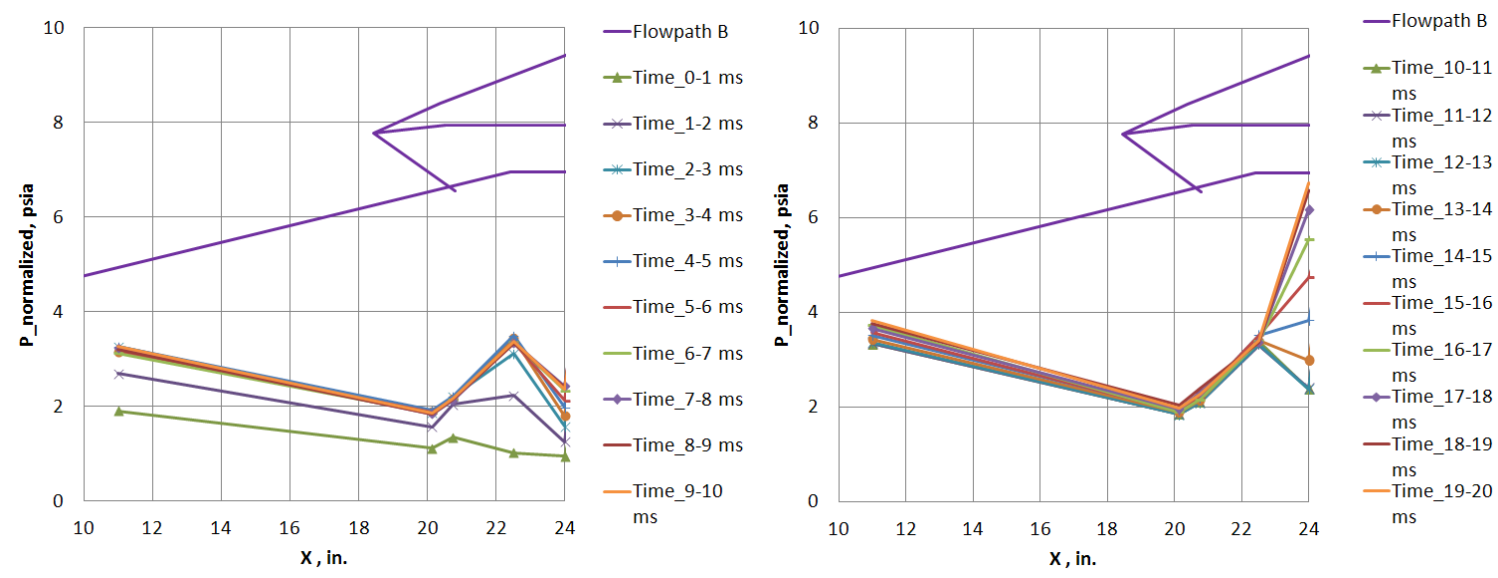

Figure C.16: Test I26 inlet pressure traces for flowpath B for a) 0-10 ms and b) 1020m 


\section{Appendix D: Monte Carlo Method Background}

This appendix serves as an introduction to Monte Carlo methods for those unfamiliar with the technique. Such methods are invaluable for evaluating expressions in highdimensional space because their accuracy does not scale with the dimensionality of the problem. This is important for evaluating the effect of many contributors on a rocket flight because each contributor modeled adds a dimension to the probability space being investigated.

In science and engineering, it is often necessary to evaluate the integral given in Equation D-1:

$I=\int_{D} g(x) d x$

where $D$ is a region, possibly in a high-dimensional space, and $g(\boldsymbol{x})$ is some function of interest. If independent and identically distributed random samples can be drawn uniformly from $D$, then an approximation for $I$ is given by Equation D-2

$\hat{I}_{m}=\frac{D}{m}\left\{g\left(x^{(1)}\right)+\cdots+g\left(x^{(m)}\right)\right\}$,

where $\mathrm{x}^{(1)}, \ldots, \mathrm{x}^{(\mathrm{m})}$ are the random samples and $\hat{I}_{m}$ is the approximation to $I$. In the limit that $m$ approaches infinity, $\hat{I}_{m}$ necessarily approaches $I$ according to the law of large numbers. Consider the a simple example in one dimension where $D=[0, a]$ and $I=\int_{0}^{a} g(x) d x$. This integral can be approximated by:

$\tilde{I}_{m}=\frac{a}{m}\left\{g\left(b_{1}\right)+\cdots+g\left(b_{m}\right)\right\}$,

where $b_{j}=a j / m$. Using the central limit theorem, one can show that this approximation 
converges in distribution to normal with a zero mean and variance of $\sigma^{2}$. Symbolically: $\sqrt{m}\left(\hat{I}_{m}-I\right) \stackrel{d}{\rightarrow} N\left(0, \sigma^{2}\right)$

where $\sigma^{2}$ is the variance of $g(x)$. Therefore the error of the Monte Carlo approximation is $O\left(m^{-1 / 2}\right)$. Since this error is independent of the dimensionality of $x$, the Monte Carlo method is especially useful for problems where $x$ has many dimensions. If again, independent and identically distributed random samples can be drawn uniformly from $D$, other methods can give lower error rates than the Monte Carlo. For example, when $g(x)$ is relatively smooth, the Riemann approximation gives an error rate of $O\left(\mathrm{~m}^{-1}\right)$ when $D$ has only one dimension. For an $n$ dimensional space, however, $O\left(m^{n}\right)$ points must be evaluated to retain this error rate of $O\left(\mathrm{~m}^{-1}\right)$ using a Riemann approximation for $I$. While other methods, such as Simpson's rule, can give more accurate numerical approximations than a Riemann approximation (Thisted, 1988), like the Riemann approximation method, they do not scale well with the dimensionality of $D$ (Liu, 2001).

To counter the fact that for a high dimensional space, $g(x)$ may have a large variance and that it may not be possible to produce uniform random samples within $D$, importance sampling is often used as was the case for the work presented here. Here, random samples $\mathrm{x}^{(1)}, \ldots, \mathrm{x}^{(\mathrm{m})}$ from a nonuniform distribution $\pi(x)$ are generated which put more probability mass on the most likely parts of the region $D$. Thus, the integral $I$, can be estimated as:

$$
\hat{\hat{I}}_{m}=\frac{1}{m} \sum_{j=1}^{m} \frac{g\left(x^{(j)}\right)}{\pi\left(x^{(j)}\right)}
$$

which has variance $\sigma_{\pi}^{2}=\operatorname{var}_{\pi}\{g(x) / \pi(x)\}$. 
In using the Monte Carlo method to study the likelihood that the SDPTE flight vehicle passes through an acceptable test point as defined by Mach number and dynamic pressure at the test time, we are essentially integrating over the probability distributions of each contributor to determine the distribution of conditions at the test time. Here each contributor is a dimension of $x$ and $g(x)$ is a function that maps a point in "contributor space" to a certain Mach number and dynamic pressure at the expected test time with all other simulation inputs (which are not modeled as random contributors) held constant. The Monte Carlo method is especially well suited to this application because of large number of contributors and the unknown function $g(x) . g(x)$, while explicitly unknown, is formed through the simulation of the vehicle trajectory given a fully defined set of initial conditions and the laws of physics and aerodynamics which govern the path of the flight vehicle and its interaction with the atmosphere. Through this Monte Carlo simulation, a statistical relationship is formed between known distributions of input contributors and the unknown distribution of the performance of the system in terms of its ability to achieve the desired test conditions.

Approved for public release; distribution is unlimited. AEDC PA 2012-083 